Representação nó-profundidade em FPGA para algoritmos evolutivos aplicados ao projeto de redes de larga-escala

Marcilyanne Moreira Gois 

SERVIÇO DE PÓS-GRADUAÇÃO DO ICMC-USP

Data de Depósito: 19 de dezembro de 2011

Assinatura:

\title{
Representação Nó-profundidade em FPGA para algoritmos evolutivos aplicados ao projeto de redes de larga-escala
}

\author{
Marcilyanne Moreira Gois
}

Orientador: Prof. Dr. Alexandre Cláudio Botazzo Delbem

Dissertação apresentada ao Instituto de Ciências Matemáticas e de Computação - ICMC/USP, como parte dos requisitos para obtenção do título de Mestre em Ciências - Ciências de Computação e Matemática Computacional. VERSÃO REVISADA.

USP - São Carlos

Dezembro de 2011 
Ficha catalográfica elaborada pela Biblioteca Prof. Achille Bassi e Seção Técnica de Informática, ICMC/USP

com os dados fornecidos pelo(a) autor(a)

\begin{tabular}{|c|c|}
\hline \multirow[t]{3}{*}{ G616r } & $\begin{array}{l}\text { Gois, Marcilyanne Moreira } \\
\text { Representação nó-profundidade em FPGA para } \\
\text { algoritmos evolutivos aplicados ao projeto de redes } \\
\text { de larga-escala / Marcilyanne Moreira Gois; } \\
\text { orientador Alexandre Cláudio Botazzo Delbem. -- São } \\
\text { Carlos, } 2011 \text {. } \\
\quad 95 \text { p. }\end{array}$ \\
\hline & $\begin{array}{l}\text { Dissertação (Mestrado - Programa de Pós-Graduação en } \\
\text { Ciências de Computação e Matemática Computacional) -- } \\
\text { Instituto de Ciências Matemáticas e de Computação, } \\
\text { Universidade de São Paulo, } 2011 \text {. }\end{array}$ \\
\hline & $\begin{array}{l}\text { 1. Representação nó-profundidade. 2. FPGA. } 3 \text {. } \\
\text { Problemas de projetos de redes. 4. Algoritmo } \\
\text { evolutivos. 5. Paralelização. I. Delbem, Alexandre } \\
\text { Cláudio Botazzo, orient. II. Título. }\end{array}$ \\
\hline
\end{tabular}


Dedico este trabalho aos meus familiares. 



\section{Agradecimentos}

Aos meus familiares que deram todo o tipo de apoio, em especial, meu pai, minha mãe e meus irmãos, que acreditaram na realização deste trabalho.

Ao meu orientador Prof. Alexandre Cláudio Botazzo Delbem, pelo apoio, amizade e enorme dedicação e incentivo à este trabalho, o qual sempre esteve preocupado em realizar uma boa pesquisa e ao mesmo tempo garantir meu aprendizado.

Ao Professor Vanderlei Bonato pelo apoio e contribuição na pesquisa.

Aos amigos do Laboratório de Computação Reconfigurável, em especial, Marcio Crocomo, Paulo Gabriel H. Ribeiro, Christiane Brasil, Erinaldo da Silva Pereira pela amizade e apoio.

Ao amigo Paulo Matias, pela amizade, apoio e contribuição nesta pesquisa.

Ao programa de pós-graduação do Instituto de Ciências Matemáticas e de Computação, pela oportunidade de participar deste mestrado.

Aos funcionários do Instituto de Ciências Matemáticas e de Computação (ICMC), pelo empenho em suas funções.

Ao Conselho Nacional de Desenvolvimento Científico e Tecnológico (CNPq), pelo fundamental suporte financeiro destinado à execução desta pesquisa. 



\section{Resumo}

Diversos problemas do mundo real estão relacionados ao projeto de redes, tais como projeto de circuitos de energia elétrica, roteamento de veículos, planejamento de redes de telecomunicações e reconstrução filogenética. Em geral, esses problemas podem ser modelados por meio de grafos, que manipulam milhares ou milhões de nós (correspondendo às variáveis de entrada), dificultando a obtenção de soluções em tempo real. O Projeto de uma Rede é um problema combinatório, em que se busca encontrar a rede mais adequada segundo um critério como, por exemplo, menor custo, menor caminho e tempo de percurso. A solução desses problemas é, em geral, computacionalmente complexa. Nesse sentido, metaheurísticas como Algoritmos Evolutivos têm sido amplamente investigadas. Diversas pesquisas mostram que o desempenho de Algoritmos Evolutivos para Problemas de Projetos de Redes pode ser aumentado significativamente por meio de representações mais apropriadas. Este trabalho investiga a paralelização da Representação Nó-Profundidade (RNP) em hardware, com o objetivo de encontrar melhores soluções para Problemas de Projetos de Redes. Para implementar a arquitetura de hardware, denominada de HP-RNP (Hardware Parallelized RNP), foi utilizada a tecnologia de FPGA para explorar o alto grau de paralelismo que essa plataforma pode proporcionar. Os resultados experimentais mostraram que o HP-RNP é capaz de gerar e avaliar novas redes em tempo médio limitado por uma constante $(O(1))$. 


\section{Abstract}

Many problems related to network design can be found in real world applications, such as design of electric circuits, vehicle routing, telecommunication network planning and phylogeny reconstruction. In general, these problems can be modelled using graphs that handle thousands or millions of nodes (input variables), making it hard to obtain solutions in real-time. The Network Design is the combinatorial problem of finding the most suitable network subject to a evaluation criterion as, for example, lower cost, minimal path and time to traverse the network. The solution of those problems is in general computationally complex. Metaheuristics as Evolutionary Algorithms have been widely investigated for such problems. Several researches have shown that the performance of Evolutionary Algorithms for the Network Design Problems can be significantly increased through more appropriated dynamic data structures (encodings). This work investigates the parallelization of Node-Depth Encoding (NDE) in hardware in order to find better solutions for Network Design Problems. To implement the proposed hardware architecture, called HP-NDE (Hardware Parallellized NDE), the FPGA technology was used to explore the high degree of parallelism that such platform can provide. The experimental results have shown that the HP-NDE can generate and evaluate new networks in average time constrained by a constant $(O(1))$. 



\section{Lista de Figuras}

2.1 (a) Árvore com 5 nós; (b) MST custo total 17. Obtida por meio do algoritmo de Kruskal. . . . . . . . . . . . . . . . . . 7

2.2 Dados para um exemplo de cálculo de um OCSTP com 4 nós. . . . . . . . . . . . 9

2.3 Exemplo de um grafo que representa um SDE . . . . . . . . . . . . . . . . 10

3.1 Fluxograma de um algoritmo evolutivo básico. . . . . . . . . . . . . . . . . . . . . 14

3.2 Recombinação de 1 ponto. . . . . . . . . . . . . . . . . . 16

3.3 Recombinação de 2 pontos. . . . . . . . . . . . . . . . . . 16

4.1 Árvore e sua representação CV. . . . . . . . . . . . . . . . . . . . . . . 21

4.2 Árvore e sua representação predecessores. . . . . . . . . . . . . . . . . . . . 22

4.3 Árvore e sua representação Número de Prüfer. . . . . . . . . . . . . . . . . . . . 23

4.4 Árvore e sua representação por Conjunto de Arestas. . . . . . . . . . . . . . . . . 24

4.5 Floresta com 3 árvores (a) e suas RNPs correspondentes (b). . . . . . . . . . . . . 25

4.6 Novas árvores geradas $\left(T_{d e}^{\prime}\right)$ e $\left(T_{\text {para }}^{\prime}\right)$ e suas representações, utilizando Operador 1.28

4.7 Nova árvore gerada $\left(T_{\text {para }}^{\prime}\right)$ e sua representação, utilizando Operador 2 . . . . . . . . 29

4.8 Novas árvores geradas $\left(T_{d e}^{\prime}\right)$ e $\left(T_{\text {para }}^{\prime}\right)$ e suas representações, utilizando o operador PAO. Um trecho do array iniciado nó $p$ da árvore $T_{d e}$ é removido e depois inserido a direita de um nó $a$ em $T_{\text {para }}$, sendo os nós $p$ e $a$ adjacentes a $G$. . . . . . . . . 32

4.9 Tempo de execução de AENG, AEN, AGCE e AGNP para problema da árvore geradora mínima com restrição de grau (Delbem, 2009). . . . . . . . . . . . 35

5.1 Arquitetura de um FPGA (adaptado de (Bobda, 2007)) . . . . . . . . . . . . 38

5.2 Comparativo de flexibilidade $\mathrm{X}$ desempenho entre as arquiteturas de hardware (adaptado de (Bobda, 2007)). . . . . . . . . . . . . . . . . . 39

5.3 Ilustração do efeito da paralelização. . . . . . . . . . . . . . . . . . . 40

5.4 (a) O esquema de geração paralela de $\sqrt{n}$ redes por HP-RNP, (b) Formulação do tempo constante. ......................... 41 
6.1 Visão geral da arquitetura de hardware. . . . . . . . . . . . . . . . . . . 48

6.2 Máquina de estados finitos de um Trabalhador. . . . . . . . . . . . . . . 50

6.3 Comparativo número de nós da floresta $\times$ tempo por operador aplicado no FPGA e no PC . . . . . . . . . . . . . . . . . . . . . . . 52

6.4 Consumo de energia FPGA $\times$ PC $\ldots \ldots \ldots \ldots \ldots$

6.5 Consumo de recursos do FPGA. . . . . . . . . . . . . . . . . . 54

6.6 Média da soma total dos pesos das 65 Florestas Inicial e 65 Florestas Finais de simulações em FPGA e em PC, variando o número de nós no grafo. . . . . . . . . 57

6.7 Proporção de redução das somas dos pesos das Floresta Iniciais e Floresta Finais (geradas em FPGA e em PC). . . . . . . . . . . . . . . . . . . . . . 59 


\section{Lista de Tabelas}

4.1 Comparativo da complexidade das representações, onde $m$ é o número de arestas do grafo e $t$ o número de florestas e $n$ o número de nós, $T_{d e}$ é a árvore de origem e $T_{\text {para }}$ é a árvore de destino. . . . . . . . . . . . . . . 34

6.1 Comparativo nós $\times$ tempo médio de processamento. . . . . . . . . . 53

6.2 Consumo de Recursos do FPGA Cyclone II Modelo EP2C70F896C6. . . . . . . . . 54

6.3 Média da soma dos pesos das arestas das 65 Florestas Iniciais e 65 Florestas Finais em FPGA, em que $n$ é a ordem do grafo. . . . . . . . . . . . . . . 56

6.4 Média da soma dos pesos das arestas das 65 Florestas Iniciais e 65 Florestas Finais em PC . . . . . . . . . . . . . . . . . . . . . . . . . 57

6.5 Proporção de Redução da soma dos pesos total em FPGA. . . . . . . . . . . . . 58

6.6 Proporção de Redução da soma dos pesos total em PC. . . . . . . . . . . . . . . 58 



\title{
Lista de Abreviaturas e Siglas
}

\author{
AE Algoritmo Evolutivo \\ ASIC Application-Specific Integrated Circuit \\ BSV Bluespec System Verilog \\ CNPq Conselho Nacional de Desenvolvimento Científico e Tecnológico \\ dc-MST Minimum Spanning Tree with degree constraint \\ DSP Digital Signal Processing \\ EDA Eletronic Design Automation \\ FPGA Field-programmable Gate Array \\ HDL Hardware Description Language \\ HP-RNP Hardware-Parallelized Representação Nó-Profundidade \\ ICMC Instituto de Ciências Matemáticas e de Computação \\ JTAG Joint Test Action Group \\ LCR Laboratório de Computação Reconfigurável \\ LFSR Linear Feedback Shift Register \\ LNB Link and Node Biased \\ MEF Máquina de Estados Finitos \\ MSTP Minimum Spanning Tree Problem \\ NB Node Biased \\ NDE Node-Depth Encoding \\ OCSTP Optimal Communication Spanning Tree Problem \\ PC Personal Computer \\ P-PAO-S Circuito Paralelo para PAO e Seleção \\ PPR Problema de Projeto de Redes \\ LB Link Biased \\ RNP Representação Nó-Profundidade
}


RNPG Representação Nó-Profundidade e Grau

SDE Sistemas de Distribuição de Energia Elétrica

SOPC System On a Programmable Chip

$T_{d e} \quad$ Árvore de origem

$T_{\text {para }}$ Árvore de destino

$T_{t m p} \quad$ Árvore temporária

USB Universal Serial Bus

VHDL VHSIC Hardware Description Language

XOR Exclusive OR 



\section{Sumário}

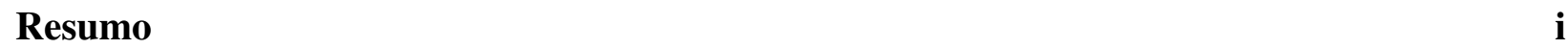

$\begin{array}{lll}\text { Abstract } & \text { iii }\end{array}$

Lista de Figuras

$\begin{array}{lll}\text { Lista de Tabelas } & \text { vii }\end{array}$

$\begin{array}{ll}\text { Lista de Abreviaturas e Siglas } & \mathbf{x}\end{array}$

1 Introdução 1

1.1 Motivação . . . . . . . . . . . . . . . . . . . . . 1

1.2 Objetivo do Projeto de Pesquisa . . . . . . . . . . . . . . . 2

1.3 Contribuições . . . . . . . . . . . . . . . . . . . . . 2

1.4 Organização da Dissertação . . . . . . . . . . . . . . . . . . . . . . . 3

2 Problemas de Projeto de Redes 5

2.1 Árvore Geradora Mínima . . . . . . . . . . . . . . . . . . . . . . . . . . 6

2.2 Problema da Árvore Geradora Mínima com Restrição de Grau . . . . . . . . . . . 8

2.3 Problema da Árvore Geradora de Comunicação Ótima . . . . . . . . . . . . . . . 8

2.4 Sistemas de Distribuição de Energia Elétrica . . . . . . . . . . . . . . . . . . 9

2.5 Problema do Roteamento de Veículos . . . . . . . . . . . . . . . . . . 10

2.6 Considerações Finais . . . . . . . . . . . . . . . . . . . . 11

3 Algoritmos Evolutivos $\quad 13$

3.1 Geração da População Inicial . . . . . . . . . . . . . . . . . . . . . . . . . . . . 14

3.2 Avaliação . . . . . . . . . . . . . . . . . . . . . . . 15

3.3 Seleção . . . . . . . . . . . . . . . . . . 15 
3.4 Recombinação . . . . . . . . . . . . . . . . . . . . . 16

3.5 Mutação . . . . . . . . . . . . . . . . . . . . . . 17

3.6 Considerações Finais . . . . . . . . . . . . . . . . . . 17

4 Representação para Algoritmos Evolutivos $\quad 19$

4.1 Representações de Árvores e Florestas . . . . . . . . . . . . . . . . . . . . . . . 19

4.2 Vetor de Características . . . . . . . . . . . . . . . . . . . 21

4.3 Predecessores . . . . . . . . . . . . . . . . . . 22

4.4 Número de Prüfer . . . . . . . . . . . . . . . . . . . . . 22

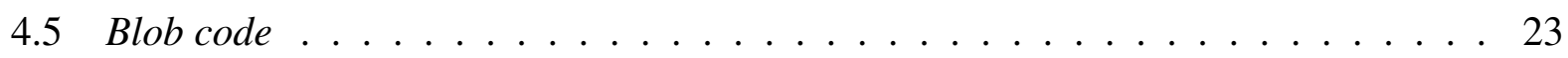

4.6 Tendência de Ligação e Nó . . . . . . . . . . . . . . . . . . . . . . . . . 24

4.7 Conjunto de arestas . . . . . . . . . . . . . . . . . . . . . . . 24

4.8 Representação Nó-Profundidade . . . . . . . . . . . . . . . . . . 25

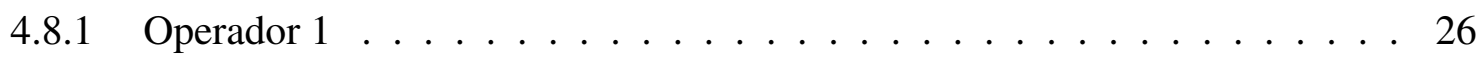

4.8 .2 Operador $2 \ldots \ldots \ldots \ldots \ldots \ldots \ldots$

4.9 Representação Nó-Profundidade e Grau ～. . . . . . . . . . . . . . . . . . . . 30

4.9 .1 Operador PAO da RNPG . . . . . . . . . . . . . . . . . . . 30

4.9 .2 Operador $\mathrm{CAO} \ldots \ldots \ldots \ldots \ldots$

4.10 Comparação entre as Representações . . . . . . . . . . . . . . . . . . . . . . . 34

4.11 Considerações Finais . . . . . . . . . . . . . . . . . . 35

5 Ferramentas para o Desenvolvimento da Arquitetura de Hardware 37

5.1 Field-Programmable Gate Arrays . . . . . . . . . . . . . . . . . . . . . 37

5.2 Paralelização em FPGA . . . . . . . . . . . . . . . . . . . . . . . . . . . 39

5.2.1 Paralelização da RNP em FPGA . . . . . . . . . . . . . . . . . . . . 40

5.3 Linguagem de Descrição de Hardware . . . . . . . . . . . . . . . . . . . . . . 41

5.3.1 Bluespec System Verilog . . . . . . . . . . . . . . . . . . . . 42

5.3 .2 Comparação BSV X VHDL . . . . . . . . . . . . . . . . . . 43

5.4 Linear Feedback Shift Register . . . . . . . . . . . . . . . . . . . . . . . 44

5.5 Ferramentas e Plataformas de Processamento utilizadas . . . . . . . . . . . . . . 44

5.6 Considerações Finais . . . . . . . . . . . . . . . . . . . . 45

6 A Arquitetura de Hardware HP-RNP e

$\begin{array}{ll}\text { Testes Experimentais } & 47\end{array}$

6.1 Visão Geral da Arquitetura de Hardware Paralela RNP . . . . . . . . . . . . . . . . 47

6.2 Circuito Paralelo para PAO e Seleção . . . . . . . . . . . . . . . . . . . . . 49

6.3 Implementação do Trabalhador . . . . . . . . . . . . . . . . . . . . . 50

6.4 Resultados Experimentais . . . . . . . . . . . . . . . . . . . . 51

6.5 Validação de Florestas Geradas pelo P-PAO-S . . . . . . . . . . . . . . . 55

6.5.1 Validação da Consistência das Florestas Geradas . . . . . . . . . . . . 55 
6.5.2 Avaliação da Qualidade das Soluções Geradas . . . . . . . . . . . . . . . 55

6.6 Considerações Finais . . . . . . . . . . . . . . . . . . . . . . 59

$\begin{array}{lll}7 & \text { Conclusão } & 61\end{array}$

A Obtenção dos nós e decodificação da RNP 


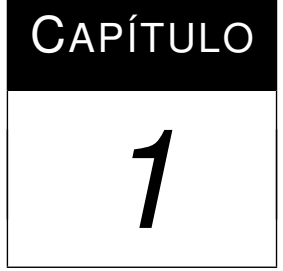

\section{Introdução}

\subsection{Motivação}

Existe uma grande quantidade de problemas presentes em aplicações do mundo real que envolvem projeto de redes como, por exemplo, redes de telecomunicações, sistemas de distribuição de energia elétrica, roteamento de veículos, reconstrução de árvores filogenéticas. Em geral, esses problemas manipulam milhares ou milhões de variáveis de entrada, que muitas vezes requerem a informação em tempo real e possuem múltiplos critérios, tornando-os computacionalmente complexos de serem resolvidos. Os Problemas de Projeto de Redes (PPRs) são problemas combinatórios com um ou mais critérios de avaliação e têm como objetivo obter a rede mais adequada para solucionar aplicações do mundo real (Karger, 1994). Os PPRs podem ser modelados por meio de grafos não orientados. Como exemplo de PPR, pode ser citado o Problema da Árvore Geradora Mínima (MSTP, do inglês Minimum Spanning Tree Problem). O MSTP consiste em encontrar a árvore geradora cuja soma dos pesos das arestas (ver Capítulo 2) é a mínima.

Em geral, pequenas alterações no MSTP resultam em problemas NP-difíceis (Knowles \& Corne, 2000). Por exemplo, apenas acrescentando uma restrição de grau no MSTP, encontrar a solução ótima torna-se um problema intratável para redes de larga-escala. De modo a lidar com a complexidade dos PPRs, Algoritmos Evolutivos (AEs) têm sido investigados para tais problemas (De Jong, 2006; Rothlauf, 2006). Em geral, os AEs têm sido utilizados para solucionar problemas complexos de busca e de otimização que não podem ser resolvidas por meio das técnicas tradicionais, como métodos de busca exaustiva (Goldberg, 1989).

Os AEs simulam processos de evolução dos organismos na natureza, baseando-se na Teoria da Evolução Natural proposta por Charles Darwin (Darwin, 1859, 2004). Todavia, esse tipo de técnica 
muitas vezes não apresenta resultados satisfatórios para problemas com grandes instâncias, pois requer escalabilidade, grande quantidade de memória e tempo de processamento. Buscando desenvolver AEs eficientes para PPRs complexos e de larga-escala, novas estruturas de dados (representações) têm sido pesquisadas. Essas representações possibilitam que o AE explore adequadamente o espaço de busca, aumentando a qualidade das soluções obtidas em termos de precisão e tempo de obtenção do resultado. Dentre as diversas linhas de representações existentes na literatura, a Representação Nó-Profundidade (RNP) (Delbem, 2009), recentemente mostrou resultados relevantes para vários PPRs de larga-escala, obtendo melhores soluções em menor tempo de processamento em comparação às representações tradicionais.

Segundo Raidl e Julstrom (2003), o processo de construção de novas árvores geradoras de grafos (novas redes) utilizando representações desenvolvidas na década de 1990 (como, Predecessores, Número de Prüfer) possui complexidade variando entre $O(n), O(n \log (n))$ e $O\left(n^{2}\right)$, sendo $n$ o número de nós do grafo. No caso da RNP, o tempo de computação médio para a construção de uma árvore geradora (ou uma floresta geradora (Diestel, 2005)) é $O(\sqrt{n})$. Esse resultado foi verificado experimentalmente e demonstrado formalmente em (Lima \& Delbem, 2011), confirmando que a RNP possui eficiência em tempo superior quando comparado a outros métodos. Por isso, essa representação é adequada para lidar com árvores relativamente grandes (Delbem, 2009). Nesse sentido, a implementação dessas estruturas diretamente em hardware pode proporcionar uma paralelização adequada dos processos dos AEs, reduzindo seu tempo computacional. Com isso, um AE com RNP implementado em hardware pode apresentar ganhos significativos no desempenho para grafos com milhares ou milhões de entradas, ou seja, para PPRs de larga-escala.

\subsection{Objetivo do Projeto de Pesquisa}

O objetivo desta pesquisa é implementar a paralelização do operador PAO da RNP em FPGA, de modo a solucionar Problemas de Projetos de Redes existentes em aplicações do mundo real, obtendo novas configurações de árvores ou florestas geradoras (novas redes, ver Capítulo 4) em tempo médio de execução limitado por uma constante $(O(1))$.

\subsection{Contribuições}

As principais contribuições deste trabalho são:

1. O HP-RNP é a primeira implementação completa de uma arquitetura de hardware que produz e avalia novas redes em tempo médio de limitado por uma constante: $O(1)$;

2. A solução paralela em FPGA supera o desempenho software executado em um PC Quad Core para redes acima de 256 nós; 
3. Em termos de consumo de energia, a solução HP-RNP consome 100 vezes menos do que a aplicação em software para PC;

4. A arquitetura proposta possibilita manipular não somente com redes que são árvores geradoras de grafos, mas também com florestas geradoras (Diestel, 2005), permitindo lidar de forma mais eficiente com PPRs com grande número de nós, uma vez que grandes sistemas requerem em geral seu desmembramento em várias árvores, formando uma floresta.

\subsection{Organização da Dissertação}

Esta dissertação está organizada da seguinte maneira:

- O Capítulo 2 apresenta os conceitos básicos de PPRs e alguns exemplos de PPRs que podem ser encontrados em aplicações do mundo real;

- O Capítulo 3 introduz alguns conceitos importantes de AEs, bem como sua utilização e operadores genéticos;

- O Capítulo 4 descreve as representações de grafos para AEs, além de suas propriedades e alguns exemplos dessas codificações, comparando-as com a RNP neste trabalho;

- O Capítulo 5 descreve alguns conceitos básicos de Computação Reconfigurável e FPGAs. Adicionalmente, esse capítulo apresenta a linguagem de descrição de hardware utilizada para a implementação, bem como o gerador de números aleatórios utilizado. Além disso, é proposto o método para a paralelização da RNP em FPGA e as ferramentas utilizadas para o desenvolvimento deste projeto;

- O Capítulo 6 descreve a arquitetura de hardware implementada no FPGA e sintetiza os resultados experimentais dessa arquitetura;

- O Capítulo 7 apresenta as conclusões, destaca as contribuições científicas oferecidas por este projeto de pesquisa e sugestões de trabalhos futuros. 



\section{Problemas de Projeto de Redes}

Em projetos de redes existem muitos problemas que podem ser modelados como grafos (Johnson et al., 1978). Esses problemas envolvem a otimização de múltiplos critérios para avaliação das soluções buscando a melhor rede. As soluções para Problemas de Projeto de Redes (PPRs) do mundo real, em geral, possuem os seguintes aspectos: larga-escala, múltiplos critérios e necessidade de resposta em tempo-real. Considerar esses aspectos tornam o problema computacionalmente complexo. Os PPRs do mundo real podem ser citados problema de redes de telecomunicações, roteamento de veículos, sistemas de distribuição de energia.

Os PPRs são representados por um grafo $G=(V, E)$, onde $V$ é um conjunto de vértices ou nós (pontos da rede) e $E$ é um conjunto de arestas (ligações da rede). Em uma rede, as arestas dos grafos podem estar, por exemplo, associadas a um conjunto de pesos $W$, ou seja, números associados a cada aresta. Como exemplo de PPR de telecomunicações, considere que uma companhia telefônica deseja projetar uma rede interligando algumas cidades. O custo para disponibilizar o serviço telefônico é conhecido, todavia a companhia almeja minimizar os gastos de conexões entre as cidades, tornando-as com menor custo financeiro e cobrindo todas as cidades. Nesse problema, os vértices do grafo podem representar cidades em que se deve fornecer o serviço telefônico, as arestas representam as possíveis conexões e o peso das arestas o custo para construir aquela conexão.

A soma dos pesos das arestas pode determinar o caminho e o custo da rede, ou seja, o caminho mais curto é aquele que possui a menor soma dos pesos das arestas. Em alguns casos, podem ser associados mais de um peso por aresta (Lima, 2009).

A resolução de um PPR corresponde, em geral, a encontrar um subgrafo $G^{\prime}$ de um grafo $G$, que satisfaz otimamente o(s) critério(s) estabelecidos e que seja atendida às restrições do problema. Em 
geral, os algoritmos tradicionais encontram soluções para PPRs em tempo exponencial em relação ao tamanho da entrada, caracterizando um problema NP-completo, tornando esses algoritmos inadequados para a solução de PPRs de larga-escala. Um dos critérios importantes para solucionar um PPR é a minimização do comprimento do percurso entre todos os vértices em uma rede, além disso, o ideal seria encontrar uma solução para problema NP-completo em tempo polinomial. As restrições de um PPR podem ser um limitante para o grau dos vértices ou para o somatório dos pesos das arestas. Nesses casos, a minimização do comprimento do percurso entre os vértices pode não ser adequado para caracterizar o que é uma rede ideal. Além dessas condições, outros fatores devem ser considerados, principalmente em projetos de redes de telecomunicações, elétricas e de computadores: como custo, desempenho e confiança da rede (Lima, 2009). O custo da rede está relacionado ao custo financeiro para sua construção e manutenção; o desempenho da rede refere-se à quantidade de tráfego e fluxo na mesma e a confiança da rede envolve o nível de integridade ou a qualidade de um caminho na rede.

Um típico PPR é descrito em (Johnson et al., 1978): dado um grafo $G=(V, E)$, uma função de pesos $L: E \rightarrow \mathbb{N}$, um orçamento $B$ e um limitante $C$ para o valor critério $(B, C \in N)$, a solução para um PPR consiste em encontrar o subgrafo $H=\left(V, E_{H}\right)$ de $G$ com pesos tais que $\sum_{(i, j) \in E_{H}} L(i, j) \leq B$ e o valor de critério $f(H) \leq C$, sendo $f(H)$ a soma dos comprimentos de caminhos mínimos entre todos os vértices em $H$.

Os PPRs podem estar relacionados em diversos problemas do mundo real, como: árvore geradora mínima com restrição de grau (Raidl \& Julstrom, 2003), árvores geradoras de comunicação ótima (Soak, 2006; Rothlauf et al., 2003), projeto de redes de telecomunicações (Kershenbaum, 1993), roteamento de veículos (Libralão et al., 2005) e reconfiguração de sistema de distribuição de energia elétrica (Delbem et al., 2005). As Seções seguintes descrevem alguns desses problemas formalmente.

\section{1 Árvore Geradora Mínima}

Considerando uma árvore não direcionada $G$, a árvore geradora $T$ é a composição do conjunto mínimo de arestas que permitem de forma acíclica conectar todos os nós de $G$. A árvore geradora mínima (MST, do inglês Minimum Spanning Tree) $M$ é a árvore geradora de $G$ que possui o menor peso total (Graham \& Hell, 1985). As árvores geradoras mínimas possuem as seguintes características (Eisner, 1997):

- Propriedade do corte: sendo $e$ uma aresta de $M, e$ será a menor aresta de alguma poda de $G$;

- Propriedade do ciclo: sendo $e$ uma aresta não pertencente à $M, e$ será a maior aresta de alguma poda de $G$.

Os métodos clássicos para determinação de MSTs são os algoritmos de Kruskal (Kruskal, 1956) e de Prim (Prim, 1957). O método de Kruskal é um algoritmo guloso simples, em que as 
arestas são selecionadas e adicionadas com base em uma ordenação crescente previamente realizada dos pesos das arestas. Uma aresta é adicionada apenas se não criar ciclos e somente uma aresta é adicionada à árvore por vez. O Algoritmo 1 descreve os passos para a obtenção de uma árvore geradora pelo método de Kruskal (adaptado de Cormen et al. (2001)) e a Figura 2.1 ilustra um exemplo de árvore geradora a partir do método de Kruskal.

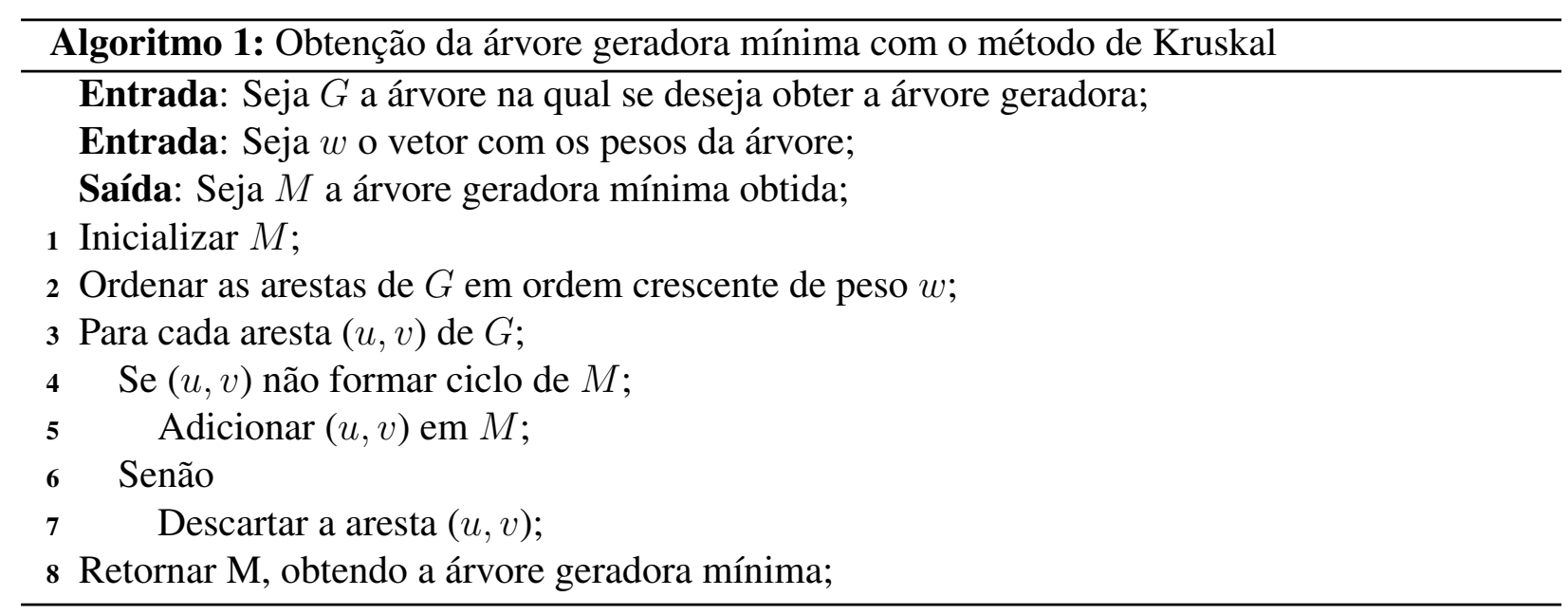

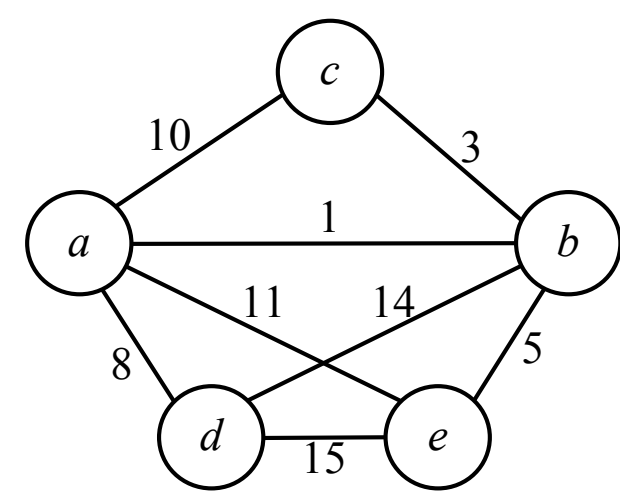

(a) $G$

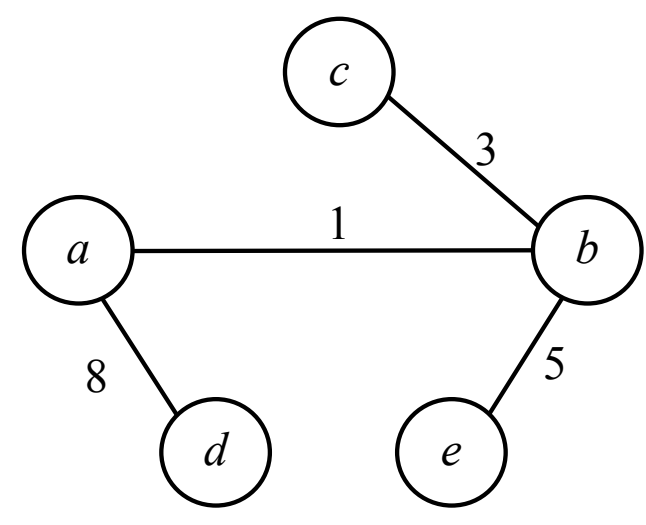

(b) $M$

Figura 2.1: (a) Árvore com 5 nós; (b) MST custo total 17. Obtida por meio do algoritmo de Kruskal.

Existem diversos problemas de roteamento nos quais são utilizadas MSTs para a determinação dos melhores caminhos. Por exemplo, tem-se a aplicação do MST no projeto e desenvolvimento de circuitos eletrônicos e de redes de telecomunicações. Outra aplicação comumente utilizada é na determinação de rotas de cabos elétricos, telefônicos ou de rede para conectar casas ou cidades (Eisner, 1997).

Um conceito expandido sobre as árvores geradoras são as florestas geradoras (Diestel, 2005). Nesse caso, assume-se que o grafo $G$ não é conexo, assim, gera-se uma árvore geradora para cada 
componente conexo. O conjunto das árvores geradoras forma a floresta geradora de $G$. Se as árvores geradoras mínimas de todos os componentes conexos de $G$ forem extraídas, será obtida uma floresta geradora mínima. Na Seção 2.2 são descritas as árvores geradoras mínimas com restrição de grau, um conceito derivado da árvore geradora mínima.

\subsection{Problema da Árvore Geradora Mínima com Restrição de Grau}

O Problema da Árvore Geradora Mínima com Restrição de Grau (dc-MSTP, do inglês $M i$ nimum Spanning Tree with degree constraint Problem) é uma extensão do problema da árvore geradora mínima $M$ obtida de um grafo $G$, adicionando a restrição de grau, sendo que o grau máximo do vértice de $M$ é limitado por uma constante $k$ (Knowles \& Corne, 1999). O problema da dc-MST consiste em encontrar a árvore geradora com a menor soma total dos pesos das arestas e que respeite a restrição de grau, não ultrapassando o grau máximo. Em Garey \& Johnson (1979), foi demonstrado que o dc-MST é um problema NP-difícil que se assemelha muito com o problema do Caixeiro Viajante. Diversas heurísticas têm sido pesquisadas para obter uma solução do dc-MST em um tempo computacional admissível (Krishnamoorthy et al., 2001).

Um dos métodos criados por (Narula \& Ho, 1980) para resolver esse problema provém da modificação do algoritmo de Prim (Prim, 1957). Em (Krishnamoorthy et al., 2001) foi utilizado o método Simulated Annealing combinado com o número de Prüfer. Além disso, AEs foram investigados para resolver juntamente com o número de Prüfer o problema de dc-MST apresentado em (Zhou \& Gen, 1997).

\subsection{Problema da Árvore Geradora de Comunicação Ótima}

O Problema de Árvore Geradora de Comunicação Ótima (OCSTP, do inglês Optimal Communication Spanning Tree Problem) corresponde à determinação de uma árvore geradora mínima que conecte todos os nós e satisfaça as restrições de comunicação da árvore com um custo total mínimo. Esse problema, proposto por Hu (1974), busca a melhor disposição possível das linhas telefônicas em uma cidade. Para o OCSTP são conhecidos previamente o número e as posições do nó da rede para o cálculo do custo da rede que é obtido por meio do custo de cada ligação (Rothlauf et al., 2003).

Formalmente, para o cálculo do custo de comunicação de uma árvore geradora, considera-se o conjunto de $n$ nós (cidades) $N_{i}(i=1, \ldots, n)$ e a distância entre $N_{i}$ e $N_{j}$ representada por $d_{i j}$. Tem-se também um conjunto de requisitos $r_{i j}$ que indica, por exemplo, a quantidade de chamadas telefônicas entre $N_{i}$ e $N_{j}$. A distância de um caminho é dada pelo somatório das distâncias de cada uma das ligações. Dessa forma, o custo da comunicação de $N_{i}$ à $N_{j}$ é o produto de $r_{i j}$ com a 
distância do caminho $d_{i j}$. Por meio da soma do custo de todos os pares de nós de $N_{i}$, obtém-se o custo de comunicação da árvore geradora, dada por $D$.

Como exemplo, considere o cálculo do custo de comunicação da árvore geradora da Figura 2.2, dadas as distâncias dos nós e os requisitos, adaptado de (Palmer, 1994)).

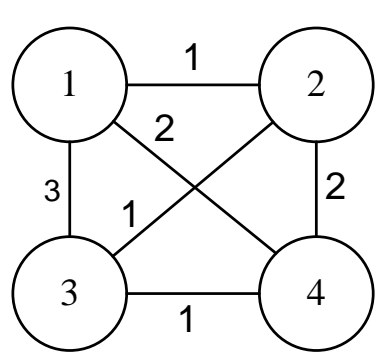

(a) Distância

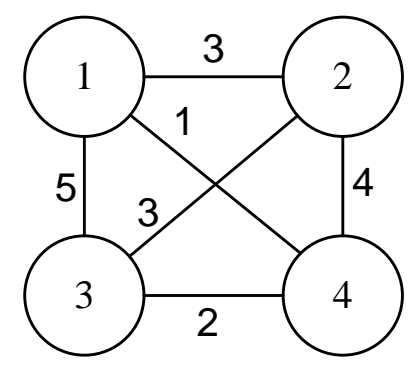

(b) Requisito

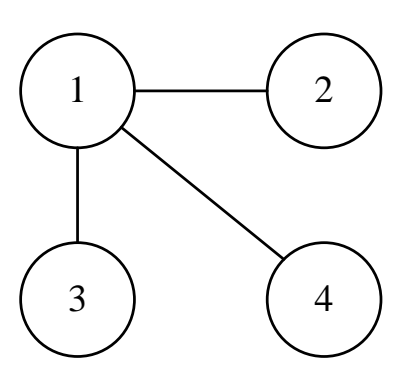

(c) Árvore Geradora

Figura 2.2: Dados para um exemplo de cálculo de um OCSTP com 4 nós.

O custo de comunicação da árvore geradora da Figura 2.2 pode ser calculado da seguinte maneira:

$$
\begin{gathered}
D=d_{12} * r_{12}+d_{13} * r_{13}+d_{14} * r_{14} \\
D=1 * 3+3 * 5+2 * 1 \\
D=20 .
\end{gathered}
$$

O custo dessa árvore geradora é 20. Entretanto, para se determinar o custo mínimo de comunicação de uma árvore seria necessário calcular os custos de comunicação para todas as árvores geradoras. Consequentemente, o custo torna-se alto para redes com muitos nós.

\subsection{Sistemas de Distribuição de Energia Elétrica}

Os Sistemas de Distribuição de Energia Elétrica (SDEs) (Delbem, 2009; Lima, 2009) comumente lidam com problemas relacionados com a configuração da rede de fornecimento de energia elétrica. Os SDEs consistem de subestações de energia que possuem alimentadores que retransmitem eletricidade para circuitos elétricos. Dependendo da disposição das subestações, bem como a quantidade de alimentadores utilizados pode resultar em um SDE ineficiente, implicando gastos adicionais e perda de potência elétrica. Esse problema pode ser modelado por um grafo, que representa os circuitos e as subestações, e uma floresta para o SDE.

Após a modelagem, pode-se estabelecer restrições físicas aos componentes do SDE, indicando as condições normais para a operação das subestações, alimentadores e circuitos elétricos. Isto é necessário para, caso se realize alguma reconfiguração na rede de distribuição, a configuração final não danifique o SDE. Nesse problema, dois objetivos principais podem ser considerados: 
- Minimizar o total de perdas de potência das subestações de energia;

- Minimizar o número de chaveamentos para a alteração da configuração da SDE.

Um exemplo de SDE é ilustrado na Figura 2.3, sendo que cada nó representa um setor e as arestas que conectam os setores aos alimentadores são as chaves seccionadoras. Sendo as arestas em linha contínua são as chaves normalmente fechadas (NF) e as linhas pontilhadas são as chaves normalmente abertas (NA).

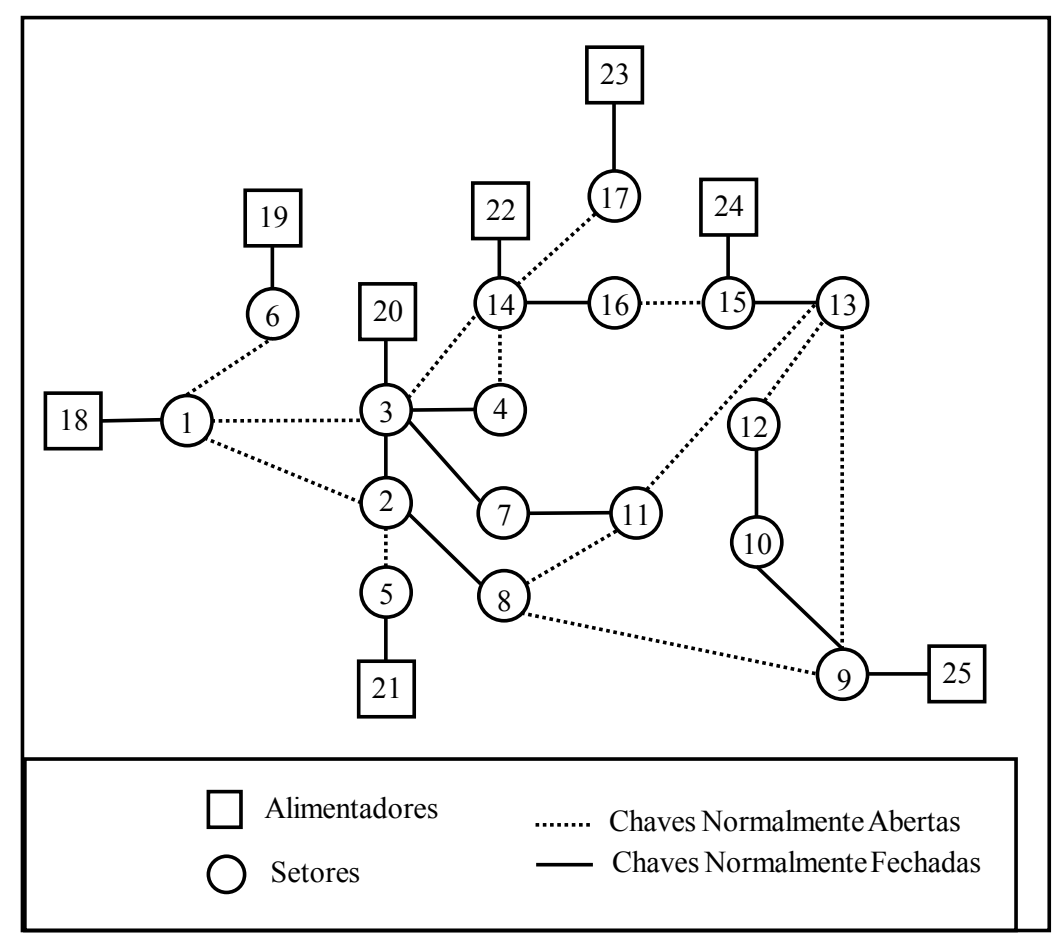

Figura 2.3: Exemplo de um grafo que representa um SDE.

Supondo que ocorra um problema em algum dos setores, deve-se isolar esse setor dos demais nós e, em seguida, encontrar um novo caminho para fornecer energia a esse setor.

\subsection{Problema do Roteamento de Veículos}

O Problema do Roteamento de Veículos (Libralão et al., 2005) é um problema encontrado na área da logística e consiste em minimizar os custos com transportes de mercadorias e custos de empresas. Nesse problema, múltiplos veículos devem atender pedidos em vários destinos (nós da rede), considerando que os veículos podem partir de um único ponto ou de múltiplos pontos espalhados na malha viária. Em geral, as soluções para esses problemas devem satisfazer alguns critérios estabelecidos, os quais podem ser: minimizar o custo total da operação, o tempo total de transporte, a distância total percorrida, o tempo de espera, a utilização de veículos. Além 
disso, deve-se maximizar o benefício e o serviço ao cliente, e também, equilibrar a utilização dos recursos, entre outros critérios. As soluções devem ser obtidas em tempo real, pois o plano de rotas deve ser atualizado a cada solicitação de um cliente.

\subsection{Considerações Finais}

Este Capítulo descreveu uma categoria de problema de alta complexidade (NP-difícil) denominado Problema de Projeto de Rede. Esses problemas lidam com cenários do cotidiano em diversas áreas da engenharia que envolvem construção de redes, como SDEs (Santos et al., 2010). Esses tipos de problemas, em geral, possuem características que inviabilizam a resolução por métodos tradicionais (como, por exemplo, busca exaustiva) quando se possui grande número de instâncias (Rothlauf, 2006). Por essa razão, são exploradas metaheurísticas como os AEs que têm apresentado resultados relevantes para solucionar PPRs pela exploração adequada do espaço de busca. No Capítulo 3, é descrito o Algoritmo Evolutivo, um método que tem sido largamente aplicado em PPRs devido a sua capacidade de busca por soluções para problemas combinatórios e de largaescala. 



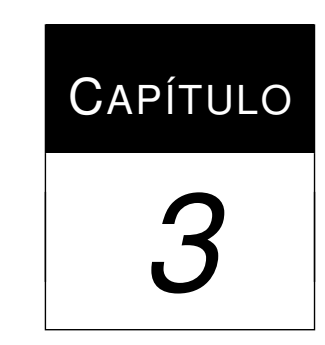

\section{Algoritmos Evolutivos}

Algoritmos Evolutivos são técnicas baseadas em heurísticas que operam sobre um conjunto de população de indivíduos (representados por cromossomos) e utilizam métodos de buscas baseadas na Teoria da Evolução das espécies. Assim, durante o processo de evolução, a população é avaliada e seus indivíduos são submetidos aos procedimentos de seleção e reprodução, no qual são aplicados operadores de recombinação e/ou ${ }^{1}$ mutação inspirados nesses mecanismos naturais da evolução das espécies (Goldberg, 1989; De Jong, 2006).

As variáveis são representadas por genes em um cromossomo e cada cromossomo corresponde a um ponto no espaço de soluções do problema de otimização. Cada valor que um determinado gene pode armazenar é denominado alelo e a posição desse gene no cromossomo é chamada de locus. Em geral, os cromossomos são representados por meio de vetores, sendo que cada campo desse vetor representa um determinado gene. Por exemplo, o valor 0 poderia indicar a ausência de uma determinada característica em um indivíduo e 1 a sua presença. Assim, uma sequência de valores de genes em um cromossomo, chamada de genótipo, determina uma característica própria do indivíduo. Um cromossomo decodificado é denominado fenótipo, o qual é determinado a partir das informações do genótipo (De Jong, 2006).

Em geral, um AE básico possui os seguintes passos:

1. Cria-se aleatoriamente uma população inicial de indivíduos;

2. Avalia-se a população de indivíduos, com base em algum critério, o qual é determinado por uma função de avaliação da qualidade do indivíduo (fitness);

\footnotetext{
${ }^{1} \mathrm{Nem}$ todo AE são aplicados operadores de mutação.
} 
3. Em seguida, selecionam-se os indivíduos mais adaptados (com maiorfitness). A partir disso, é criado um novo conjunto de possíveis soluções, denominado nova população;

4. Os indivíduos que foram selecionados são submetidos aos mecanismos de recombinação e mutação. Isso possibilita que as características de adaptação adequadas perpetuem-se nas próximas populações;

5. O processo de seleção, recombinação e mutação são sequencialmente repetidos até que um critério de parada seja satisfeito. Esse critério pode ser:

- Uma solução adequada ser encontrada (nos casos em que se conhece o resultado esperado);

- Um certo número de iterações ser atingido;

- Os indivíduos não evoluírem mais, isto é, estagnação do processo evolutivo.

A estrutura básica de um AE é sintetizada na Figura 3.1.

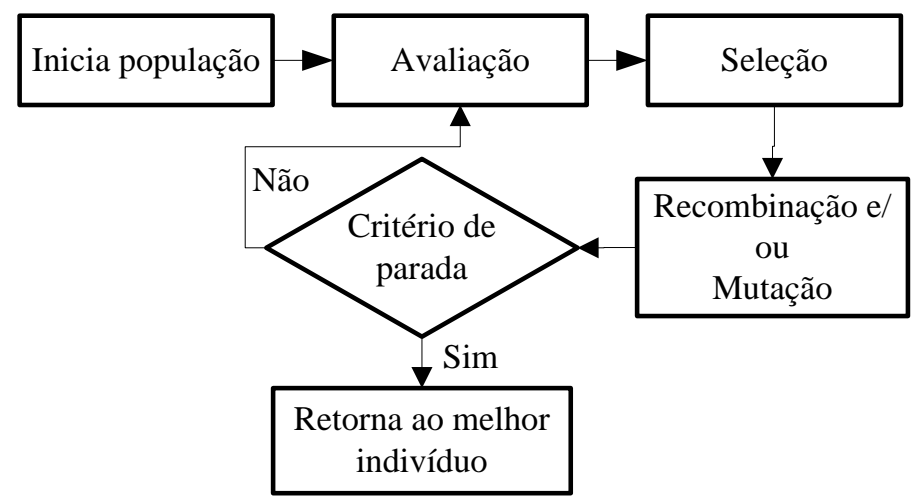

Figura 3.1: Fluxograma de um algoritmo evolutivo básico.

As Seções seguintes explicam detalhadamente cada etapa de um AE, como a geração da população inicial, avaliação dos indivíduos, a seleção e a aplicação dos operadores de recombinação e mutação.

\subsection{Geração da População Inicial}

O primeiro passo no desenvolvimento de um AE é a geração da população inicial, sendo que cada indivíduo dessa população representa uma possível solução para um problema. Essas soluções podem ser representadas de diversas formas: strings binárias, números inteiros ou vetores. Usualmente, a população inicial é gerada atribuindo-se valores aleatórios aos seus genes. Após a população inicial ter sido gerada, cada indivíduo é avaliado e recebe um valor de aptidão. 


\subsection{Avaliação}

Em uma determinada população, é necessário estabelecer uma pontuação que define o quanto um indivíduo é adequado para solucionar o problema. Esse valor é denominado de fitness, e possibilita encontrar os melhores e piores cromossomos em uma população. A função de fitness, por estar ligada diretamente ao problema, muitas vezes é igual à própria função objetivo ou uma modificação dela. Por exemplo, um problema que envolve o cálculo do máximo da função $f(x)=$ $-x^{2}+10$ pode utilizar a própria função objetivo para determinar o fitness. Nesse caso, pode-se dizer que o indivíduo com valor 0 (fitness $=10$ ) é melhor que um indivíduo com valor 1 (fitness $=$ 9).

A avaliação é um pré-requisito para a fase de seleção, pois a escolha dos indivíduos depende diretamente do fitness dos indivíduos. Consequentemente, os cromossomos que possuem os maiores fitness terão melhores condições para se reproduzir e, assim, transmitir os seus genes para as gerações seguintes (De Jong, 2006). A Seção 3.3 apresenta mais detalhes sobre os métodos de seleção.

\subsection{Seleção}

A fase de seleção tem como objetivo básico escolher indivíduos de uma dada população através de critérios pré-definidos, de forma a estabelecer um conjunto de cromossomos aptos a se reproduzirem. Essa fase pode ser comparada ao processo de seleção natural proposto em (Darwin, 2004). Existem diversos métodos de seleção na literatura, dentre os quais podem ser citados: torneio, truncamento e método do fitness proporcional (De Jong, 2006).

No método de seleção por torneio, primeiramente sorteia-se aleatoriamente um conjunto de $k$ indivíduos da população. Desses, escolhe-se apenas o melhor indivíduo, que posteriormente será indicado para a fase de recombinação. A escolha do valor de $k$ afeta diretamente o desempenho do método. Assim, é interessante analisar o efeito desse parâmetro em certas situações. É comum utilizar $k=2$ (torneio de dois). Os dois indivíduos que foram selecionados competem entre si e o vencedor do torneio é o individuo com melhor fitness. São realizados torneios para a seleção de $k$ indivíduos. Analisando o parâmetro $k$, pode-se observar que quanto maior esse valor, maior será a chance de ser selecionado um indivíduo com o fitness maior que a média da população. Sendo assim, se $k=N_{p}$ (sendo $N_{p}$ o tamanho da população), será escolhido o melhor indivíduo desse conjunto, implicando a convergência prematura da população. Entretanto, para $k=2$, obtémse uma maior variedade populacional, dando chance para indivíduos com baixa aptidão serem selecionados, implicando também a diminuição da velocidade de convergência (Goldberg, 2002).

No método de truncamento, são selecionados $k$ indivíduos com o melhor fitness e os outros são descartados do processo. Com esse método, são definidos os $k$ indivíduos que sobreviverão para a próxima geração, participando do processo de reprodução. 
O método de fitness proporcional é também chamado de método da roleta. Isso é explicado pelo fato dessa estratégia seguir o mesmo raciocínio de uma roleta, com cada setor possuindo um tamanho proporcional ao fitness de cada indivíduo. Assim, quanto maior o fitness do indivíduo, maior será a chance do mesmo ser selecionado. O problema do método da roleta é a redução da eficiência da seleção nos casos em que os indivíduos possuam fitness com poucas diferenças. Isso ocorre normalmente quando a população está convergindo. Outro aspecto a ser considerado é o caso em que a aptidão do indivíduo admite valores negativos, não permitindo o uso do fitness proporcional (Bäck, 1996).

\subsection{Recombinação}

Os operadores de recombinação são responsáveis pelo cruzamento de características entre indivíduos pais durante o processo de reprodução. Nesse processo é realizado a troca ou combinação de valores (alelos) de dois ou mais indivíduos, resultando em indivíduos (ou filhos) com parte da informação genotípica de cada um de seus pais (Goldberg, 1989). Existem vários tipos de operadores de recombinação, entre os quais podem ser citados: o operador de recombinação de 1 ponto, o de 2 pontos e o uniforme. O operador de recombinação de 1 ponto é o mais comum. Nessa operação, escolhe-se aleatoriamente um ponto de corte nos cromossomos e trocam-se os fragmentos selecionados entre os pais. Um exemplo de recombinação de 1 ponto é apresentado na Figura 3.2, em que os indivíduos são strings binárias.

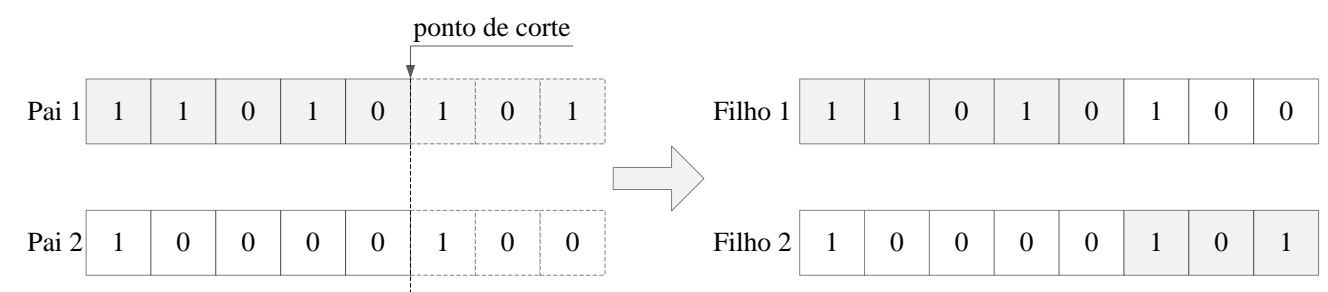

Figura 3.2: Recombinação de 1 ponto.

Na recombinação de 2 pontos, um dos filhos recebe a parte central de um dos pais e as partes dos extremos do outro pai, conforme ilustrado na Figura 3.3.

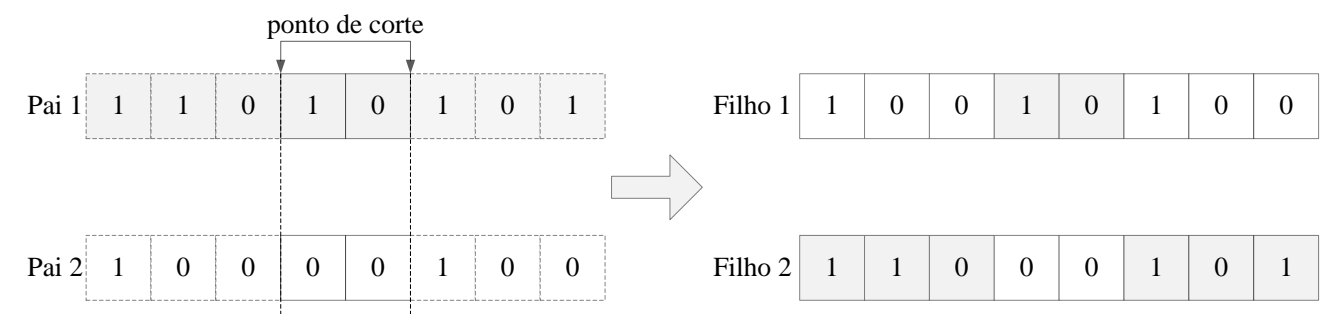

Figura 3.3: Recombinação de 2 pontos.

Na recombinação uniforme diferentemente da recombinação por 1 ou 2 pontos, é associada uma probabilidade uniforme no intervalo de $[0,1]$ a cada posição do cromossomo dos filhos, que 
define se o valor dessa posição será preenchido com o respectivo valor do cromossomo pai 1, ou do cromossomo pai 2.

A recombinação insere apenas diversidade fenotípica na população, pois essa estratégia cruza os genes já existentes na população sem, no entanto, alterá-los.

\subsection{Mutação}

Após a recombinação, os cromossomos tendem a ficar homogêneos. Assim, é importante aplicar o operador de mutação, que evita a convergência prematura, inserindo mudanças nos cromossomos. A mutação consiste em um operador responsável por fazer uma modificação aleatória de um ou mais genes de um cromossomo, gerando um novo indivíduo (filho) para a população. Por essa razão, essa operação é responsável pela manutenção da diversidade dos cromossomos que compõem a população, o que permite estabelecer novas possibilidades de solução para o problema (Eiben \& Smith, 2003).

Diferentemente da recombinação, a mutação é um operador unário, ou seja, ela é aplicada individualmente a cada cromossomo. Por realizar alterações aleatórias, o operador de mutação é sempre estocástico. Sendo assim, o descendente a ser gerado depende do resultado de uma série de escolhas aleatórias. A probabilidade de um determinado cromossomo a ser mutado é dada por um valor denominado "taxa de mutação".

Deve-se ressaltar a importância de escolher uma taxa de mutação adequada, pois a mesma interfere no processo de evolução: Se a taxa escolhida for muito baixa, é possível que as mudanças causadas ocorram de forma mais lenta do que desejada. Se a taxa for muito alta, cresce a probabilidade de que os indivíduos percam características desejadas e já encontradas. Por isso, devem-se atribuir taxas de mutação adequadas aos problemas propostos.

A manutenção da diversidade na população é importante para que o AE possa explorar todo o espaço de busca. Dessa forma, o operador de mutação pode prover uma busca aleatória nas proximidades dadas de soluções da população atual para garantir que nenhum ponto do espaço tenha uma probabilidade zero de ser explorado. Além disso, a introdução de elementos mutados na população pode evitar que o AE fique preso em ótimos locais, possibilitando a continuidade da busca pelo ótimo global.

\subsection{Considerações Finais}

Os Algoritmos Evolutivos (AEs) são mecanismos eficientes para a resolução de problemas complexos baseados no modelo biológico da evolução das espécies. Basicamente os AEs vasculham um espaço de busca para a obtenção do resultado por meio dos operadores de seleção, recombinação e/ou mutação. Para cada problema aplicado no AE, é utilizada uma estrutura de dados específica para a representar a população, sendo fundamental para a qualidade do resultado 
obtido (tempo de resposta e qualidade da solução encontrada). Os AEs em si não garantem a eficiência de uma solução para um PPR. As representações tracionais utilizadas para a resolução dos PPRs possuem complexidade de pelo menos $O(n)$ na execução de um grafo com $n$ nós (Lima, 2009), tornando inviáveis em aplicações críticas como redes de larga-escala. Nesse sentido, são necessárias representações adequadas para PPRs que envolvem um grande número de nós. No Capítulo 4 é descrita a Representação Nó-Profundidade, uma estrutura que possibilita a um AE melhor explorar o espaço de busca, melhorando significativamente seu desempenho, encontrando novas configurações de redes em tempo de $O \sqrt{n}$. 


\section{CAPÍTULO \\ 4 \\ Representação para Algoritmos \\ Evolutivos}

Este Capítulo introduz algumas das representações de grafos para AEs. Essas representações foram desenvolvidas para aumentar o desempenho do AE, explorando adequadamente o seu espaço de busca. No entanto, em problemas que envolvem redes grandes, torna-se impraticável utilizar representações tradicionais, pois muitas vezes geram redes infactíveis e em tempo inadequado. Nesse sentido, é apresentada a Representação Nó-Profundidade e seus operadores, que têm demonstrado ser adequada para PPRs. A RNP foi utilizada neste trabalho. Adicionalmente, é mostrado um comparativo de complexidade computacional entre algumas representações.

\subsection{Representações de Árvores e Florestas}

Para solucionar PPRs de larga-escala são necessários AEs que utilizam representações (estruturas de dados) eficientes de grafos. Isso significa que as codificações tradicionais, como um string binário de características, podem ser inadequadas para solucionar problemas com milhares de arestas, obtendo soluções que correspondem a grafos que não podem ser considerados como redes úteis na prática. Com isso, o tempo de computação para gerar redes adequadas, nesses casos, tende a se tornar proibitivo para grafos de larga-escala, inviabilizando o uso de AEs para PPRs (Lima, 2009). Como forma de resolver problemas das representações convencionais, novas representações têm sido propostas (Rothlauf, 2006). Algumas das principais representações utilizadas para esse problema são: 
1. Vetor de características (Palmer, 1994);

2. Predecessores (Abuali et al., 1995);

3. Número de Prüfer (Zhou \& Gen, 1997);

4. Blob Code (Julstrom, 2005);

5. Tendência de Ligação e Nó (Palmer, 1994);

6. NetKeys (Rothlauf et al., 2002);

7. Conjunto de Arestas (Raidl, 2000b);

8. Representação Nó-Profundidade (Delbem et al., 2004);

9. Representação Nó-Profundidade e Grau (Lima \& Delbem, 2011).

Para a análise da eficiência de uma representação aplicada a AEs, deve-se considerar um conjunto de propriedades, apresentadas em (Raidl \& Julstrom, 2003):

- Espaço: as representações não devem utilizar muita memória;

- Tempo: a complexidade de tempo para realizar a avaliação (que inclui também a decodificação), recombinação e mutação das representações deve ser o menor possível;

- Factibilidade: todos os indivíduos gerados pelos operadores (em particular os obtidos por recombinação e mutação) devem representar soluções factíveis do problema;

- Cobertura: as representações devem ser capazes de representar todas as possíveis soluções do problema, explorando todo o espaço de busca;

- Tendência: todas as soluções devem ser igualmente prováveis de serem representadas. Representações com maior tendência em codificar algumas soluções são favoráveis se somente tais soluções estiverem próximas do ótimo global;

- Localidade: pequenas alterações na representação devem produzir poucas modificações na árvore correspondente;

- Hereditariedade: os operadores de recombinação devem preservar a maioria da arestas dos indivíduos pais nos filhos. Idealmente, espera-se que todas as arestas presentes nos pais estejam nos filhos;

- Restrições: as restrições dos problemas devem ser facilmente respeitadas, sem causar grandes modificações; 
- Hibridismo: os operadores da representação devem possibilitar a inserção de heurísticas específica para o problema considerado;

- Grafos esparsos: a representação deve codificar soluções em grafos não completos, mantendo as características que possuíam anteriormente.

Além das propriedades citadas por Raidl \& Julstrom (2003), deve-se considerar outros dois aspectos para avaliar uma representação apresentados em (Rothlauf, 2006):

- Escalabilidade: representações que privilegiam alguns genes em detrimento de outros reduzem a velocidade de convergência dos AEs. Por isso, é desejável que as representações não possuam preferência entre os genes;

- Redundância: múltiplas representações codificam uma mesma árvore. Se árvores iguais são representadas por codificações similares, a complexidade do problema não é modificada, caso contrário, é alterada, aumentando ou diminuindo tal complexidade.

A seguir são descritas algumas representações, as quais são comparadas em relação as suas propriedades.

\subsection{Vetor de Características}

A codificação Vetor de Características (CV, do inglês Characteristic Vector) é uma representação utilizada para codificar árvores. Essa representação é dada por um vetor binário que indica a presença ou a ausência de uma possível aresta em um grafo (Rothlauf et al., 2002). Considerando que um grafo com $n$ nós e $m=n(n-1) / 2$ possíveis arestas, o tamanho do vetor que representa a $\mathrm{CV}$ é $m$. Cada aresta do grafo é associada a um índice entre 1 e $m$. A codificação de uma árvore por meio do $\mathrm{CV}$ é realizado pela inserção do valor 1 na posição correspondente a cada uma das arestas do grafo; caso não haja aresta, é inserido o valor 0. A Figura 4.1 ilustra um exemplo da representação $\mathrm{CV}$.

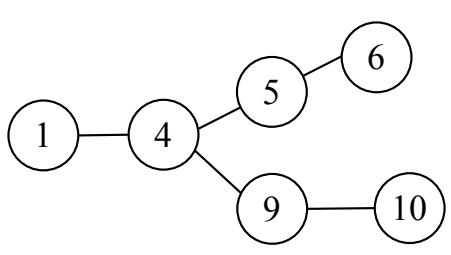

\begin{tabular}{|c|c|c|c|c|c|c|c|c|c|c|c|c|c|c|}
\hline 1 & 0 & 0 & 0 & 0 & 1 & 0 & 1 & 0 & 1 & 0 & 0 & 0 & 0 & 1 \\
\hline $1-4$ & $1-5$ & $1-6$ & $1-9$ & $1-10$ & $4-5$ & $4-6$ & $4-9$ & $4-10$ & $5-6$ & $5-9$ & $5-10$ & $6-9$ & $6-10$ & $9-10$ \\
\hline
\end{tabular}

Figura 4.1: Árvore e sua representação CV. 
A codificação CV é uma das representações que apresentam complexidade mais alta quando comparada as existentes na literatura. Em relação aptidão em representar todas as árvores possíveis, com esta codificação podem ser gerados grafos que não correspondem a árvores. Possui alta localidade, pois, ao modificar a posição do vetor na representação, altera-se também a posição da aresta do grafo, inserindo ou removendo a mesma, independente da árvore representada. Outra propriedade do CV crítica é a complexidade de tempo e espaço, sendo $O(m)$ para grafos esparsos e $O\left(n^{2}\right)$ grafos densos e completos. Em relação a complexidade de tempo para grafos completos é $O\left(n^{2}\right)$.

\subsection{Predecessores}

A codificação predecessores também conhecida como codificação determinante é baseada no Teorema de Even (Even, 1979). Nessa representação, o número de árvores geradoras de um grafo orientado com uma determinada raiz é estabelecido por meio de uma matriz de adjacências. Assim, uma árvore é codificada armazenado-se para cada nó um predecessor (a partir do nó raiz $r$ ), dado que a orientação da árvore está no sentido da raiz para as folhas. Caso Pred[i] $=j$, então $j$ é o primeiro nó no caminho de $i$ até $r$ na árvore. Sendo assim, em geral, Pred $[r]=r$. A Figura 4.2 ilustra um exemplo da árvore e sua representação correspondente com predecessores.

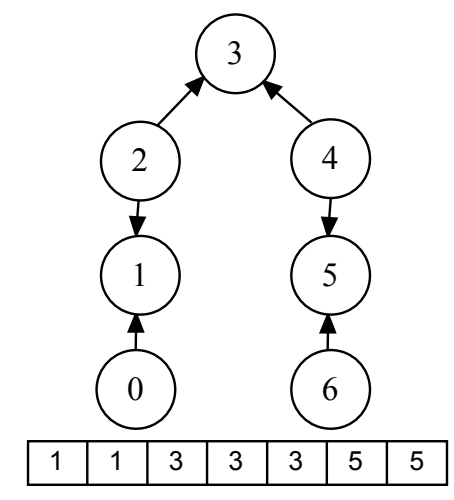

Figura 4.2: Árvore e sua representação predecessores.

Uma propriedade crítica dessa representação é que a mesma produz muitas soluções infactíveis, representando árvores com ciclos ou desconexas. Além disso, complexidade de tempo é alta sendo $O\left(n^{2}\right)$, tornando inviáveis especialmente para PPRs de larga-escala.

\subsection{Número de Prüfer}

Número de Prüfer é uma representação que codifica árvores. Considerando uma árvore $T$, com $n$ nós, a codificação Número de Prüfer é uma sequência de $n-2$ dígitos, rotulados de 1 a $n$. A 
codificação é realizada com sucessivas remoções da folha de menor rótulo da árvore e adicionando o valor do rótulo vizinho (vértice adjacente). O processo de remoção das folhas é finalizado quando restam duas folhas na árvore, obtendo-se, ao final, o Número de Prüfer. A Figura 4.3 ilustra o a Codificação por Número de Prüfer.

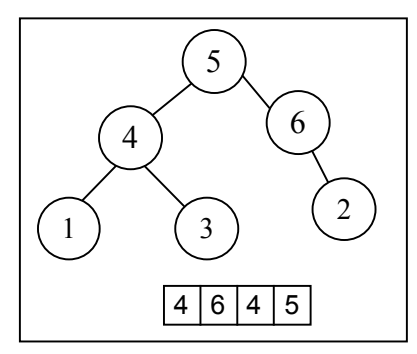

Figura 4.3: Árvore e sua representação Número de Prüfer.

Essa representação possui como fator crítico que é a sua localidade que é relativamente baixa, alterando um dos dígitos de um Número de Prüfer, pode resultar em uma árvore muito diferente e essa codificação apenas pode representar árvores. Além disso, é inviável para manipular com grafos esparsos, tornando inadequado para solucionar PPRs. A representação Número de Prüfer pode ser decodificada e codificada em complexidade de tempo $O(n \log n)$. A Seção 4.10 apresenta uma tabela com um comparativo entre complexidades de representações, incluindo as citadas.

\subsection{Blob code}

A representação Blob code, apresentada por Picciotto, surgiu com o propósito de preencher os problemas de hereditariedade e de localidade existentes na representação de Prüfer. Além disso, apresenta um melhor desempenho nos algoritmos evolutivos no problema de One-Max-Tree (Julstrom, 2005). Na representação por Blob code, da mesma forma como no Prüfer, a árvore também é representada por uma sequência de $n$ - 2 dígitos.

Blob code utiliza uma estrutura denominada blob que armazena um ou mais vértices. Essa estrutura contém os vértices $i+1, i+2, \ldots, n-1$. O algoritmo de decodificação consiste na análise da sequência de dígitos, realizando ajustes necessários na árvore que está sendo gerada, de acordo com a intersecção realizada pelos vértices com o blob. Em termos de complexidade de tempo, no pior caso, a representação por Blob code possui complexidade de tempo $O\left(n^{2}\right)$. No entanto, em Julstrom (Julstrom, 2005) apresenta que utilizando os operadores de recombinação de dois pontos e mutação padrão a complexidade de tempo é $O(n)$. 


\subsection{Tendência de Ligação e Nó}

A representação Tendência de Ligação e Nó (LNB, do inglês Link and Node Biased) proposta por Palmer (Palmer, 1994), possibilita que na busca em um algoritmo genético seja priorizado nós mais importantes para a solução de um problema. Essa representação possui duas formas de ser realizada: a Tendência de Nó (NB, do inglês Node Biased) que define o grau de importância dos nós e a Tendência de Ligação (LB, do inglês Link Biased) que caracteriza o grau de importância das ligações (Palmer, 1994). Esta representação foi criada com o intuito de superar problemas existentes na representação de vetor característica, predecessor e Número de Prüfer.

A LNB utiliza o algoritmo de Prim (Prim, 1957) para encontrar as árvores geradoras e possui complexidade de tempo $O\left(n^{2}\right)$ e em termos de complexidade de espaço para grafos completos $O\left(n^{2}\right)$ e para grafos não completos é $O(m+n)$.

\subsection{Conjunto de arestas}

Conjunto de arestas é uma representação que codifica uma árvore baseado no seus conjuntos de arestas. Essa representação pode ser codificada por meio de dois métodos: um vetor ou uma tabela hash. No método da tabela hash as entradas são pares de nós que representam as arestas. A representação por conjunto de arestas possibilita a inserção, busca e remoção das arestas em tempo constante (Raidl, 2000b). Além disso, essa representação possui complexidade em espaço $O(n)$, sendo $n$ o número de nós no grafo. As soluções por representação Conjunto de Arestas pode ser encontrada por meio de três algoritmos, sendo a extensão de dois algoritmos tradicionais de Prim e de Kruskal e um algoritmo de geração por caminhos aleatórios (Raidl, 2000b). Nos algoritmos de Prim e Kruskal, a complexidade de tempo varia de $O(m)$ a $O(n)$.

Para trabalhar com algoritmos evolutivos, essa representação utiliza um operador para a criação de uma população inicial que obtém árvores geradoras aleatoriamente. No operador de recombinação é derivada uma nova estrutura a partir da união de dois conjuntos de arestas. A Figura 4.4 ilustra um exemplo de uma árvore e sua representação por Conjunto de arestas.

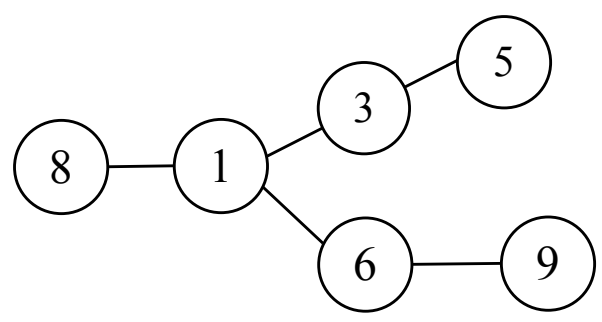

$$
\{(8,1),(6,9),(5,3),(1,3),(6,1)\}
$$

Figura 4.4: Árvore e sua representação por Conjunto de Arestas. 


\subsection{Representação Nó-Profundidade}

A Representação Nó-Profundidade (RNP) baseia-se nos conceitos de caminho e profundidade do nó em uma árvore de grafos (Delbem \& de Carvalho, 2003). É uma codificação criada com o objetivo de melhorar o desempenho dos AEs para a resolução de PPRs, buscando gerar soluções factíveis (Lima, 2009).

A RNP armazena informações relativas à profundidade de cada nó de uma árvore. A estrutura de uma RNP consiste basicamente em um array ou uma lista contendo um par de valores $\left(n_{x}, d_{x}\right)$. O primeiro campo $\left(n_{x}\right)$ informa o nó e o segundo $\left(d_{x}\right)$ indica a profundidade desse nó na árvore (Libralão \& Delbem, 2005). A árvore é obtida por meio de uma busca em profundidade no grafo a partir do nó raiz. Na Figura 4.5 é ilustrada uma floresta de grafos, possuindo 3 árvores $A_{1}, A_{2}$ e $A_{3}$ e suas raízes os nós 1, 2 e 3 respectivamente. Além disso, são apresentadas as RNPs das 3 árvores.

Um aspecto importante a ser ressaltado na RNP, que inexiste na maioria das outras representações, é a possibilidade de codificar também florestas geradoras, além das árvores geradoras ${ }^{1}$. Para isso, é utilizado um conjunto de RNPs que são acessados por meio de um array que armazena os ponteiros para cada uma das RNPs das árvores da floresta (Delbem \& de Carvalho, 2003).

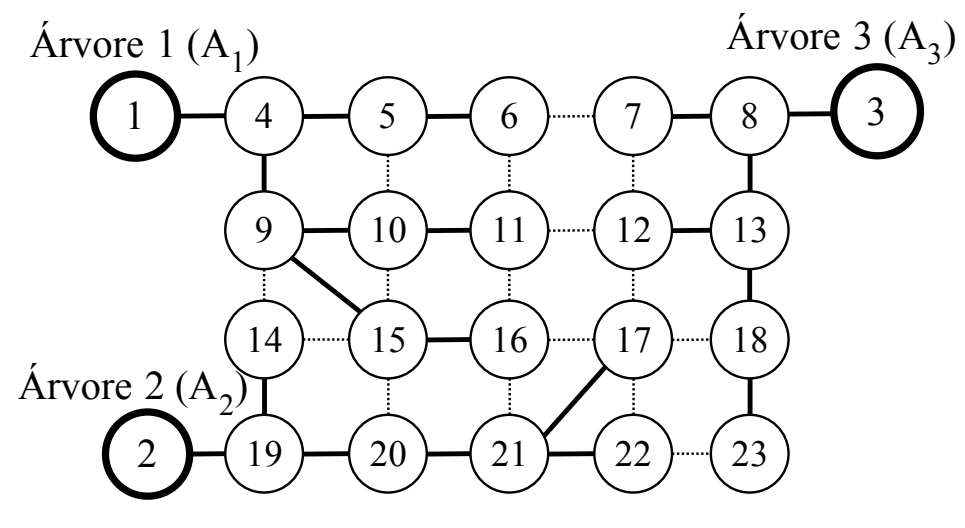

(a)

$$
\begin{aligned}
& \mathrm{A}_{1}=\left[\begin{array}{c}
\text { profundidade } \\
\text { nó }
\end{array}\right]=\left[\begin{array}{rrrrrrrrr}
0 & 1 & 2 & 3 & 2 & 3 & 4 & 3 & 4 \\
1 & 4 & 5 & 6 & 9 & 10 & 11 & 15 & 16
\end{array}\right] \\
& \mathrm{A}_{2}=\left[\begin{array}{c}
\text { profundidade } \\
\text { nó }
\end{array}\right]=\left[\begin{array}{ccccccc}
0 & 1 & 2 & 2 & 3 & 4 & 4 \\
2 & 19 & 14 & 20 & 21 & 17 & 22
\end{array}\right] \\
& \mathrm{A}_{3}=\left[\begin{array}{c}
\text { profundidade } \\
\text { nó }
\end{array}\right]=\left[\begin{array}{rrrrrrr}
0 & 1 & 2 & 2 & 3 & 3 & 4 \\
3 & 8 & 7 & 13 & 12 & 18 & 23
\end{array}\right]
\end{aligned}
$$

(b)

Figura 4.5: Floresta com 3 árvores (a) e suas RNPs correspondentes (b).

\footnotetext{
${ }^{1}$ Árvore é dita geradora quando todos os nós do grafo estão interligados entre si, sem nós isolados
} 
Com o objetivo de produzir novas florestas geradoras, ou árvores de grafos, de forma eficiente, foram desenvolvidos dois operadores de reprodução, também chamados de operadores de mutação, por meio dos quais uma nova solução é gerada a partir de apenas uma outra solução. Esses operadores foram nomeados de Operador 1 e Operador 2 (Delbem et al., 2004). Ambos os operadores funcionam de forma similar, transferindo uma subárvore (árvore podada) a partir de uma árvore origem $T_{d e}$ para uma árvore destino $T_{\text {para }}$. Ambos os operadores estão descritos nas subseções 4.8.1 e 4.8.2.

\subsubsection{Operador 1}

O algoritmo do Operador 1 utiliza como entrada os nós $p$ e $a$, os quais são previamente determinados. Um método eficiente para a escolha adequada desses nós é descrito no Apêndice A. O nó de poda $p$ oriundo da árvore de origem $T_{d e}$, indica a raiz da nova subárvore que será podada e o nó adjacente $a$ indica o nó da árvore de destino $T_{\text {para }}$, onde a subárvore podada será inserida. A RNP é implementada por meio de um array. É necessário informar também os índices de $p\left(i_{p}\right)$ e $a$ ( $i_{a}$ ) nos arrays $T_{d e}$ e $T_{\text {para }}$. O Algoritmo 2 descreve os passos do funcionamento desse algoritmo. A Figura 4.6 apresenta um exemplo da aplicação do Operador 1, considerando que os nós $p$ e $a$ foram previamente escolhidos.

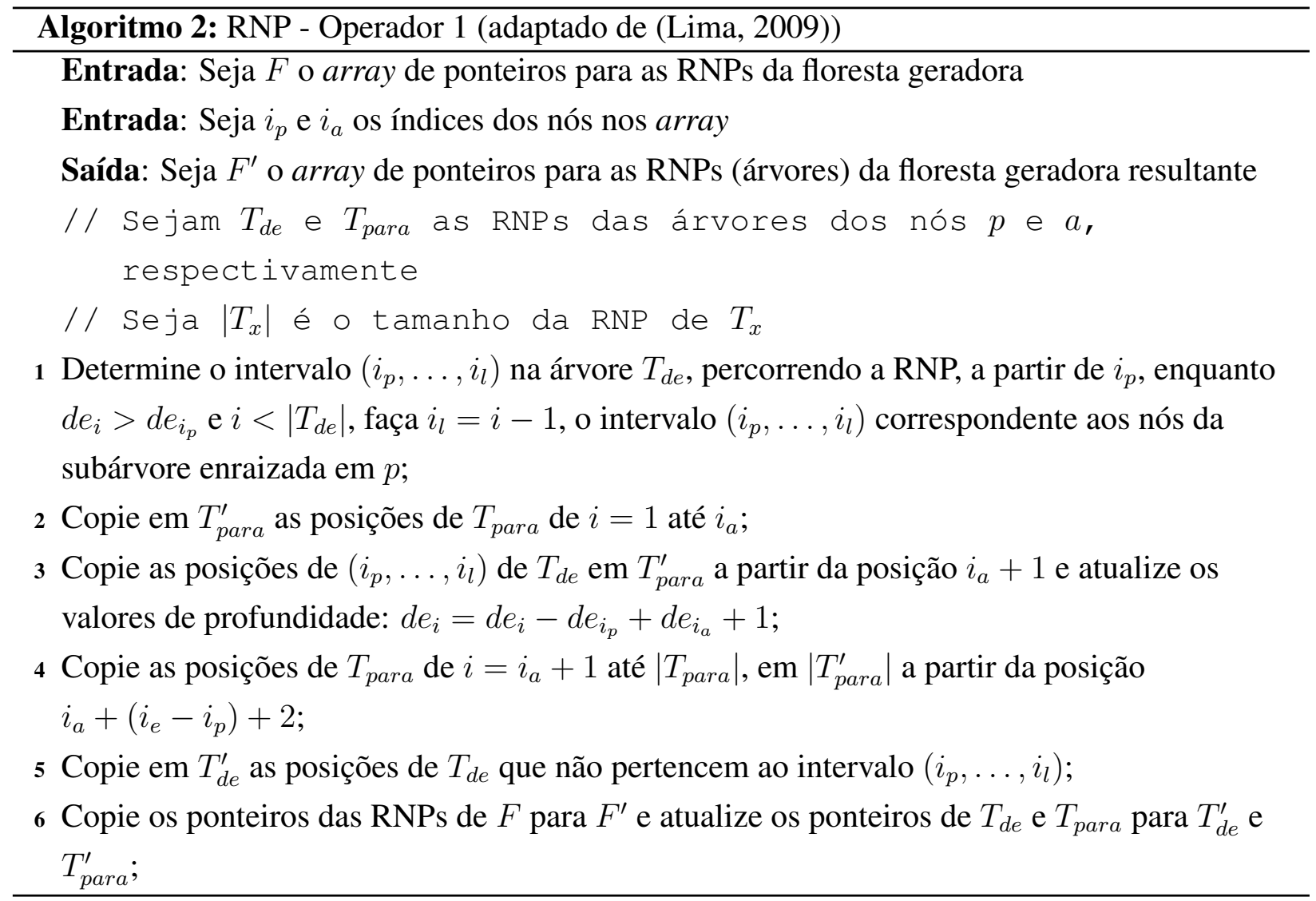




\subsubsection{Operador 2}

Diferentemente do Operador 1, que requer dois argumentos para manipular uma árvore, com auxílio do Operador 2 deve-se ter três argumentos predefinidos: além dos nós $p$ e $a$, é acrescido o nó $r$, que indica a nova raiz da subárvore. Para manipulação por meio desse operador são realizadas algumas alterações no Algoritmo 2 apresentado na Seção 4.8.1. As modificações estão nos Passos 2 e 3 do algoritmo, sendo assim, ambos diferem na criação e armazenamento das subárvores podadas (Delbem et al., 2004).

O Passo 1 equivale ao Passo 2 do Operador 1, substituindo o intervalo $i_{p}-i_{l}$ por $i_{r}-i_{l}$. Essa etapa devolve também um array $T_{t m p 1}$. O Passo 2 considera o caminho entre os nós $r$ e $p$ como nós da subárvore, ou seja, tendo-se $r_{0}, r_{1}, r_{2}, \ldots, r_{n}$, faz-se $r_{0}=r$ e $r_{n}=p$. Dessa forma, a subárvore que tem $r_{1}$ como raiz conterá a subárvore com a raiz $r_{0}$. A subárvore com raiz em $r_{2}$ conterá a subárvore com raiz em $r_{1}$ e assim por diante. No Passo 2, são copiadas as subárvores enraizadas em $r_{j}(j=1, \ldots, n)$ excluindo-se a subárvore com raiz em $r_{j-1}$. Posteriormente, atualizam-se as profundidades e armazena-se o resultado em um array temporário $T_{t m p 2}$. O Passo 3 é similar ao realizado no Operador 1, trocando-se $T_{t m p 1}$ pela união de $T_{t m p 1} \operatorname{com} T_{t m p 2}$. Os Passos 4 e 5 são os mesmos nos dois operadores.

A Figura 4.7 ilustra o exemplo de aplicação do Operador 2, considerando as mesmas árvores de origem $\left(T_{d e}^{\prime}\right)$ e de destino $\left(T_{\text {para }}\right)$ da Figura 4.6.

A diferença existente entre eles é que, no Operador 1, a raiz da árvore podada não é alterada em $T_{d e}$ e $T_{\text {para }}$ enquanto que, no Operador 2 , é escolhido um novo nó em $T_{\text {para }}$ como a raiz da árvore podada. Por essa razão, o primeiro operador depende do nó $p$, pertencente à $T_{d e}$, no qual é representada a raiz da subárvore a ser podada, e do nó $a$, pertencente à $T_{\text {para }}$, que indica onde $p$ será inserida. O segundo operador depende desses dois nós e do nó $r$, que será a nova raiz da subárvore podada em $T_{\text {para }}$. 


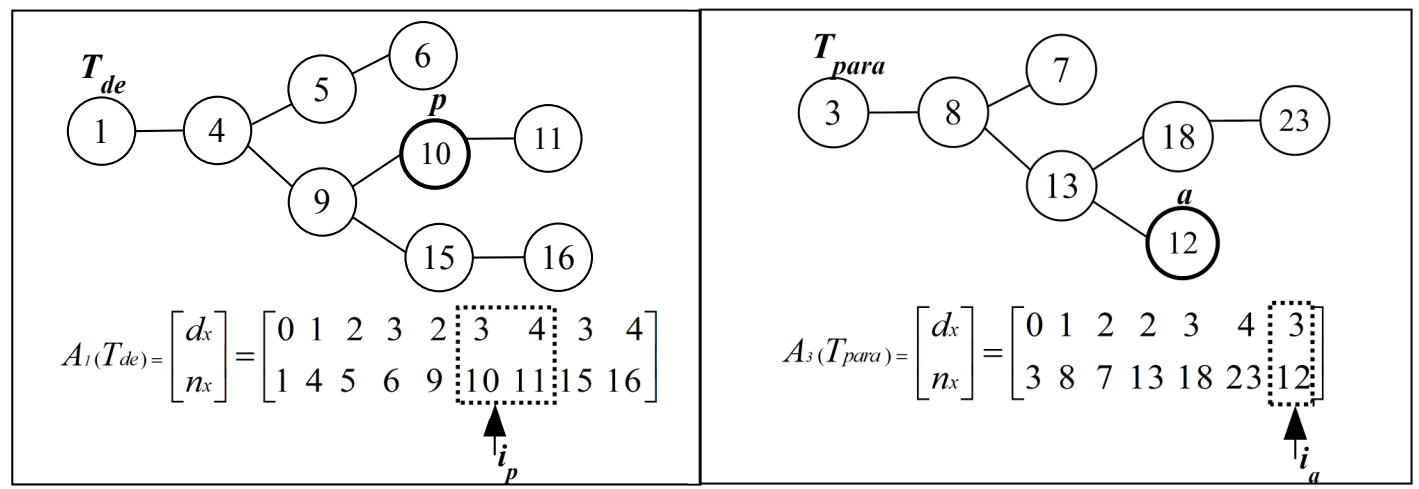

(a) Árvore de origem $\left(T_{d e}\right)$ e Árvore de destino $\left(T_{\text {para }}\right)$ e suas representações nó-profundidade.

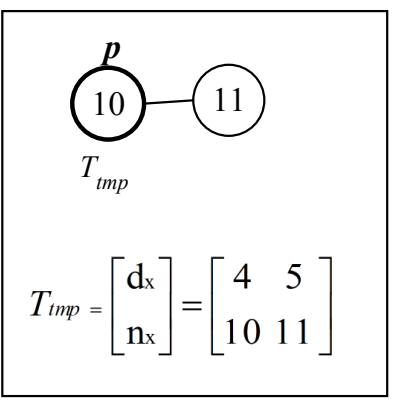

(b) Árvore podada $\left(T_{t m p}\right)$ e sua representação nó-profundidade.

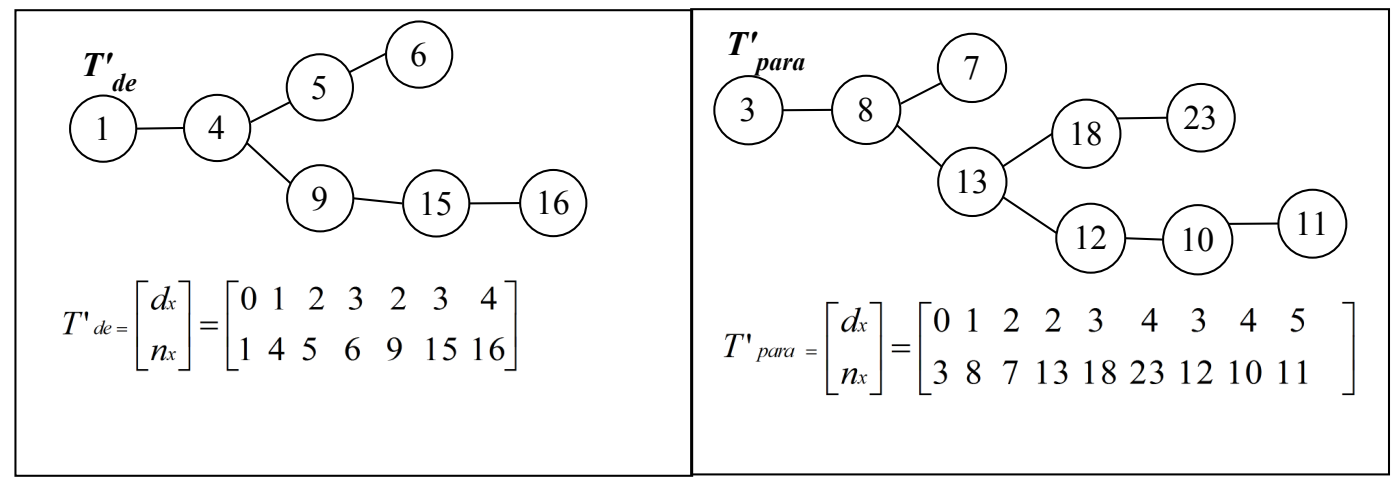

(c) Novas árvores geradas $\left(T_{d e}^{\prime}\right)$ e $\left(T_{\text {para }}^{\prime}\right)$ e suas representações.

Figura 4.6: Novas árvores geradas $\left(T_{d e}^{\prime}\right)$ e $\left(T_{\text {para }}^{\prime}\right)$ e suas representações, utilizando Operador 1. 


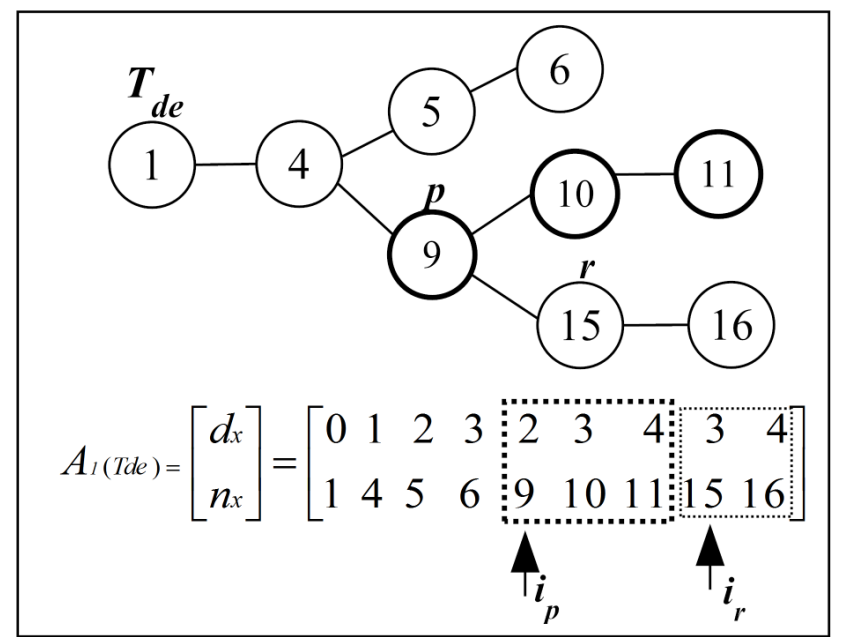

(a) Árvore de origem $\left(T_{d e}\right)$ e sua representação nó-profundidade.

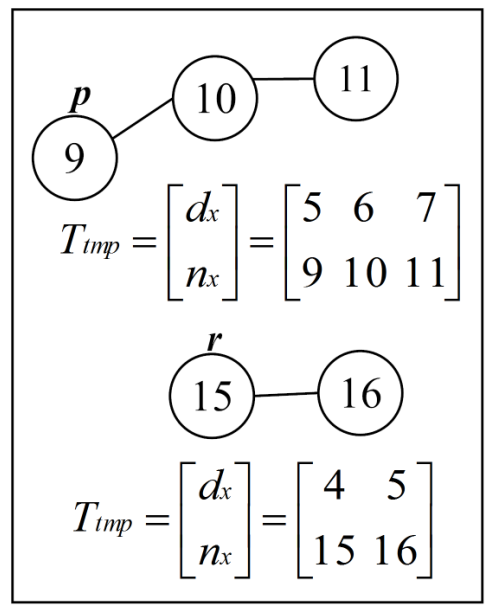

(b) Árvore podada $\left(T_{t m p}\right)$ e sua representação nó-profundidade.

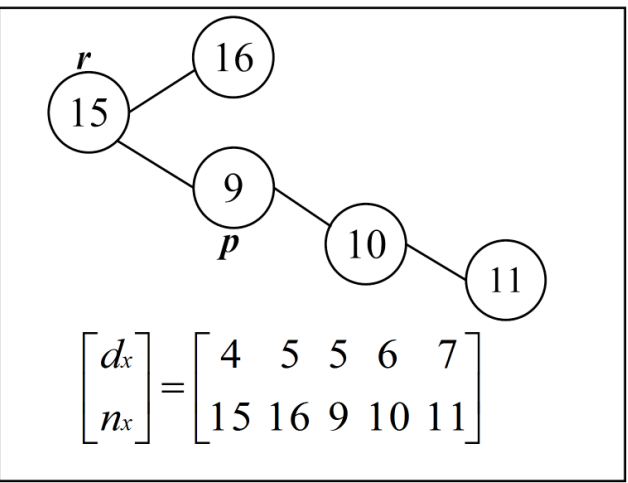

(c) Novas árvores geradas $\left(T_{d e}^{\prime}\right)$ e $\left(T_{\text {para }}^{\prime}\right)$ e suas representações.

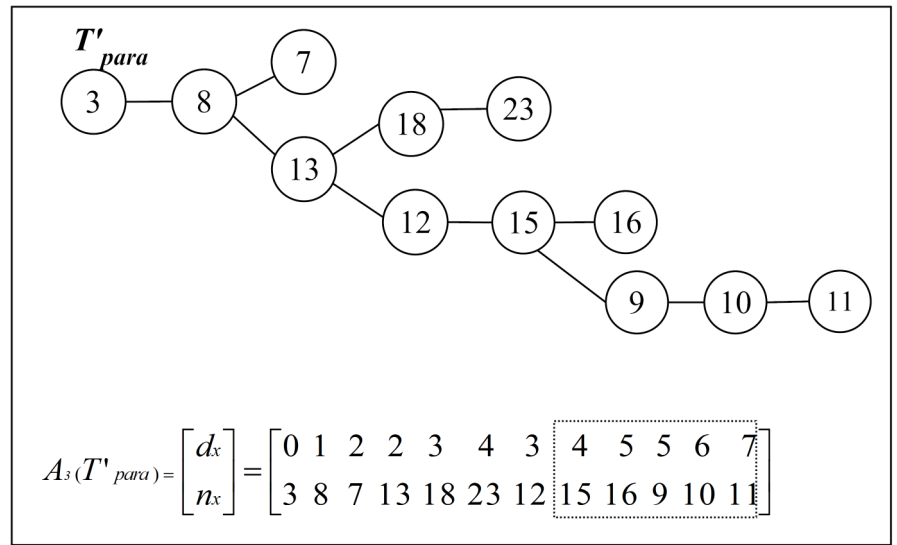

(d) Árvore podada $\left(T_{t m p}\right)$ e sua representação nó-profundidade.

Figura 4.7: Nova árvore gerada $\left(T_{\text {para }}^{\prime}\right)$ e sua representação, utilizando Operador 2. 


\subsection{Representação Nó-Profundidade e Grau}

A Representação Nó-Profundidade e Grau (RNPG) é uma estrutura de dados que foi desenvolvida com base na melhoria dos operadores da RNP. A RNPG de uma árvore é representada por uma sequência tripla de argumentos ordenados $\left(n_{x}, d_{x}, g_{x}\right)$, onde $n_{x}$ é um nó, $d_{x}$ é a profundidade e $g_{x}$ é o grau do nó na árvore (Delbem et al., 2004). O grau de um nó de uma árvore é a soma dos vértices o qual o determinado nó está conectado.

O desenvolvimento da RNPG possibilita a redução da complexidade de tempo da representação para a resolução de grandes problemas (milhares e milhões de instâncias) e o aumento da eficiência para soluções de PPRs em tempo real. Isso ocorre devido ao terceiro argumento armazenado, o grau do nó de uma árvore. Essa informação adicional possibilita determinar eficientemente os vértices necessários para a construção da nova árvore. Deve-se observar que muitas das representações existentes possuem baixa eficiência para trabalhar com PPRs em larga-escala e em tempo real. É comprovado, teoricamente e experimentalmente, que o tempo de computação médio da RNPG é $O(\sqrt{n})$ (Lima et al., 2011; Delbem, 2009). No entanto, a implementação dessa representação é mais difícil que a RNP devido ao argumento grau. É importante ressaltar que a RNP possui tempo médio de computação aproximado ao da RNPG para florestas com $O(\sqrt{n})$ árvores. Por isso, a RNP torna-se mais adequada para vários PPRs do mundo real (Delbem, 2009).

A RNPG possui dois operadores similares ao da RNP para manipular florestas geradoras, denominados PAO (do inglês, Preserve Ancestor Operator) e o CAO (do inglês, Change Ancestor Operator). Similarmente aos operadores da RNP, nos operadores PAO e CAO é transferida uma subávore podada da árvore de origem para uma árvore de destino. Assim, para ambos operadores, são necessárias duas árvores, uma de origem e uma de destino. Dessa maneira, remove-se uma subárvore de uma árvore de origem $T_{d e}$ para, então, inserílla em outra árvore de destino $T_{\text {para }}$ pertencente à mesma floresta, gerando uma nova floresta.

Com o operador PAO, a raiz da nova árvore permanece a mesma da árvore de origem, ao contrário do operador CAO. Por isso, em geral, o operador PAO produz alterações menores, enquanto que o operador CAO gera maiores mudanças (Lima, 2009). Na sequência, as subseções 4.9.1 e 4.9.2 são descritos os operadores PAO e CAO.

\subsubsection{Operador PAO da RNPG}

Para manipular árvores por meio do operador PAO são necessários dois vértices de entrada: o vértice de corte $p$ e o vértice $a$, adjacente a $p$. O funcionamento do operador PAO é dado pela remoção de um segmento de um array iniciado em $p$ da árvore de origem $\left(T_{d e}\right)$; em seguida, esse segmento é inserido à direita de um nó $a$ na árvore de destino $\left(T_{\text {para }}\right)$. O operador PAO realiza a recombinação de duas árvores a fim de gerar duas novas árvores. Para isso, é escolhido um ponto de recombinação no array de profundidade das duas árvores e, posteriormente, trocam-se 
apenas os segmentos correspondentes às profundidades. O array dos nós é mantido e os filhos são copiados. A Figura 4.8 ilustra as estruturas das árvores pais, a operação PAO e os filhos resultantes.

Um pseudocódigo do operador PAO é apresentado no Algoritmo 3, considerando que foram previamente selecionados o nó $p$ e seu índice $i_{p}$ em $T_{d e}$ e o nó a e seu índice $i_{a}$ em $T_{\text {para }}$.

Existe também a possibilidade de efetuar a recombinação entre duas RNPs de tamanhos diferentes. Nesse caso, é necessário recalcular a profundidade do nó remanescente a partir do ponto de recombinação.

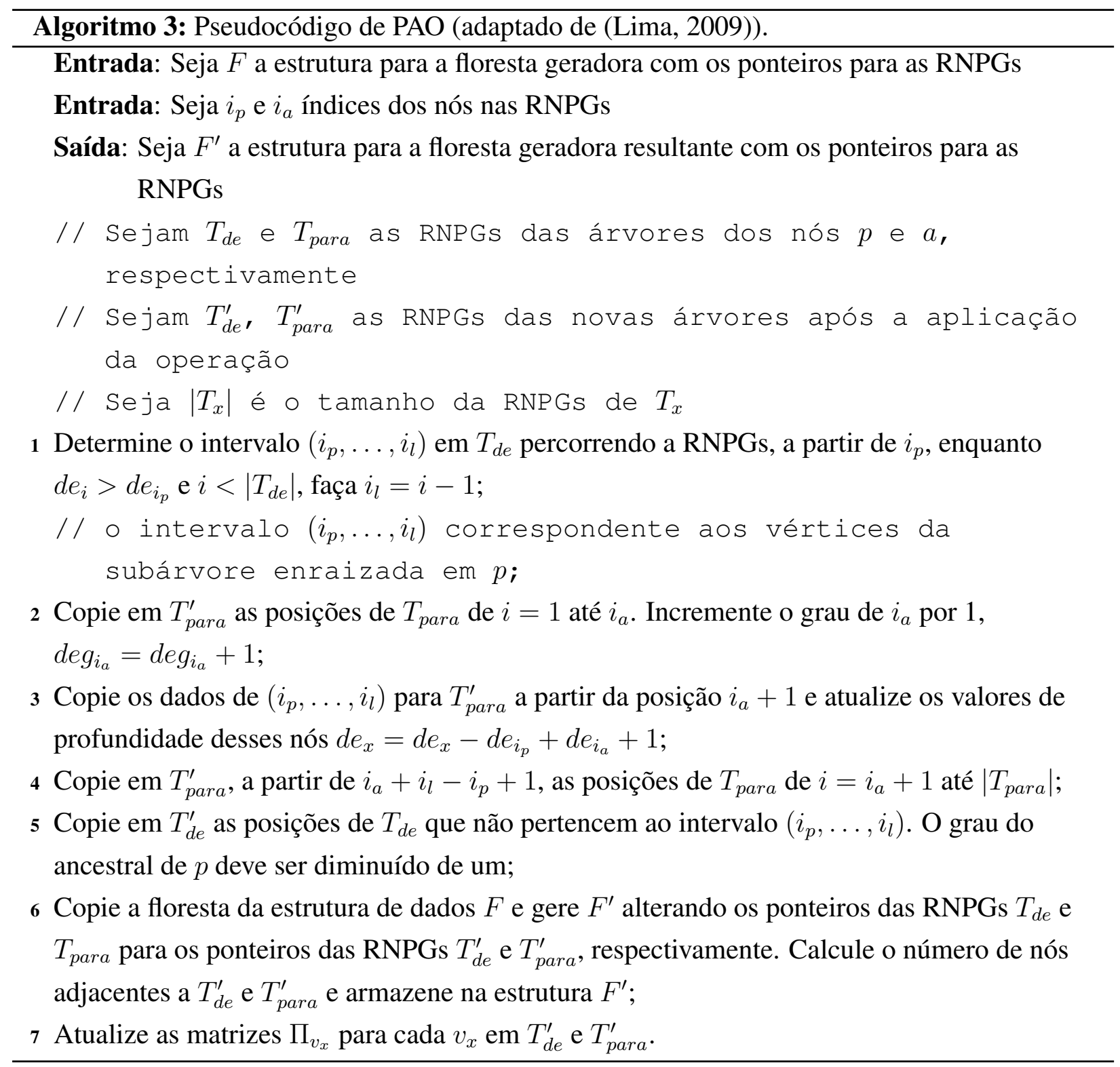



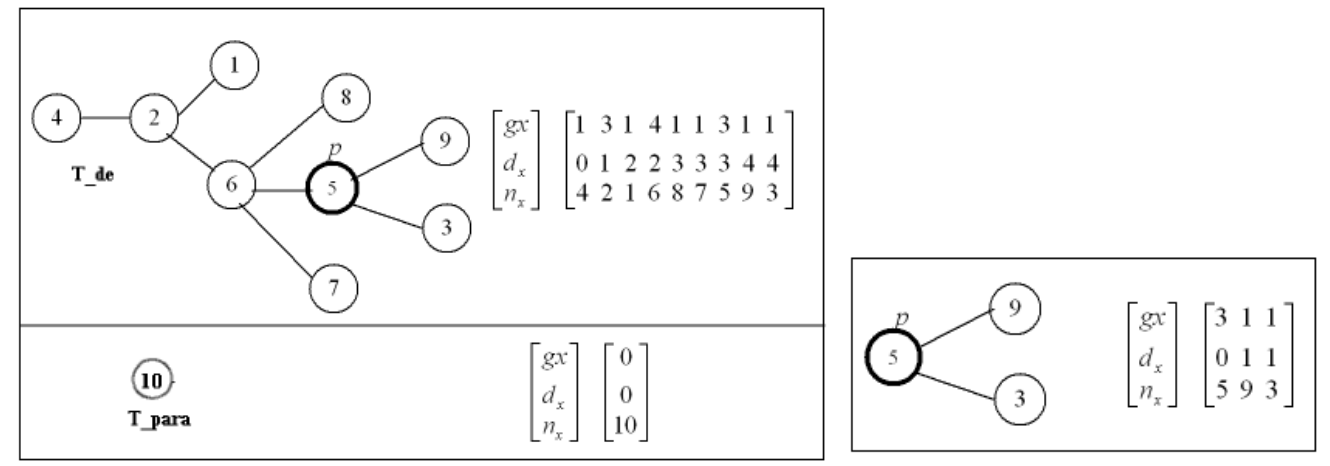

(a) Árvore de origem $\left(T_{d e}\right)$ e Árvore de destino $\left(T_{p a r a}\right)$ e (b) Árvore podada $\left(T_{t m p}\right)$ e sua suas representações nó-profundidade e grau representação nó-profundidade e grau

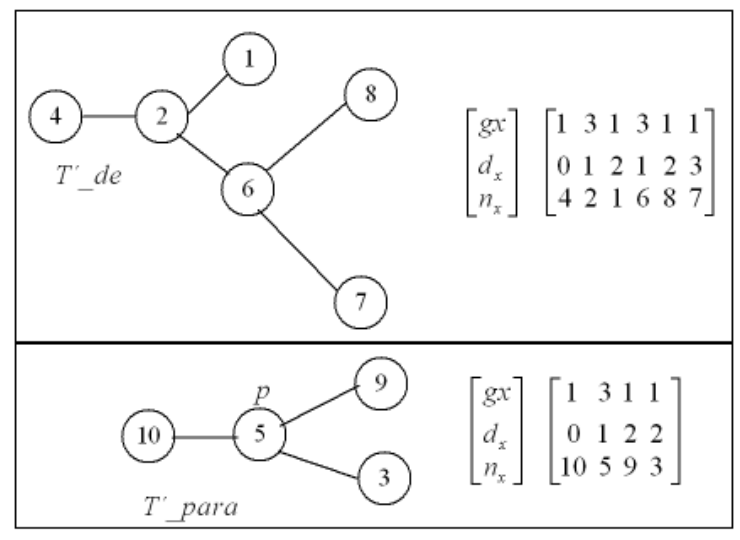

(c) Novas árvores geradas $\left(T_{d e}^{\prime}\right)$ e $\left(T_{\text {para }}^{\prime}\right)$ e suas representações.

Figura 4.8: Novas árvores geradas $\left(T_{d e}^{\prime}\right)$ e $\left(T_{\text {para }}^{\prime}\right)$ e suas representações, utilizando o operador PAO. Um trecho do array iniciado nó $p$ da árvore $T_{d e}$ é removido e depois inserido a direita de um nó $a$ em $T_{\text {para }}$, sendo os nós $p$ e $a$ adjacentes a $G$. 


\subsubsection{Operador CAO}

O operador CAO é similar ao operador 2 da RNP. É armazenado, porém, o terceiro argumento referente ao grau da árvore. Para realizar a recombinação por meio do operador PAO são necessários três vértices como entrada: um vértice de corte $p$, o novo vértice raiz $r$ e o vértice adjacente $a$, além de seus índices $i_{p}, i_{r}$ e $i_{a}$, respectivamente. O pseudocódigo do CAO é apresentado no Algoritmo 4.

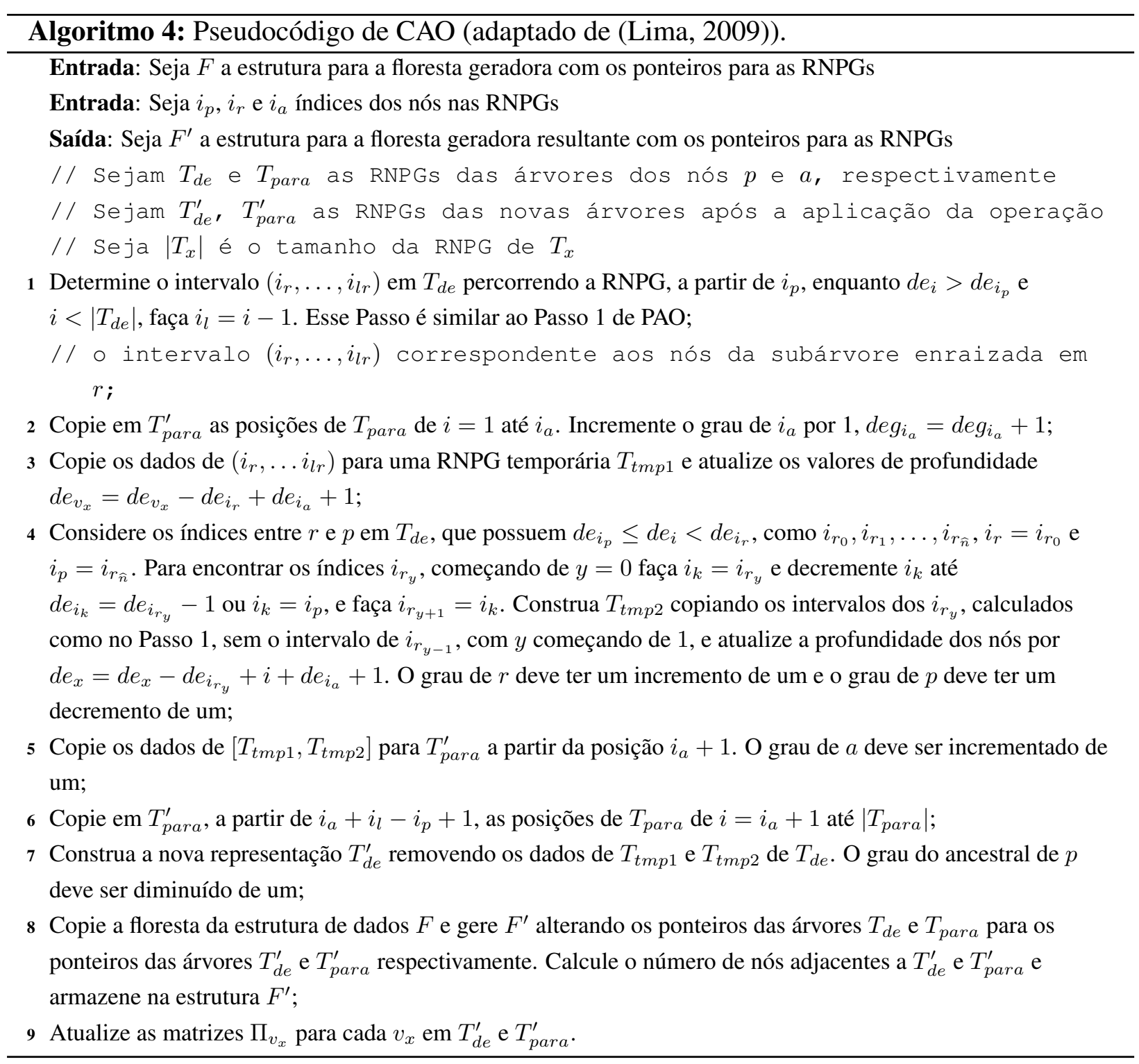




\subsection{Comparação entre as Representações}

Em (Raidl \& Julstrom, 2003), diversas representações na construção de árvores são comparadas. Em (Lima, 2009), tais representações são comparadas com a RNP, mostrando que essa representação é mais eficiente que as demais. A Tabela 4.1 apresenta o comparação entre a complexidade entre tais representações, considerando a complexidade de tempo necessárias para obter somente redes factíveis em grafos completos. A factibilidade é a capacidade de gerar somente redes factíveis para grafos completos e não-completos.

Tabela 4.1: Comparativo da complexidade das representações, onde $m$ é o número de arestas do grafo e $t$ o número de florestas e $n$ o número de nós, $T_{d e}$ é a árvore de origem e $T_{\text {para }}$ é a árvore de destino.

\begin{tabular}{|c|c|c|c|c|c|}
\hline Representação & Espaço & Tempo & \multicolumn{2}{|c|}{ Factibilidade } & Representação \\
\cline { 4 - 5 } & & & Completo & Esparso & $\begin{array}{c}\text { Explata } \\
\text { de Florestas }\end{array}$ \\
\hline $\begin{array}{c}\text { Vetor de } \\
\text { Características }\end{array}$ & $O(m)$ & $O(m)$ & Sim & Sim & Não \\
\hline Predecessores & $O(n)$ & $O\left(n^{2}\right)$ & Sim & Não & Não \\
\hline Blob Code & $O(n)$ & $O\left(n^{2}\right)$ & Sim & Não & Não \\
\hline $\begin{array}{c}\text { Número de } \\
\text { Prüfer }\end{array}$ & $O(n)$ & $O(n \log n)$ & Sim & Não & Não \\
\hline $\begin{array}{c}\text { Tendência de } \\
\text { Ligação e Nó }\end{array}$ & $O(m+n)$ & $O(m+n \log n)$ & Sim & Sim & Não \\
\hline NetKeys & $O(m)$ & $O(m \operatorname{logm})$ & Sim & Sim & Não \\
\hline $\begin{array}{c}\text { Conjunto de } \\
\text { Arestas }\end{array}$ & $O(n)$ & $O(n)$ & Sim & Sim & Não \\
\hline RNP & $O\left(\left|T_{d e}\right|+\right.$ & $\begin{array}{c}O\left(\left|T_{d e}\right|+\right. \\
\left.\left|T_{\text {para }}\right|+t\right)\end{array}$ & Sim & Sim & Sim \\
\hline RNPG & $O(\sqrt{n})$ & $O(\sqrt{n})$ & Sim & Sim & Sim \\
\hline
\end{tabular}

Os processos de construção de árvores de grafos, utilizando os métodos enumerados na Tabela 4.1, possuem complexidade variando entre $O(n), O(n l o g(n))$ e $O\left(n^{2}\right)$, onde $n$ é o número de nós do grafo (Santos et al., 2010). No caso da RNP, o tempo de computação médio para a construção de uma árvore geradora é $O(\sqrt{n})$. Esse resultado foi verificado experimentalmente e mostra que a RNP possui uma eficiência em tempo superior a dos outros métodos (Delbem, 2009). Dessa forma, as vantagens da RNP são mais relevantes para PPRs que envolvem árvores muito grandes.

A fim de ilustrar a eficiência da RNP, considera-se a implementação de AEs para o Problema da árvore geradora mínima com restrição de grau, em relação a grafos de diferentes tamanhos. A Figura 4.9 traz um gráfico comparativo dos tempos de execução dos AEs. Foram empregadas as seguintes representações: RNPG para o AENG; RNP para o AEN; Número de Prüfer para o AGNP e Conjunto de Arestas para o AGCE (Delbem, 2009).

Com base nesse gráfico, pode-se observar que o AE que possui melhor desempenho é o AENG, ou seja, o AE que emprega a RNPG. Nos casos acima de 500 e 1000 nós o AENG possui, em 


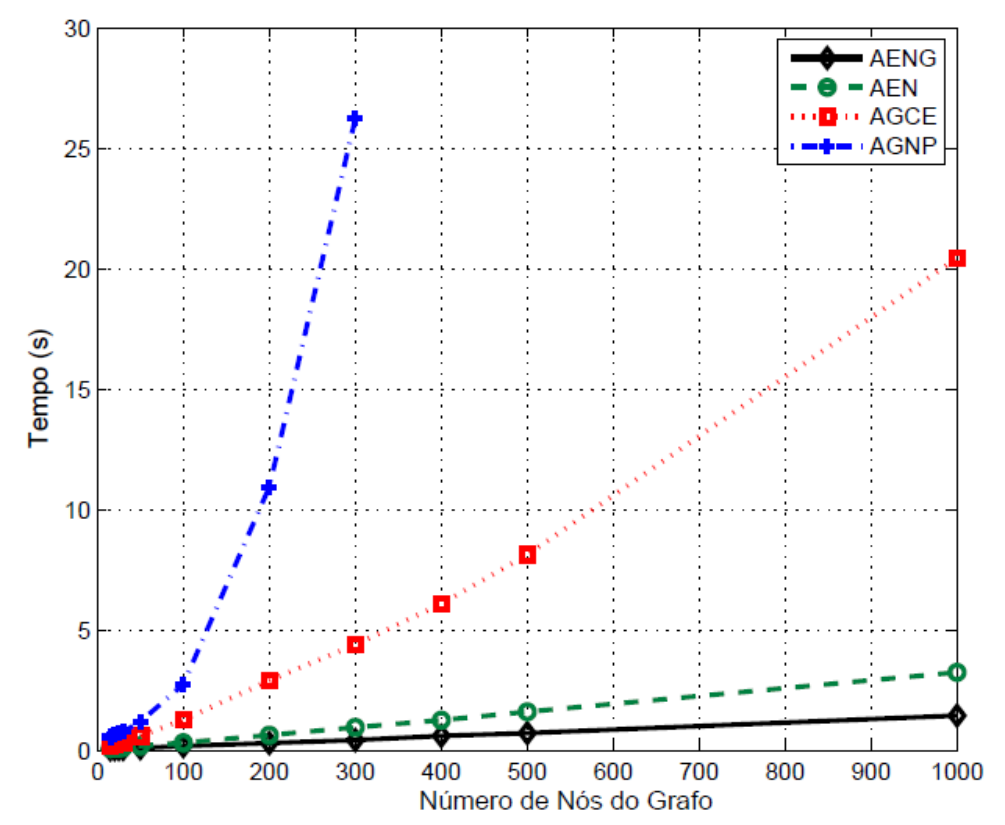

Figura 4.9: Tempo de execução de AENG, AEN, AGCE e AGNP para problema da árvore geradora mínima com restrição de grau (Delbem, 2009).

termos de tempo de execução desempenho até 10 vezes superior ao AGCE que trabalha com Conjunto de Arestas. Além disso, o AEN, que possui a RNP, apresenta resultados aproximados aos do AENG. No entanto quando comparado as representações tradicionais AGCE e AGNP que utiliza Número de Prüfer, a diferença em termos de tempo de execução é significativamente elevada.

\subsection{Considerações Finais}

$\mathrm{Na}$ literatura são encontradas diversas representações que podem ser aplicadas em conjunto com os AEs para a resolução dos PPRs como, por exemplo, Vetor Característica, Número de Prüfer e Conjunto de Arestas. Apesar dessas representações atingirem resultados em tempo satisfatórios para grafos com poucos nós (em ordem inferior a centenas de nós), tornam-se inviáveis para problemas de escala maior, como no caso dos PPRs. A RNP, apresentada neste Capítulo, consiste em uma estrutura de dados capaz de codificar árvores e florestas geradoras e possui operadores que facilitam a manipulação desses grafos. Já foram demonstradas por outros trabalhos as vantagens da RNP em relação as outras representações em termos de espaço utilizado e tempo de execução. Porém, visando obter respostas em tempo real, pode-se melhorar esse resultado por meio de recursos computacionais, como o uso de um hardware voltado para aplicações críticas e a utilização de processamento paralelo. No Capítulo 5 é apresentada a tecnologia de hardware denominada Field-Programmable Gate Array (FPGA) que apresenta, em alguns casos, desempenho superior ao PC. Além disso, essa tecnologia possui um alto grau de paralelismo, possibilitando ganhos significativos em termos de tempo de execução. 



\section{CAPÍTULO \\ 5 \\ Ferramentas para o Desenvolvimento da Arquitetura de Hardware}

Este Capítulo introduz alguns conceitos sobre FPGA e a linguagem de descrição de hardware Bluespec, além de outras ferramentas e plataformas utilizadas para o desenvolvimento desse trabalho. Adicionalmente, são apresentados conceitos de paralelização, a arquitetura proposta da paralelização da RNP no FPGA e o gerador de números pseudo-aleatório LFSR, utilizado neste trabalho.

\subsection{Field-Programmable Gate Arrays}

Nos últimos anos, um novo paradigma para desenvolvimento de hardware tem sido muito abordado, denominado computação reconfigurável (Bobda, 2007). Os sistemas reconfiguráveis possuem alto grau de paralelismo, podendo ser utilizados para diversas aplicações com capacidade de alcançar alto desempenho. Um dos dispositivos que tem sido utilizado como tecnologia de lógica reconfigurável é o FPGA (do inglês, Field-Programmable Gate Array). FPGAs têm demonstrado que, em termos de velocidade e capacidade de armazenamento, são adequados para implementações que envolvem sistemas computacionalmente complexos de larga-escala (ou seja, com grande quantidade de portas lógicas), além de serem eficientes para aplicações de tempo real (Bobda, 2007).

Os FPGAs foram introduzidos em meados da década de 1980 pela empresa americana Xilinx Inc (Xilinx, 2008). Esses dispositivos possibilitam que o usuário realizasse a reconfiguração parcial ou dinâmica de seus processos, além de disponibilizarem vários recursos, produzindo ganho 
de flexibilidade e de desempenho comparado à flexibilidade dos computadores da arquitetura de Von Neumann (Aspray, 1989) e desempenho do ASIC (do inglês, Application-Specific Integrated Circuit) (Smith, 1997a). O DSP (do inglês, Digital Signal Processor) consiste em um processador específico utilizado em processamento digital de sinal (vídeo, som) (Smith, 1997b), possui desempenho superior quando comparado a arquitetura de Von Neumann (Bobda, 2007).

Os FPGAs têm se mostrado adequados principalmente na obtenção de soluções para problemas mais complexos, tanto de caráter específico como de propósito geral, devido a seu alto grau de paralelismo e capacidade de processamento (Comptom \& Hauck, 2000). A configuração de seus blocos e de suas interconexões permitem ao usuário grande flexibilidade no desenvolvimento de soluções complexas de alto desempenho com custo de projeto relativamente baixo.

O FPGA é constituído basicamente por três componentes:

- Blocos lógicos que podem ser configurados independentemente;

- Blocos de entrada e saída para conexão dos pinos do dispositivo;

- Chaves de interconexão para a conexão entre blocos lógicos.

A arquitetura de um FPGA é ilustrada na Figura 5.1 e a Figura 5.2 ilustra um gráfico comparativo entre as diferentes arquiteturas de hardware, analisando flexibilidade e desempenho (Bobda, 2007).

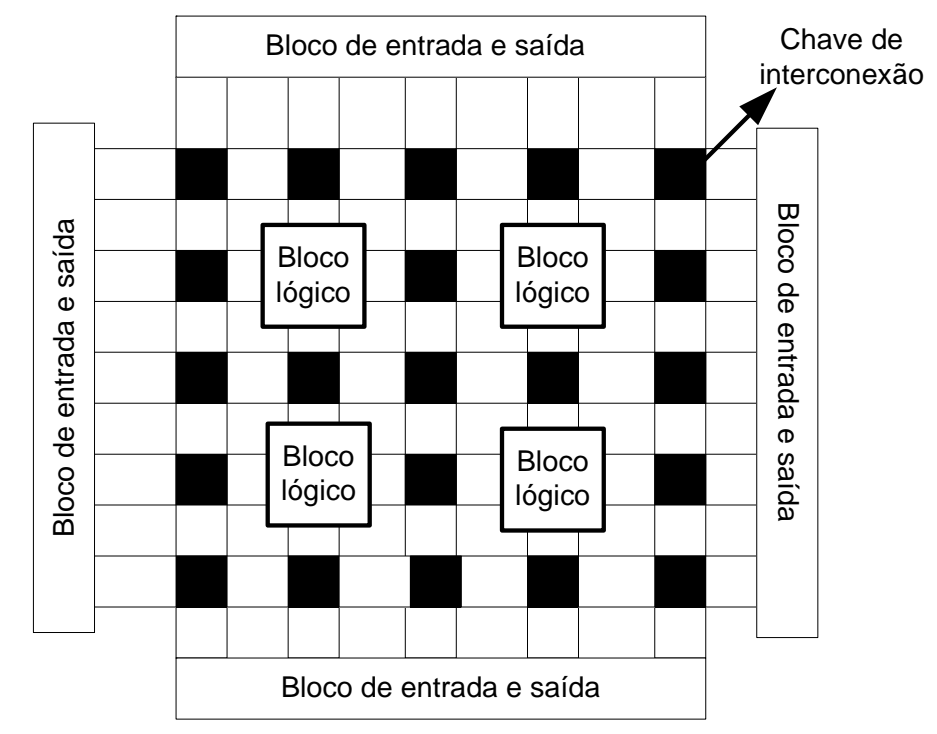

Figura 5.1: Arquitetura de um FPGA (adaptado de (Bobda, 2007)).

Observa-se no gráfico da Figura 5.2 que a arquitetura de Von Neumann baseada em processadores programados por software, (denominada de propósito geral) apresenta grande flexibilidade. No entanto, o desempenho é inferior às outras arquiteturas pois suas tarefas são executadas predominantemente em modo sequencial. Nas arquiteturas ASIC, a flexibilidade é reduzida, uma vez 


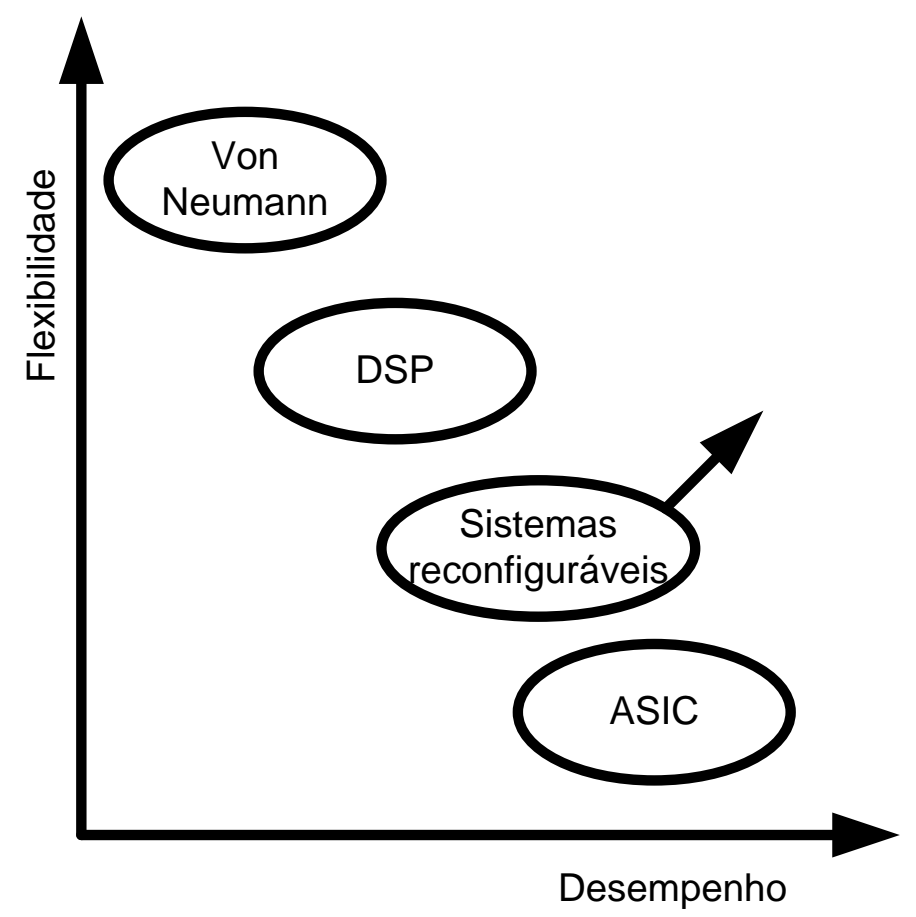

Figura 5.2: Comparativo de flexibilidade $X$ desempenho entre as arquiteturas de hardware (adaptado de (Bobda, 2007)).

que tais dispositivos foram desenvolvidos especialmente para atender tarefas específicas e são programados de fábrica, não havendo a possibilidade de reprogramá-los, por esse motivo, apresenta alto desempenho. Para superar as desvantagens dessas três arquiteturas, a computação reconfigurável apresenta resultados intermediários, conseguindo atingir um alto grau de desempenho quando comparados as arquiteturas de Von Neumann e DSP, além disso, os sistemas reconfiguráveis são mais flexíveis que ASIC.

\subsection{Paralelização em FPGA}

A programação concorrente tem sido muito explorada em computação de alto desempenho para algoritmos de busca em grandes espaços de pesquisa em tempo real. Além disso, paradigmas convencionais, como o sequencial, podem não ser adequados para problemas em larga-escala. Para essas tarefas, os algoritmos paralelizados tem sido essenciais e eficientes, não apenas pela redução de tempo de processamento, mas pelas grandes dimensões de população presente no problema, conforme mostra a Figura 5.3. A implementação desses algoritmos diretamente em FPGAs possibilita um alto desempenho para diversas aplicações de larga-escala e em tempo hábil. Isso ocorre devido à flexibilidade que essa plataforma proporciona, podendo ser reconfigurável a um custo médio em relação a arquiteturas tradicionais, gerando soluções mais eficientes. 


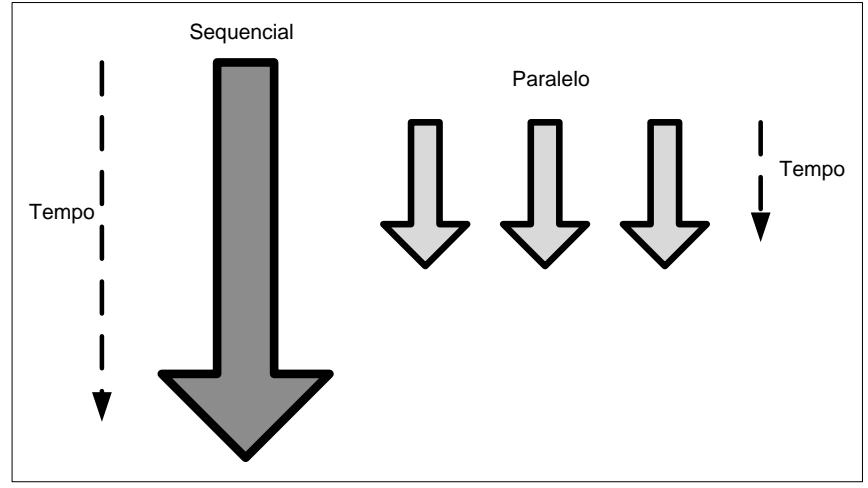

Figura 5.3: Ilustração do efeito da paralelização.

O ganho de desempenho com essa técnica está relacionado à possibilidade de várias operações poderem ser executadas simultaneamente. Por outro lado, antes de utilizar essa técnica, deve-se avaliar a estratégia de gerência dos recursos disponíveis a serem paralelizados, pois na paralelização há uma grande demanda de recursos computacionais, como, por exemplo, memória. Devido a esse consumo de recursos, a implementação de algoritmos paralelizados pode demandar alto custo financeiro e tempo de desenvolvimento, apesar de serem eficientes e possuírem melhor desempenho. Para o desenvolvimento de algoritmos paralelos, devem ser observados os seguintes casos (Grama et al., 2003):

- Identificar porções do problema que podem ser executadas concorrentemente;

- Mapear as partes concorrentes em múltiplos processos;

- Gerenciar os dados que serão acessados pelos vários processadores;

- Sincronizar os processos.

\subsubsection{Paralelização da RNP em FPGA}

A paralelização da RNP em FPGA foi realizada considerando que cada rede possui uma RNP e que essa RNP pode ser vista como um conjunto de arrays de inteiros que podem ser implementados na forma de blocos de memória, sendo o número de bits proporcional ao tamanho do array (Delbem, 2009). Nesse caso, cada array possui tamanho médio de $O(\sqrt{n})$ onde $n$ é o número de nós no grafo, e os arrays são manipulados em paralelo. Esta estratégia de paralelizar a RNP em hardware foi denominada HP-RNP (Hardware-Parallelized Representação Nó-Profundidade). A Figura 5.4(a) ilustra em alto nível de abstração a aplicação do HP-RNP organizada de modo paralelo.

Para cada floresta $F$ a RNP gera uma nova floresta $F^{\prime}$, manipulando pares de árvores de $F$. Deve-se ressaltar que para o funcionamento dos operadores da RNP são necessárias apenas as RNPs de duas árvores da floresta a serem alterada para, então, realizar a remoção de segmentos de uma RNP (subárvores correspondentes) e inserir esses segmentos removidos em outra RNP. 


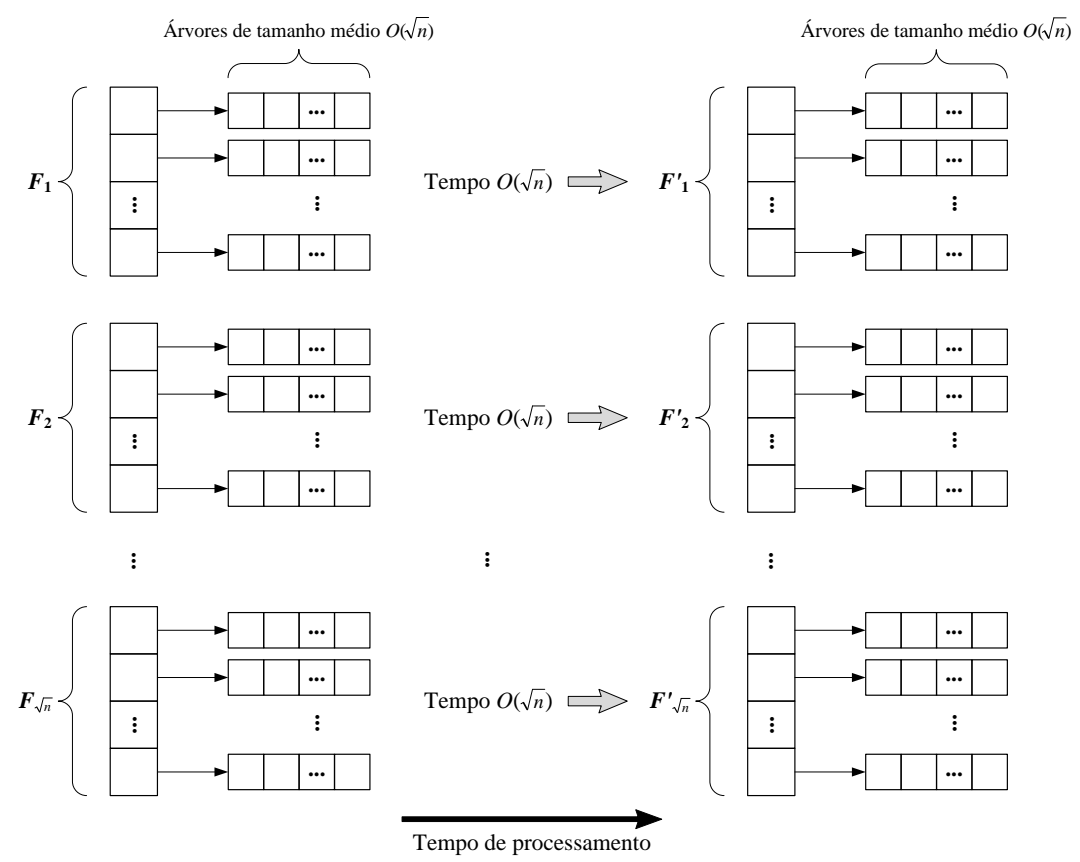

(a)

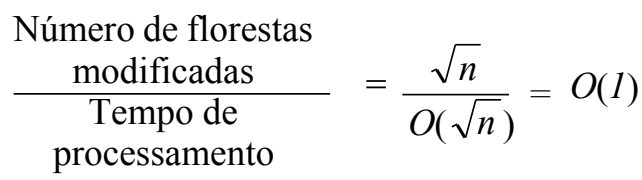

(b)

Figura 5.4: (a) O esquema de geração paralela de $\sqrt{n}$ redes por HP-RNP, (b) Formulação do tempo constante.

O HP-RNP paraleliza o processo executando $\sqrt{n}$ modificações na floresta geradora. Na Figura 5.4(a) mostra as florestas iniciais com os seguintes rótulos $F_{1}, F_{2}, \ldots F_{\sqrt{n}}$. As novas florestas $\left(F_{1}^{\prime}, F_{2}^{\prime}, \ldots F_{\sqrt{n}}^{\prime}\right)$ são todas geradas em tempo médio $O(\sqrt{n})$, logo, o tempo de processamento para gerar uma nova floresta é limitado por uma limitado por uma constante $(O(1))$. A Figura 5.4(b) ilustra a formulação matemática para o cálculo da complexidade computacional da HP-RNP.

\subsection{Linguagem de Descrição de Hardware}

As técnicas tradicionais para descrever hardware, por meio de especificação de interconexões dos elementos lógicos, tornaram-se proibitivas para projetos que envolvam grande quantidade de elementos lógicos. Nesse sentido, para auxiliar modelagem de circuitos lógicos digitais complexos (com muitos elementos lógicos) tem-se utilizado linguagens de descrição de hardware (HDLs, do inglês, Hardware Description Language). Essas linguagens são capazes de realizar a descrição dos sistemas no nível físico e comportamental, proporcionando alto nível de abstração, possibilitando ao projetista a facilidade de testar o funcionamento dos circuitos digitais por meio de simulações, a fim de sintetizá-lo após a descrição. Existem várias linguagens de descrição de hardware, entre 
as quais podem ser citadas: System C (Müller et al., 2003), Handel C (Martin, 2001), Verilog (Palnitkar, 2003), VHDL (do inglês, Very High Speed Integrated Circuit Hardware Description Language) (Brown \& Vranesic, 2008), sendo VHDL e Verilog as linguagens tradicionais mais utilizadas atualmente. A HDL utilizada na implementação do HP-RNP foi a Bluespec System Verilog (Dave et al., 2007), será descrita na subseção 5.3.1.

\subsubsection{Bluespec System Verilog}

A BSV (do inglês, Bluespec System Verilog) é uma linguagem de descrição de hardware de alto nível proposta por Arvind em 2003. Essa linguagem foi baseada em System Verilog e foi desenvolvida para projetos com ASICs e FPGAs (Dave et al., 2007). A escolha da linguagem a ser utilizada para a codificação das soluções, seja em software ou em hardware, é uma decisão muitas vezes difícil de ser tomada, dada a sua influência nos diversos aspectos do produto final. Dentre os fatores a linguagem de programação pode determinar o tempo de desenvolvimento, a velocidade de execução da aplicação e o consumo de memória. Um dos maiores atrativos da linguagem BSV é a sua facilidade de implementação devido a sua alta capacidade de abstração para lidar com projetos de hardware. Em contrapartida, as linguagens de alto nível acabam perdendo a capacidade de gerar um código compilado com a máxima otimização e dessa forma reduzem o desempenho da aplicação final. BSV é uma linguagem com alto nível de abstração formada por módulos que representam os circuitos lógicos (Nikhil, 2004). Módulos BSV podem ser sintetizados em Verilog RTL. Os módulos são compostos por três elementos (chieh Lin, 2007; Dave, 2004):

- Estados, que podem ser registradores, flip-flops ou memórias descritas no módulo;

- Ações atômicas protegidas ou regras, sendo que cada regra especifica um conjunto de critérios, ou seja, a condição para que seja executada;

- Métodos de interface que possibilitam a interação com o módulo descrito.

A principal vantagem dessa linguagem em relação a outras HDLs é sua composição modular, facilitando a verificação, pois cada regra pode ser analisada isoladamente em cada ciclo. Além disso, é totalmente sintetizável, ou seja, o código HDL é traduzido em estruturas de hardware disponíveis no dispositivo. As mudanças dos estados podem ser vistas como regras. Outra vantagem dessa linguagem é a redução de tempo em projetos. Consequentemente, isso resulta em melhorias significativas no time-to-market, test e debug. Além de modularidade e flexibilidade, com uma descrição por BSV, em geral, permite gerar código com menor número de linhas, comparando a VHDL. No entanto, em relação a área ocupada, podem ser obtidos resultados inferiores quando comparados aos obtidos com VHDL. Conforme o estudo de caso apresentado em (Gruian \& Westmijze, 2008), foi analisada e escolhida a linguagem BSV. A Subseção 5.3.2 apresenta as análises realizadas no estudo de caso e que refletiu na escolha da linguagem BSV para o desenvolvimento deste trabalho. 


\subsubsection{Comparação BSV X VHDL}

Baseado no estudo caso apresentando em (Gruian \& Westmijze, 2008) foi escolhida a linguagem BSV para a implementação da paralelização do operador PAO em FPGA. O estudo de caso consistiu na implementação de um processador Java e uma unidade de gerenciamento de memória em um FPGA nas linguagens BSV e VHDL. Alguns dos fatores principais para a escolha da linguagem foi em relação ao tempo de desenvolvimento e as facilidades que a linguagem proporciona. Após a implementação, as linguagens foram comparadas em termos quantitativos e qualitativos. $\mathrm{Na}$ análise quantitativa, foram comparados os seguintes aspectos:

- Tempo de desenvolvimento: o tempo levado para a implementação (compreendendo na codificação e no teste) do processador Java por meio do VHDL para a conclusão da unidade de gerenciamento de memória foi $50 \%$ maior que em BSV, considerando que BSV ter suporte nativo para a implementação de máquinas de estado finito;

- Linha de código: com o VHDL, foram utilizadas ao todo 3580 linhas de código e com o BSV foram necessárias 1880 linhas de código. Esta grande diferença pode ser explicada pelo alto nível de abstração do BSV, dessa forma, diversas funções podem ser facilmente invocadas, além da existência de bibliotecas que facilitam o desenvolvimento de máquinas de estado finito;

- Consumo de memória: neste quesito, foi observado que a implementação no VHDL utiliza aproximadamente 4 vezes menos memória em relação ao BSV. Este talvez seja um dos impactos causados pelo alto nível de abstração da linguagem, que acaba não otimizando o uso de recursos para garantir a facilidade no desenvolvimento;

- Desempenho: a solução em VHDL que combina o processador Java e a unidade de gerenciamento de memória é executada com velocidade de $71 \mathrm{MHz}$. Em contrapartida, o BSV consegue atingir $68 \mathrm{MHz}$. Uma diferença que pode ser considerada pequena, porém, pode ser determinante em aplicações críticas.

$\mathrm{Na}$ análise qualitativa, foram comparados os seguintes critérios:

- Capacidade de teste e depuração: a depuração das implementações em VHDL normalmente são realizadas por meio da análise de sinais e o uso de mecanismos de saída (displays) o que torna esta tarefa tediosa e suscetível a erros. Ao contrário do BSV que conta com simuladores mais completos que permitem, por exemplo, exibir mensagens ao usuário;

- Modularidade: ambas as linguagens possuem a capacidade de modularizar o código, entretanto, no BSV foi notada uma capacidade superior de reutilização e de desenvolvimento modular; 
- Flexibilidade: a linguagem BSV apresentou uma facilidade maior para alterar ou incluir micro-instruções em comparação com VHDL, devido a presença de funcionalidades que auxiliam a execução dessas operações;

\subsection{Linear Feedback Shift Register}

O LFSR (do inglês Linear Feedback Shift Register) é um registrador de deslocamento com $n$ bits, no qual a entrada é resultado de operações de porta XOR (do inglês, exclusive or) de algumas de suas entradas. O LFSR é uma técnica muito utilizada na geração de números pseudoaleatórios, principalmente em sistemas digitais (Zenner, 2004). Em geral, o LFSR é composto por duas partes: um registrador de deslocamento e uma função de realimentação. O bit de entrada do registrador de deslocamento é uma função linear com os seus estados prévios. O registrador de deslocamento possui a função de identificar as mudanças no conteúdo do registro (a saída). O valor inicial de um LFSR é denominado semente para a operação do registrador ser determinístico.

Em geral, o registrador de deslocamento possui entradas binárias. Considerando um registrador de deslocamento padrão 1011, realizando uma operação de deslocamento, resultaria 0101. A função de realimentação do LFSR são operações com portas lógicas XOR, essa função, em geral funciona da seguinte maneira: primeiramente são adicionados os valores dos bit selecionados, caso a soma seja ímpar, a saída da função é 1 , senão a saída é 0 . Um LFSR de $n$ bits pode produzir por padrão, $2^{n}-1$ valores possíveis, caso seja utilizado um polinômio ótimo (Zenner, 2004).

\subsection{Ferramentas e Plataformas de Processamento utili- zadas}

Para o desenvolvimento do projeto foram necessárias algumas ferramentas de hardware e plataforma de software. Para a implementação em um PC, os recursos utilizados foram:

- Processador: Intel(R) Core(TM)2 Quad CPU Q6600 2.40GHz;

- Cache: $4 \mathrm{MB}$;

- Memória RAM: 8 GB (4x 2GB DDR2 1.2ns);

- Placa mãe: Intel Desktop Board DP35DP;

- Sistema Operacional: Ubuntu Server 10.10 - 64 bits;

- Compilador: Intel C Compiler 12.0.2, 64 bits;

- Para o paralelismo: todos os 4 cores utilizados, com OpenMP (Chapman et al., 2007) . 
Para a implementação em FPGA foram utilizados as ferramentas da Altera.

- Placa: Altera DE2-70;

- FPGA: Altera Cyclone II modelo EP2C70F896C6 (Altera, 2007);

- Quartus 10.1 (Altera, 2011a);

- PowerPlay Power Analyzer: ferramenta do Quartus para estimativa de potência;

- SOPC builder (Altera, 2010).

O software Quartus é uma ferramenta EDA (do inglês, Eletronic Design Automation) produzida pela Altera. Por meio desse ambiente é possível realizar síntese, simulações, análises e programação em dispositivos FPGAs ( síntese $^{1}$ de HDLs). Essa ferramenta visa reduzir o tempo de desenvolvimento de projetos em hardware reconfigurável, automatizando suas tarefas. A implementação de um projeto de circuito divide-se nas seguintes etapas: descrição do projeto, compilação, simulação e programação do dispositivo.

SOPC (do inglês, System on a Programmable Chip) Builder (Altera, 2010) é uma ferramenta da Altera que está integrada ao Quartus para auxiliar o desenvolvimento de um projeto de circuito. Essa ferramenta possibilita ao projetista definir e gerar um completo SOPC, automatizando as conexões entre os componentes de hardware criando sistemas de alto desempenho. As interconexões são realizadas por meio do barramento Avalon. Além disso, o SOPC builder possui uma ampla biblioteca de componentes como, por exemplo, processadores, (incluindo o Processador NIOS II), coprocessadores, controladores de memória, interfaces e periféricos.

\subsection{Considerações Finais}

A tecnologia FPGA possibilita adequar o projeto do hardware de acordo com a aplicação, obtendo um desempenho maior em relação ao PC em termos de tempo de execução, utilização de memória e consumo de energia. Outro aspecto que torna a FPGA superior a arquiteturas tradicionais (PC) é a capacidade de paralelização da aplicação, uma característica importante para aplicações que dependem de respostas em tempo real, como no caso dos PPRs. A linguagem de descrição de hardware para implementação na FPGA também influencia no produto final. O estudo de caso relatado em (Gruian \& Westmijze, 2008) apresentou que em BSV possibilitou na redução do tempo de desenvolvimento em mais de $65 \%$ e reduzir em $50 \%$ o tamanho do código em relação ao VHDL, linguagem tradicional muito utilizada por projetistas de hardware. Com base, nesses dados apresentados foi escolhida a linguagem BSV para desenvolvimento deste trabalho. No Capítulo 6 é descrito o desenvolvimento da implementação do AE utilizando a RNP paralelizada em FPGA e os resultados.

\footnotetext{
${ }^{1}$ Síntese é o processo de mapeamento da linguagem HDL para gerar hardware
} 



\section{CAPÍTULO \\ 6 \\ A Arquitetura de Hardware HP-RNP e Testes Experimentais}

Este Capítulo apresenta a arquitetura de hardware implementada em FPGA, bem como os detalhes da implementação da paralelização do operador PAO da RNP. A arquitetura implementada no FPGA EP2C70F896C6N é em si resultado da pesquisa. Além disso, são apresentados os resultados experimentais obtidos que comparam as implementações da RNP em PC e em FPGA para solucionar o problema da árvore geradora mínima com restrição de grau e a verificação e validação das novas florestas geradas (redes), quanto a redução da soma dos pesos das arestas da floresta. Considera-se, para isso, principalmente a variação da ordem do grafo manipulado, que é dada pelo número de nós no grafo.

\subsection{Visão Geral da Arquitetura de Hardware Paralela RNP}

A arquitetura de hardware HP-RNP (Figura 6.1) foi implementada em uma FPGA, é constituída pelos seguintes componentes:

1. Microprocessador softcore (NIOS-II);

2. Memória Externa;

3. Barramento Avalon;

4. Interface JTAG; 
5. Módulo P-PAO-S (Circuito Paralelo para PAO e Seleção); que é o módulo principal de hardware que contém o Controlador de Trabalhador e Trabalhadores, esses por sua vez contêm uma máquina de estados finitos (MEF) que implementa o algoritmo do operador PAO da RNP.

O sistema proposto utiliza sementes aleatórias a partir de fontes externas para definir o estado inicial do gerador de números pseudo-aleatórios. Para a determinação das sementes, o HP-RNP utiliza fontes aleatórias do kernel Linux (/dev/urandom). Essas sementes são geradas no PC e enviadas ao sistema HP-RNP por meio da interface JTAG. Com base nessas sementes aleatórias, são escolhidos os nós $p$ e $a$ utilizados no PAO por meio de um gerador LSFR configurado com um polinômio com período máximo de $2^{32}-1$. Cada Trabalhador possui seu próprio LSFR. A Figura 6.1 ilustra a visão geral da Arquitetura de hardware implementada.

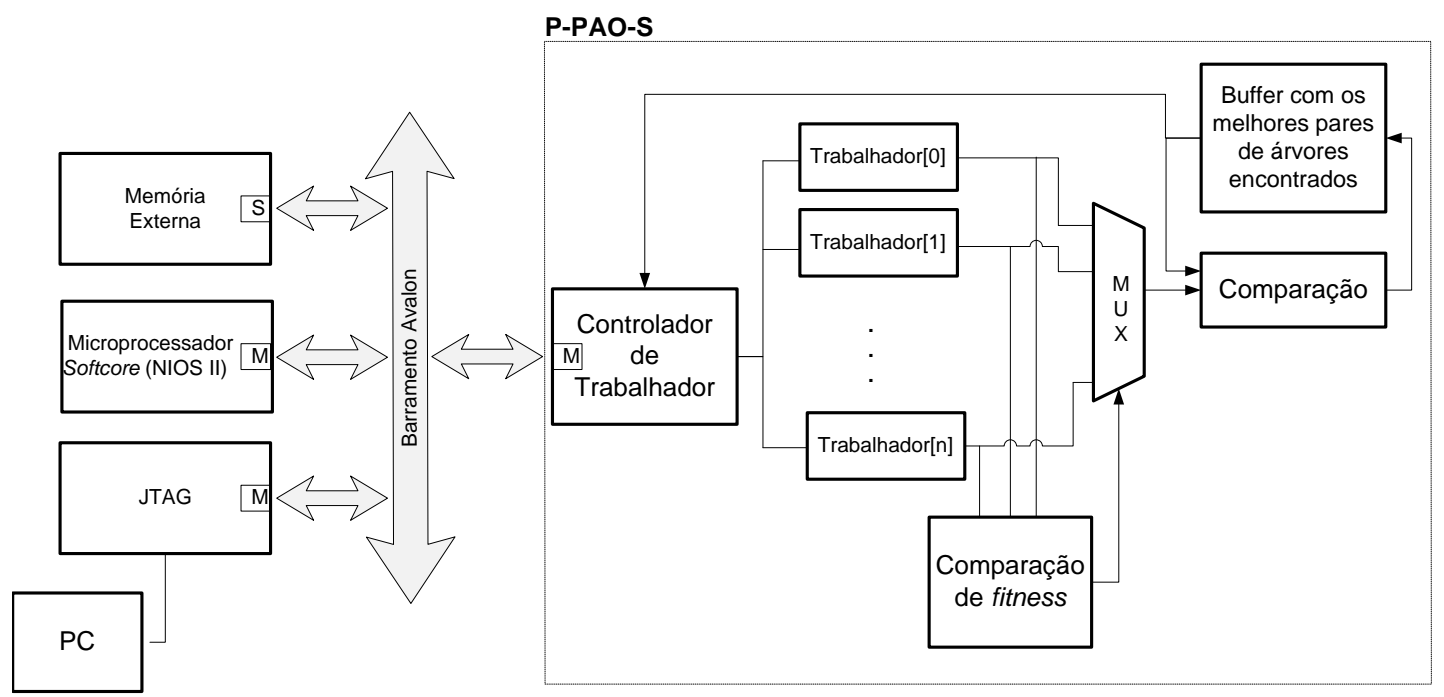

Figura 6.1: Visão geral da arquitetura de hardware.

O barramento Avalon é utilizado para realizar a comunicação entre a memória externa, o microprocessador softcore e o controlador de trabalhadores. A memória externa armazena uma floresta geradora $F$ do grafo $G$ (representado pelo RNP), a matriz de peso das arestas do grafo $G$ e o código do microprocessador softcore. O microprocessador softcore realiza a leitura da memória externa e executa os seguintes comandos:

1. Transfere um par de árvores da memória externa para o Trabalhador do P-PAO-S (por meio do controlador de Trabalhador) e copia o melhor par de árvores encontrado a partir do PPAO-S para a memória externa;

2. Verificação de término das operações dos Trabalhadores.

O Controlador de Trabalhador gerencia a comunicação entre o microprocessador softcore e a memória externa de forma a enviar/receber $T_{d e}$ e $T_{\text {para }}$ para os Trabalhadores. Cada Trabalhador 
implementa a MEF com o algoritmo do operador PAO da RNP. O módulo P-PAO-S contém, também, dois blocos para efetuar a comparação das novas árvores geradas, o comparador de fitness realiza a comparação das novas árvores geradas em cada Trabalhador, após a aplicação do operador PAO e o outro bloco compara com as árvores antigas, os melhores pares de árvores selecionados são armazenados em um Buffer. O Controlador de Trabalhador acessa esse Buffer e copia o melhor par de árvores para a memória externa. A Seção 6.2 apresenta em detalhes o módulo P-PAO-S e a Seção 6.3 descreve a MEF implementado em cada Trabalhador.

\subsection{Circuito Paralelo para PAO e Seleção}

O software que executa no microprocessador softcore gera uma matriz de peso das arestas do grafo e a armazena na memória externa. Uma floresta geradora inicial é também gerada no microprocessador softcore através do algoritmo modificado de Kruskal (Kruskal, 1956). A modificação consiste na inclusão do grau de cada nó à estrutura de dados que armazena a floresta gerada. A informação de grau é utilizada pelo PAO (4.9.1). Essa floresta seria a melhor floresta geradora para o grafo se não houvesse a restrição de grau. Observe que o problema considerado nos testes é de floresta geradora mínima com restrição de grau (NP-difícil) (Garey \& Johnson, 1979), (ver Seção 2.2).

Novas florestas são geradas com os seguintes passos:

1. Um par de árvores é escolhido aleatoriamente a partir da floresta armazenada na memória externa;

2. Esse par é então enviado ao Controlador de Trabalhador que, por sua vez, replica-o para cada Trabalhador que o armazena em um bloco de memória on-chip;

3. Cada Trabalhador processa o par de árvore recebido, executando a MEF que possui o algoritmo do operador PAO, gerando duas novas árvores;

4. O comparador de fitness do P-PAO-S é utilizado para comparar e selecionar os melhores novos pares de árvores, ou seja, o que obtiver o menor custo (soma de pesos das arestas) encontrados após cada processamento paralelo dos Trabalhadores. Observe que o PAO implementado garante que a restrição de grau foi respeitada. Esses melhores pares são selecionados e são comparados com o custo das árvores antigas;

5. Finalmente, o melhor par de novas árvores $T_{d e}^{\prime}$ e $T_{\text {para }}^{\prime}$ são armazenados no Buffer e enviados de volta por meio do controlador P-PAO-S para a memória externa substituindo as árvores originais $T_{d e}$ e $T_{\text {para }}$ e consequentemente alterando a floresta geradora atual. Após $65.536 \times\lceil\sqrt{n}\rceil$ iterações de aplicações do PAO, o microprocessador softcore completa todo processo de otimização, e em seguida envia o grafo aleatório inicial e a floresta geradora final ao PC para a avaliação da eficiência e eficácia do sistema. 
Outra tarefa do P-PAO-S é arbitrar o acesso dos trabalhadores à memória externa. Na prática, o funcionamento do sistema é da seguinte maneira: quando um trabalhador qualquer necessita saber qual o peso de uma aresta do grafo, é enviada uma requisição para consultar a posição correspondente da matriz de pesos armazenada na memória externa; P-PAO-S verifica que um dos trabalhadores realizou uma requisição, a qual é armazenada em um buffer e guarda o trabalhador de origem da requisição. Após isso, a requisição vai para uma das memórias externas. Quando a memória externa responde, o P-PAO-S verifica qual foi o trabalhador que solicitou consultando o buffer e manda a resposta para o mesmo.

\subsection{Implementação do Trabalhador}

Cada Trabalhador possui uma MEF que implementa o operador PAO, o gerador de número aleatório LFSR e o bloco de memória. A Figura 6.2 mostra essa MEF. Após iniciar a execução, o microprocessador softcore recebe a semente aleatória do PC. Posteriormente, o microprocessador softcore alimenta a primeira semente aleatória no gerador LFSR de cada Trabalhador a qual é utilizada para produzir os números aleatórios subsequentes requisitados pelos Trabalhadores.

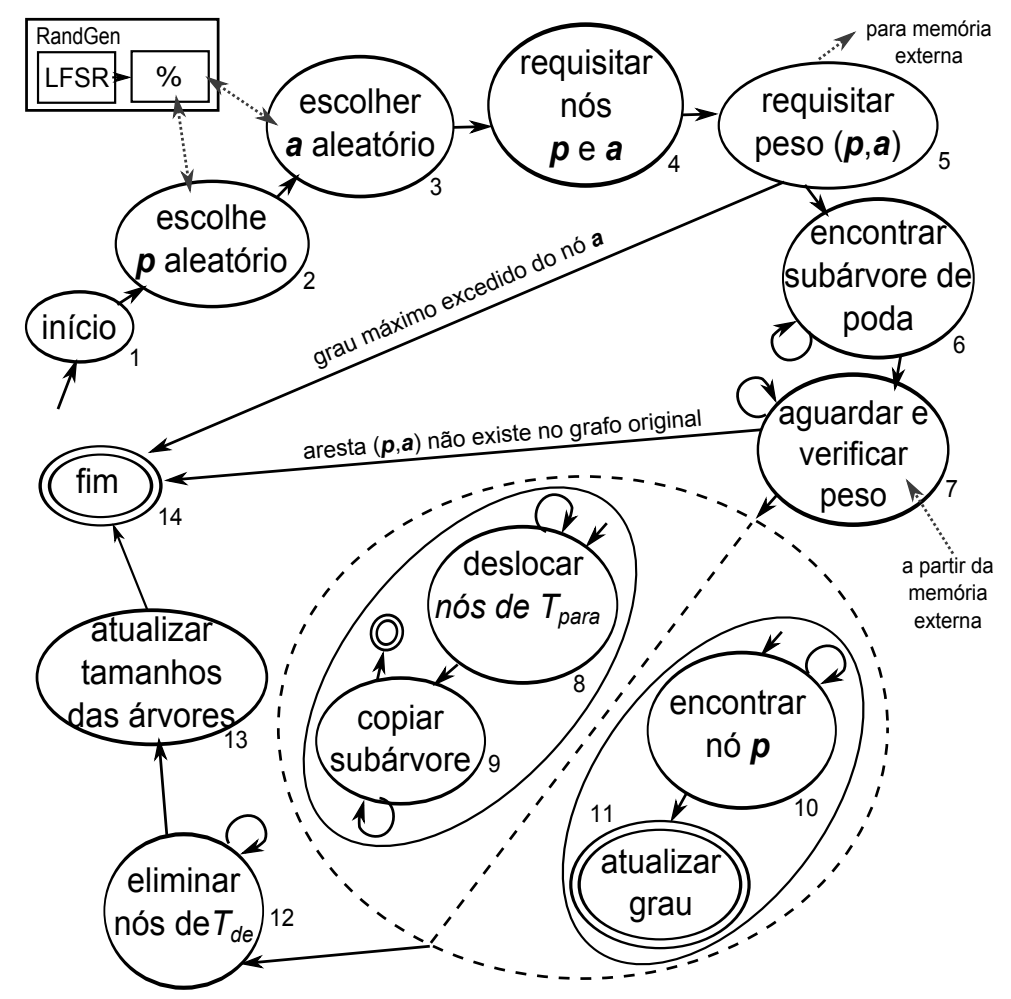

Figura 6.2: Máquina de estados finitos de um Trabalhador.

Cada iteração de um Trabalhador executa vários passos como descrito a seguir:

- Estado 1: inicia MEF do Trabalhador; 
- Estados 2-3: requisita ao gerador de números aleatórios LFSR de cada Trabalhador, dois números aleatórios, esses números representam os índices dos nós ( $p)$ da $T_{d e}$ e $(a)$ da $T_{p a r a}$ e são requisitados seus vetores RNP correspondentes;

- Estado 4: aguarda a resposta do LFSR e requisita da memória de bloco os nós $p$ e $a$ e suas correspondentes RNPs, as quais são armazenadas nos blocos de memória dos Trabalhadores;

- Estado 5: requisita à memória externa o peso da aresta que conecta o nó $p$ e $a$ no grafo original. Além disso, é verificado também se o grau de $a$ é menor que um limite dado por uma restrição de grau. Se o grau do nó $a$ em $T_{\text {para }}$ é igual ao limite, dado pela restrição de grau, é prossegue para o estado final do MEF; senão, avança para o próximo estado;

- Estado 6: determina a subárvore de poda percorrendo por todos os nós de $T_{d e}$;

- Estado 7: aguarda o retorno do peso requisitado no Estado 5. Se o peso é nulo, significando que a aresta não existe no grafo, avança para o Estado final do MEF; senão, prossegue para o próximo estado;

- Estados 8-9 e 10-11: são executados em paralelo, esses estados podem ser executados em paralelo pois os Estados 8-9 são manipuladas apenas as árvores de destino e o Estados 10-11 são alteradas as árvores de origem. O Estado 8 desloca para frente a quantidade de nós de $T_{\text {para }}$ necessários para alocar espaço para copiar a subárvore podada. O Estado 9 copia os nós da subárvore podada de $T_{d e}$ para $T_{p a r a}$, incrementando o grau do nó $a$ e atualizando a profundidade de todos os nós copiados. O Estado 10 procura o nó ancestral de $p$ em $T_{d e}$. $\mathrm{O}$ Estado 11 decrementa o grau do nó ancestral $p$ em $T_{d e}$;

- Estado 12: elimina a subárvore podada de $T_{d e}$, deslocando os nós de $T_{d e}$ sobre os nós que faziam parte dessa subárvore, formando a $T_{d e}^{\prime}$;

- Estado 13: atualiza o tamanho das novas árvores $T_{d e}^{\prime}$ e $T_{\text {para }}^{\prime}$, subtraindo o tamanho do tamanho da árvore podada do tamanho de $T_{d e}$ e adicionando esse tamanho ao de $T_{\text {para }}$;

- Estado 14: finaliza o MEF.

\subsection{Resultados Experimentais}

Os resultados experimentais apresentados comparam as implementações da RNP em PC e em FPGA para solucionar o problema da dc-MST (Raidl, 2000a). Esse problema consiste em encontrar a árvore geradora (rede) que possua a menor soma total de pesos das arestas e que respeite o limite de restrição de grau (ver Seção 2.2).

Os experimentos foram realizados para medir o tempo de processamento necessário para o HP-RNP gerar uma configuração de rede. Para a comparação, foi implementado o mesmo algoritmo em um PC com um processador Intel Core 2 Quad Q6600 (2.40GHz). O HP-RNP foi 
implementado na linguagem Bluespec SystemVerilog na placa Altera DE2-70 contendo um FPGA EP2C70F896C6N, que é capaz de manipular árvores com até 512 nós. A avaliação do tempo de processamento foi repetida 65 vezes, sendo conjuntos de 5 medições realizados com as mesmas restrições de grau, que foi variada de 3 a 15 , resultando em $(15-3+1) \times 5=65$ medidas para cada número de nós (16, 32, 64, 128 e 512 nós).

A Figura 6.3 ilustra o tempo de processamento médio obtido pelo HP-RNP e a implementação do RNP no PC. Cada Trabalhador executa o operador PAO 2 vezes (configurado em tempo de compilação), de forma a tornar útil e justificar a aplicação do PAO em paralelo. Caso fosse realizada uma única aplicação, a escolha dos nós $p$ e $a$ que levassem à maior redução de peso poderia ser realizada em um estágio sequencial, mantendo a mesma complexidade do algoritmo e dispensando a existência do paralelismo. A linha serrilhada reflete a necessidade de utilizar um número inteiro de Trabalhadores no FPGA (o valor arredondado para cima de $\sqrt{n}$, isto é, $\lceil\sqrt{n}\rceil$ ). Quanto maior o número de nós, menor será o desvio causado pelo arredondamento.

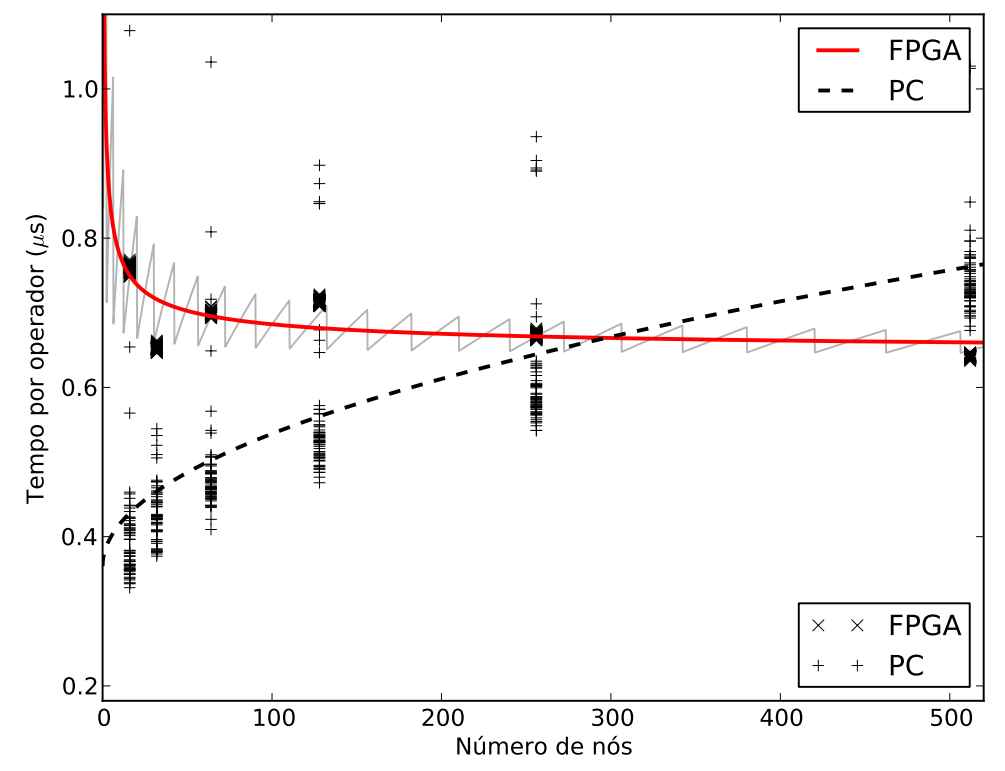

Figura 6.3: Comparativo número de nós da floresta $\times$ tempo por operador aplicado no FPGA e no PC.

A curva pontilhada na Figura 6.3 representa o tempo medido no PC, com o mesmo método implementado em C com OpenMP (Chapman et al., 2007) executando em paralelo nos quatro núcleos da CPU. O programa foi compilado no Intel C Compiler(Intel, 2009) configurado para nível máximo de otimização (-O3 -ipo -xHOST) (Intel, 2010) e específica para o processador.

A Figura 6.3 ilustra que o tempo cresce no PC na ordem de $O(\sqrt{n})$, enquanto que no FPGA o tempo médio por Trabalhador é limitado por uma constante: $O(1)$. Para $n$ pequeno, o gráfico apresenta uma queda no tempo requerido por operador, isso ocorre pois outros efeitos afetam o tempo para alimentar os geradores LFSR. Para $n$ grande, esse tempo é desprezível. 
Os resultados são sumarizados na Tabela 6.1, com o tempo de computação para construção das árvores no FPGA e no PC. O tempo médio no PC para problemas com até 256 nós é menor que no FPGA. Entretanto, quando o número de nós é dobrado para 512, o tempo de execução no FPGA é menor devido ao seu paralelismo. Tal resultado indica que quando o tamanho do problema aumenta no FPGA, o tempo médio de processamento é limitado por uma constante $O(1)$.

Tabela 6.1: Comparativo nós $\times$ tempo médio de processamento.

\begin{tabular}{|c|c|c|c|c|c|}
\hline Nós & $\begin{array}{c}\text { Trabalhadores } \\
\text { em FPGA }\end{array}$ & $\begin{array}{c}\text { Trabalhadores } \\
\text { em PC }\end{array}$ & $\begin{array}{c}\text { Árvores } \\
\text { Geradas por } \\
\text { Aplicação de P-PAO-S }\end{array}$ & $\begin{array}{c}\text { Tempo médio } \\
\text { em PC(s) }\end{array}$ & $\begin{array}{c}\text { Tempo médio } \\
\text { em FPGA(s) }\end{array}$ \\
\hline 16 & 4 & 4 & 8 & $4,0249 \mathrm{e}-07$ & $7,5968 \mathrm{e}-07$ \\
\hline 32 & 6 & 4 & 12 & $4,6474 \mathrm{e}-07$ & $6,5265 \mathrm{e}-07$ \\
\hline 64 & 8 & 4 & 16 & $5,3350 \mathrm{e}-07$ & $6,9877 \mathrm{e}-07$ \\
\hline 128 & 11 & 4 & 22 & $5,7561 \mathrm{e}-07$ & $7,1446 \mathrm{e}-07$ \\
\hline 256 & 16 & 4 & 32 & $6,2333 \mathrm{e}-07$ & $6,6970 \mathrm{e}-07$ \\
\hline 512 & 23 & 4 & 46 & $7,6293 \mathrm{e}-07$ & $6,4172 \mathrm{e}-07$ \\
\hline
\end{tabular}

Foi analisado também o consumo de energia no PC e no FPGA. O consumo de energia é expresso em joules e é calculado pela multiplicação da potência em watts pelo intervalo de tempo necessário para executar o PAO. A potência do FPGA foi estimada utilizando o software PowerPlay Analysis da Altera do Quartus II 10.1 Service Pack 1, adotando a taxa de alternância para 12,5\%. Para calcular o consumo de energia aproximado em joules para um número de nós, a energia elétrica em watts foi multiplicada pela média de todos os 65 intervalos de tempo de computação para cada tamanho de grafo (número de nós). No caso do PC, foi considerada a especificação do fabricante, que indica que um programa utilizando os quatro núcleos tipicamente dissipa uma energia de 102W. A Figura 6.4 mostra que o FPGA dissipa aproximadamente 100 vezes menos energia que o processador do PC. É importante ressaltar que em termos de consumo de energia, a solução em FPGA apresenta redução significativa quando comparada em PC. No entanto, se o foco desse trabalho fosse energia a solução em FPGA poderia não ser a melhor, pois, por exemplo, a arquitetura de processadores ARM (Seal, 2000) em geral possui consumo de energia significativamente mais baixo.

O consumo de recursos de FPGA necessário para a implementação de todo o sistema HP-RNP são ilustrados na Figura 6.5 e sumarizados na Tabela 6.2. Para 512 nós, foi utilizado $65 \%$ dos blocos de memória e 78\% dos elementos lógicos da FPGA Cyclone II modelo EP2C70F896C6 (Altera, 2006) por esse motivo houve limitação para realizar testes com uma rede com o dobro de nós (1024). No entanto, utilizando uma FPGA com maior número de recursos, como por exemplo a Stratix IV (Altera, 2011b), é possível trabalhar com redes maiores. 


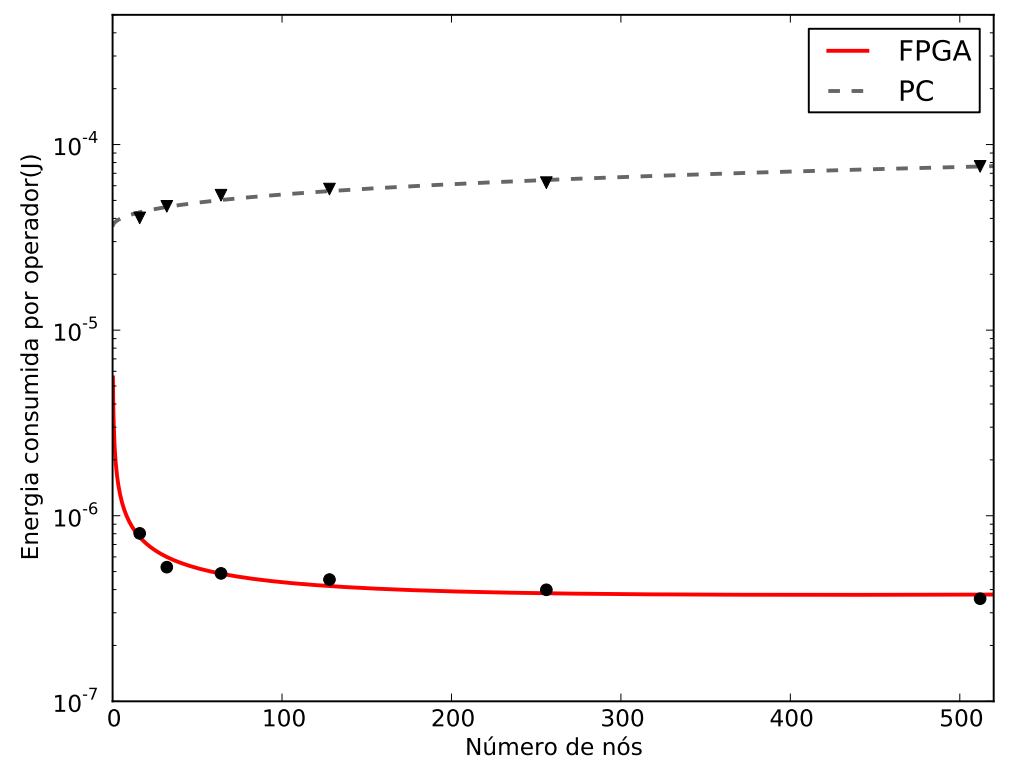

Figura 6.4: Consumo de energia FPGA $\times$ PC.

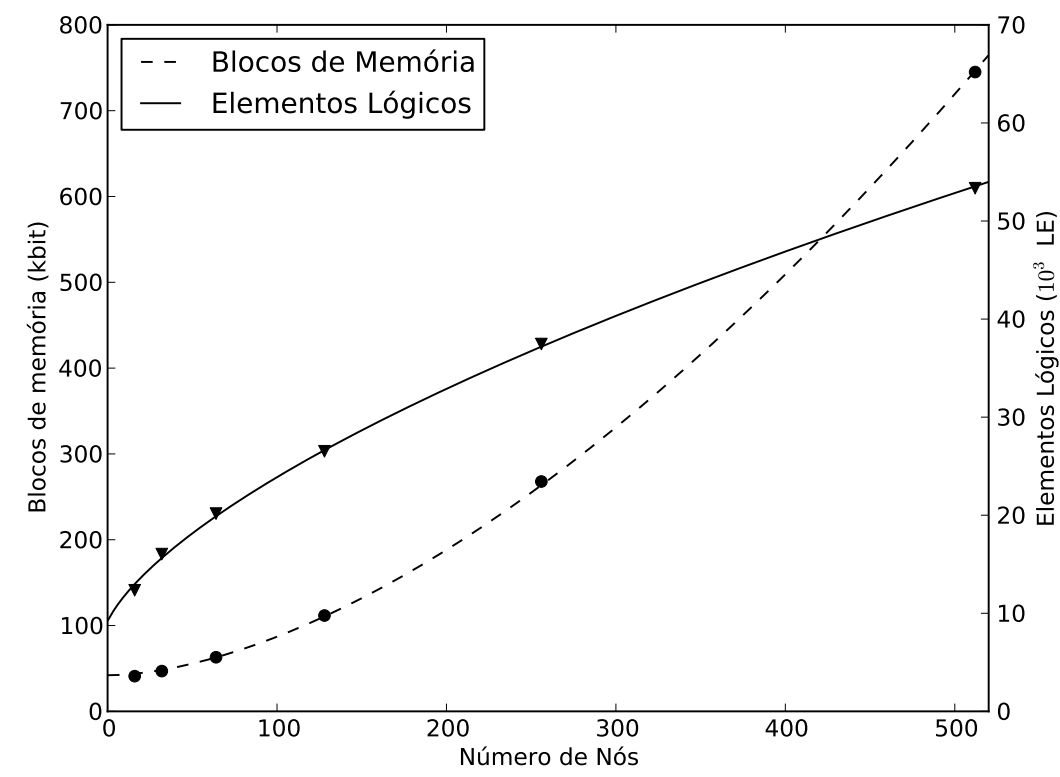

Figura 6.5: Consumo de recursos do FPGA.

Tabela 6.2: Consumo de Recursos do FPGA Cyclone II Modelo EP2C70F896C6.

\begin{tabular}{|c|c|c|l|}
\hline Nós & Elementos Lógicos & Registrador lógico & Bits de memória \\
\hline 16 & $12.348(18 \%)$ & $6.532(10 \%)$ & $41.024(4 \%)$ \\
\hline 32 & $16.035(23 \%)$ & $8.064(12 \%)$ & $46.912(4 \%)$ \\
\hline 64 & $20.166(29 \%)$ & $9.789(14 \%)$ & $63.040(5 \%)$ \\
\hline 128 & $26.520(39 \%)$ & $12.437(18 \%)$ & $111.680(10 \%)$ \\
\hline 256 & $37.455(55 \%)$ & $16.960(25 \%)$ & $267.840(23 \%)$ \\
\hline 512 & $53.345(78 \%)$ & $23.610(35 \%)$ & $745.024(65 \%)$ \\
\hline
\end{tabular}




\subsection{Validação de Florestas Geradas pelo P-PAO-S}

Para confirmar a qualidade das soluções geradas pelo P-PAO-S foi elabarado um algoritmo que verifica a compatibilidade dessas soluções com as soluções produzidas em software, no PC. Basicamente, é verificado se cada Floresta gerada corresponde a uma RNP correta e se possuem soma de pesos total significativamente menor que a da Floresta Inicial. Essa validação é importante pois a construção das soluções em FPGA envolve grande quantidade de troca de dados e comunicação com memórias, além de realizar muitos processamentos em paralelo, assim, a possibilidade de erros na implementação do hardware não é desprezível. Com base nisso, dois tipos de validações foram realizadas, sendo uma para verificar a consistência das RNPs geradas e outra para avaliar a qualidade das Florestas geradas. Tais validações são descritas nas Subseções 6.5.1 e 6.5.2.

\subsubsection{Validação da Consistência das Florestas Geradas}

A verificação de eventuais erros nas florestas geradas pelo P-PAO-S foi realizada por meio de um algoritmo de validação aplicado à cada Floresta Final obtida pelo P-PAO-S. Tal algoritmo possui os seguintes passos:

1. Percorre cada nó $b$ da floresta na representação RNP, da esquerda para a direita, procurando o seu ancestral $a$ e verificando se a diferença de profundidade entre $a$ e $b$ é consistente;

2. Em seguida, é verificado se o peso associado à aresta $(a, b)$ na RNP (especificamente para o caso do dc-MSTP) é igual ao peso na matriz de adjacências do grafo (ver algoritmo do PAO no Capítulo 4).

Caso algum peso não seja consistente, isto é, se algum peso for diferente na estrutura RNP em relação à matriz de pesos, um erro é indicado pelo algoritmo de validação. Além disso, caso haja alguma inconsistência nas profundidades indicadas na estrutura da RNP, o algoritmo também indica a presença de erro. Além dessas verificações automatizadas, diversas florestas geradas foram inspecionadas visualmente com o auxílio do software Graphviz (Gansner, 2011). Por fim, destacase que nenhum erro foi detectado para todas as florestas geradas nos experimentos descritos neste texto.

\subsubsection{Avaliação da Qualidade das Soluções Geradas}

O algoritmo de validação verifica, além da consistência, a capacidade de busca do método. Com este fim, foi realizada uma análise da redução da soma dos pesos das arestas das novas florestas (redes) geradas. Experimentos em software (no PC) e com o HP-RNP (no FPGA) possibilitaram validar a qualidade das soluções geradas pelo P-PAO-S em relação as geradas pelo PAO em software. 
Cada entrada de teste é um grafo completo (isto é, existem todas as possíveis arestas entre os nós) com pesos das arestas (valores inteiros) escolhidos aleatoriamente entre 0 e 255 . O número de nós de cada grafo (ou seja, a sua ordem) variou entre os seguintes valores: 16, 32, 64, 128, 256 e 512 nós. Para todos esses grafos, a restrição de grau variou entre os 13 valores inteiros de 3 a 15 . Para cada restrição de grau, foram realizados 5 experimentos utilizando diferentes sementes para o gerador de número aleatórios. Dessa forma, totalizaram-se $65(13 \times 5)$ execuções do HP-RNP para cada ordem de grafo, como explicado na Seção 6.4.

As Florestas Iniciais relativas a cada ordem de grafo foram geradas aleatoriamente tanto para os experimentos em FPGA quanto em software em PC. As Tabelas 6.3 e 6.4 especificam algumas diferenças entre os experimentos no PC e no FPGA. As operações de PAO em PC foram limitadas a utilizar 4 Trabalhadores em paralelo (utilizou-se processador Intel Core (TM) 2 Quad CPU Q6600) independentemente do número de nós na Floresta e utilizou-se 1 Trabalhador por core do PC (Tabela 6.4). No FPGA foi utilizado $\lceil\sqrt{n}\rceil$ Trabalhadores para cada ordem de grafo, conforme é mostrado na Tabela 6.3. As Tabelas 6.3 e 6.4 contrastam as médias da soma dos pesos entre as Florestas Iniciais e Florestas Finais obtidas. Essa média é calculada da seguinte forma: somam-se todos os valores de pesos de todas as 65 Florestas Finais de teste e divide-se o resultado dessa soma por 65 .

Tabela 6.3: Média da soma dos pesos das arestas das 65 Florestas Iniciais e 65 Florestas Finais em FPGA, em que $n$ é a ordem do grafo.

\begin{tabular}{|c|c|c|c|c|c|c|}
\hline $\begin{array}{c}\mathrm{N}^{\circ} \\
\text { de Nós }\end{array}$ & $\begin{array}{c}\text { Trabalhadores } \\
\text { em FPGA }\end{array}$ & $\begin{array}{c}\text { Árvores } \\
\text { Geradas por } \\
\text { Aplicação } \\
\text { do P-PAO-S }\end{array}$ & $\begin{array}{c}\text { Média da } \\
\text { Soma dos Pesos } \\
\text { (Floresta Inicial) }\end{array}$ & $\begin{array}{c}\text { Desvio } \\
\text { Padrão }\end{array}$ & $\begin{array}{c}\text { Média da } \\
\text { Soma dos Pesos } \\
\text { (Floresta Final) }\end{array}$ & $\begin{array}{c}\text { Desvio } \\
\text { Padrão }\end{array}$ \\
\hline 16 & 4 & 8 & $1.524,22$ & 195,62 & 836.94 & 188,94 \\
\hline 32 & 6 & 12 & $3.309,99$ & 428,07 & $1.438,34$ & 223,12 \\
\hline 64 & 8 & 16 & $7.144,52$ & 569,49 & $2.536,69$ & 244,98 \\
\hline 128 & 11 & 22 & $14.923,35$ & 909,17 & $4.335,62$ & 371,69 \\
\hline 256 & 16 & 32 & $30.652,28$ & $1.138,69$ & $7.236,79$ & 718,36 \\
\hline 512 & 23 & 46 & $62.418,66$ & $1.825,03$ & $11.815,31$ & $1.457,29$ \\
\hline
\end{tabular}

A Figura 6.6 ilustra a soma dos pesos das arestas para Floresta Inicial e Floresta Final usando tanto FPGA quanto PC. Cada ponto nessa figura indica a média da soma dos pesos das arestas nas florestas (Iniciais e Finais) para cada número de nós no grafo. As barras de erro (linhas verticais em torno de cada ponto) expressam o desvio padrão para cada ordem de grafo. Na ordenada é apresentada a média da soma total dos pesos depois de aplicar o P-PAO-S 65.536 $\lceil\lceil\sqrt{n}\rceil$ vezes (ou seja, 65.536 vezes o número de Trabalhadores), para cada uma das 65 Florestas Iniciais. Observe que para o PAO em PC, como o número de Trabalhadores é fixo em 4 para qualquer ordem de grafo, são geradas $65.536 \times 4$ novas florestas. Na Figura 6.6 pode ser observado que a redução de peso total na Floresta varia de forma aproximadamente linear com o número de nós. 
Tabela 6.4: Média da soma dos pesos das arestas das 65 Florestas Iniciais e 65 Florestas Finais em PC.

\begin{tabular}{|c|c|c|c|c|c|c|}
\hline $\begin{array}{c}\mathrm{N}^{\circ} \\
\text { de Nós }\end{array}$ & $\begin{array}{c}\text { Trabalhadores } \\
\text { em PC }\end{array}$ & $\begin{array}{c}\text { Árvores } \\
\text { Geradas por } \\
\text { Aplicação } \\
\text { do PAO }\end{array}$ & $\begin{array}{c}\text { Média da } \\
\text { Soma dos Pesos } \\
\text { (Floresta Inicial) }\end{array}$ & $\begin{array}{c}\text { Desvio } \\
\text { Padrão }\end{array}$ & $\begin{array}{c}\text { Média da } \\
\text { Soma dos Pesos } \\
\text { (Floresta Final) }\end{array}$ & $\begin{array}{c}\text { Desvio } \\
\text { Padrão }\end{array}$ \\
\hline 16 & 4 & 8 & $1.268,83$ & 224,45 & 712,71 & 173,69 \\
\hline 32 & 4 & 12 & $2.872,97$ & 362,52 & $1.424,71$ & 239,78 \\
\hline 64 & 4 & 16 & $6.183,19$ & 499,25 & $2.877,83$ & 314,96 \\
\hline 128 & 4 & 22 & $15.995,66$ & 722,49 & $7.204,62$ & 450,51 \\
\hline 256 & 4 & 32 & $32.144,23$ & 973,22 & $14.719,51$ & 657,71 \\
\hline 512 & 4 & 46 & $65.065,60$ & $1.683,06$ & $29.528,09$ & 887,33 \\
\hline
\end{tabular}

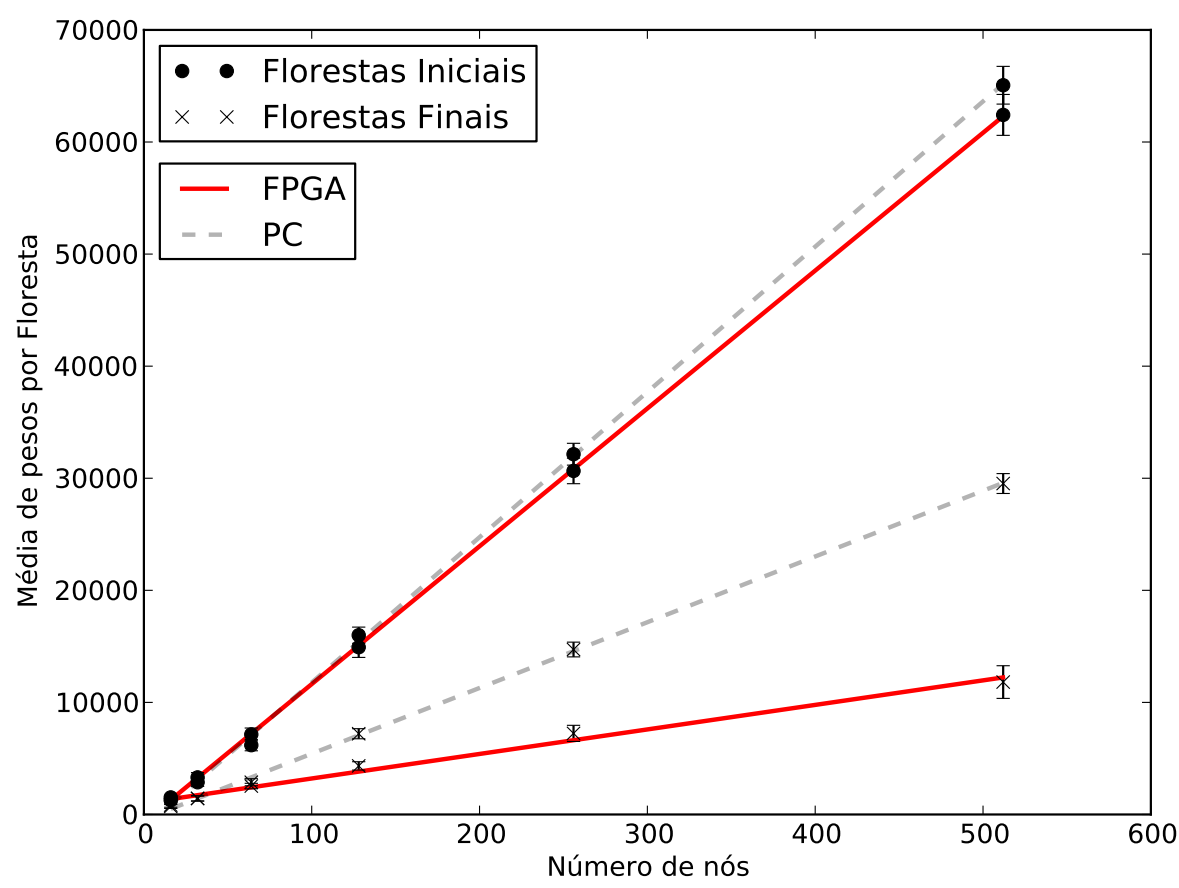

Figura 6.6: Média da soma total dos pesos das 65 Florestas Inicial e 65 Florestas Finais de simulações em FPGA e em PC, variando o número de nós no grafo.

Além disso, observa-se que as soluções obtidas por software com o PAO (em PC) apresentam a soma média de pesos maior. Isso ocorre devido ao grau de paralelismo em PC ser inferior ao do HP-RNP em FPGA, pois o método em software possue menos Trabalhadores executando aplicações de PAO.

Com base nas Tabelas 6.3 e 6.4 foi calculada também a proporção de redução de pesos por Floresta. Tais reduções são sumarizadas nas Tabelas 6.5 e 6.6. A Redução do peso é dada pela diferença entre a média da soma dos pesos da Floresta Inicial (colunas 4 das Tabelas 6.3 e 6.4) e a média da soma dos pesos da Floresta Final (colunas 6 das Tabelas 6.3 e 6.4). A proporção de 
redução é dada pela redução de pesos (colunas 3 das Tabelas 6.5 e 6.6) dividida pela média da soma dos pesos da Floresta Inicial.

Tabela 6.5: Proporção de Redução da soma dos pesos total em FPGA.

\begin{tabular}{|c|c|c|c|c|c|}
\hline Nós & Trabalhadores & Redução de Peso & $\begin{array}{c}\text { Desvio } \\
\text { Padrão }\end{array}$ & Proporção de Redução & $\begin{array}{c}\text { Desvio } \\
\text { Padrão }\end{array}$ \\
\hline 16 & 4 & 687,28 & 270,69 & 0,44 & 0,14 \\
\hline 32 & 6 & $1.871,65$ & 448,88 & 0,56 & 0,09 \\
\hline 64 & 8 & $4.607,83$ & 602,24 & 0,64 & 0,04 \\
\hline 128 & 11 & $10.587,74$ & $1.028,06$ & 0,71 & 0,03 \\
\hline 256 & 16 & $23.415,49$ & $1.427,79$ & 0,76 & 0,03 \\
\hline 512 & 23 & $50.603,35$ & $2.563,04$ & 0,81 & 0,02 \\
\hline
\end{tabular}

Tabela 6.6: Proporção de Redução da soma dos pesos total em PC.

\begin{tabular}{|c|c|c|c|c|c|}
\hline Nós & Trabalhadores & Redução de Peso & $\begin{array}{c}\text { Desvio } \\
\text { Padrão }\end{array}$ & Proporção de Redução & $\begin{array}{c}\text { Desvio } \\
\text { Padrão }\end{array}$ \\
\hline 16 & 4 & 556,12 & 277,67 & 0,42 & 0,17 \\
\hline 32 & 4 & $1.448,26$ & 340,37 & 0,50 & 0,08 \\
\hline 64 & 4 & $3.305,35$ & 607,91 & 0,53 & 0,07 \\
\hline 128 & 4 & $8.791,05$ & 799,12 & 0,55 & 0,03 \\
\hline 256 & 4 & $17.424,72$ & $1.277,82$ & 0,54 & 0,03 \\
\hline 512 & 4 & $35.537,51$ & $2.009,57$ & 0,55 & 0,02 \\
\hline
\end{tabular}

A Figura 6.7 ilustra a proporção entre a soma total dos pesos das arestas para as Florestas Finais e Iniciais. Na ordenada tem-se a proporção de redução (\%) na soma total dos pesos das arestas das florestas. As linhas pontilhadas simbolizam valores obtidos em PC, enquanto que as contínuas indicam valores em FPGA. As barras de erro vermelhas simbolizam o desvio padrão para PC e as pretas para FPGA. 


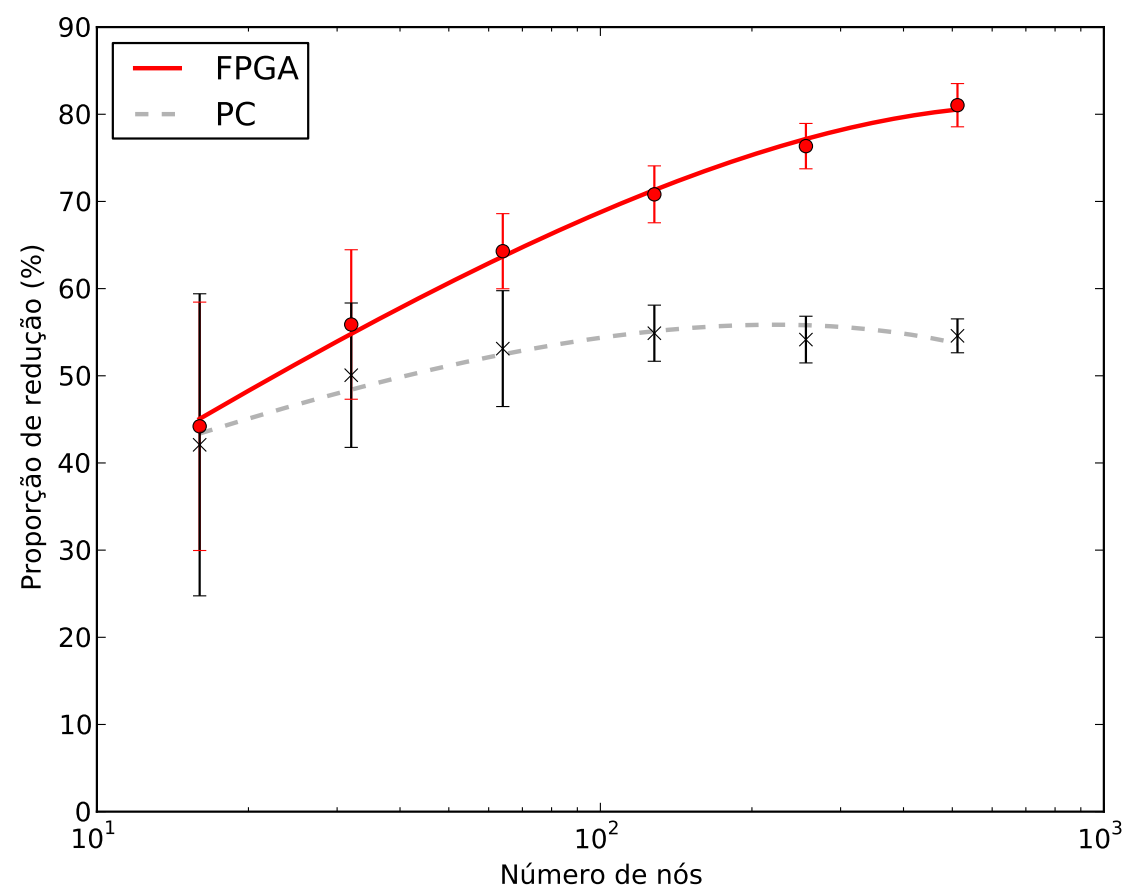

Figura 6.7: Proporção de redução das somas dos pesos das Floresta Iniciais e Floresta Finais (geradas em FPGA e em PC).

\subsection{Considerações Finais}

Este Capítulo apresentou a arquitetura de hardware implementada em FPGA, bem como os resultados da proposta dessa pesquisa. Os resultados mostram que é possível gerar novas configurações de florestas geradoras (novas redes) em tempo constante, por meio da arquitetura proposta, a HP-RNP. Dada a capacidade de blocos de memória do FPGA utilizado, foi possível realizar operações com tamanho máximo de 512 nós. Análises baseadas em estimativas mostraram que utilizando, por exemplo, um FPGA da família Stratix IV, seria possível realizar operações de RNP com florestas de até 2048 nós. A avaliação da consistência e qualidade das soluções geradas mostrou que o HP-RNP em FPGA conseguiu encontrar soluções melhores que o método em software no PC devido ao maior nível de paralelismo da arquitetura em FPGA. Outros avanços que podem ser derivados a partir da arquitetura HP-RNP são apresentados no Capítulo 7, o qual conclui esta dissertação. 



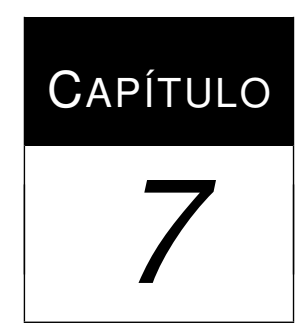

\section{Conclusão}

PPRs podem estar envolvidos em diversas aplicações do mundo real. Além disso, tais problemas no mundo real são em geral de larga-escala. Vários PPRs também requerem soluções em tempo real. Dessa forma, é importante o desenvolvimento de métodos cada vez mais eficientes para geração de soluções para PPRs.

Um aspecto importante para obter métodos eficientes em PPRs é a estrutura de dados (codificação) utilizada pelas metaheurísticas de busca por melhores configurações de redes. A RNP, comparada a outras codificações da literatura, mostrou-se uma estrutura de dados mais adequada, uma vez que possibilita que uma metaheurística investigue o espaço de configurações de redes em em tempo médio $O(\sqrt{n})$, enquanto as demais pelo menos requerem tempo $O(n)$.

Neste trabalho buscou-se aumentar o desempenho da RNP por meio de sua paralelização em hardware. Para esse fim, foi proposta a arquitetura denominada HP-RNP, implementada em FPGA. O HP-RNP possui diversos Trabalhadores (ver Seção 6.1), cada um executando em paralelo a MEF correspondente ao principal operador (PAO) da RNP.

Os resultados experimentais mostraram que o HP-RNP possibilita gerar e avaliar novas redes com centenas de nós em tempo limitado por uma constante $(O(1))$, o que o torna adequado, por exemplo, para PPRs em tempo real. Os experimentos foram realizados com florestas (redes) de 16 a 512 nós. Quase foi possível lidar com redes com 1024 nós, uma vez que, para grafos de 512 nós foram utilizados $65 \%$ de memória e $78 \%$ de elementos lógicos dos recursos disponíveis no FPGA Altera Cyclone II modelo EP2C70F896C6. Isso é um indicativo de que será possível trabalhar com grafos com cerca de 1.000 ou 2.000 nós com, por exemplo, um FPGA da família Stratix IV. Além disso, há perspectivas de trabalhar com grafos com dezenas de milhares de nós pela utilização de um cluster de FPGAs que executaria paralelamente em cada placa de FPGA um P-PAO-S. 
A implementação da HP-RNP envolveu grande quantidade de troca de dados e comunicação com memórias devido a projetos em FPGA explorarem muito processamento paralelo. Nesse sentido, o custo de comunicação entre um microprocessador softcore e FPGAs poderia se tornar uma restrição. Esse custo pode ser amortizado com uma reutilização de dados nos Trabalhadores, ou seja, a partir dos mesmos pares de árvores $T_{d e}$ e $T_{\text {para }}$ um número significativamente maior de novos pares de árvores pode ser gerado para gerar vários novos pares de árvores sem acessar a memória externa.

Os resultados dos experimentos realizados neste Trabalho foram os seguintes:

1. A HP-RNP apresentou ganhos significativos de desempenho em termos de tempo, obtendo novas florestas (redes) em tempo de processamento limitado por uma constante $O(1)$;

2. Houve uma redução no consumo de energia em duas ordens de magnitude quando comparado a implementação em PC Quad CPU Q6600 com 2.40GHz;

3. As florestas geradas pelo P-PAO-S foram validadas e comparadas com as geradas em software em PC. Essa validação consistiu na avaliação de sua qualidade e consistência das RNPs geradas por meio do P-PAO-S. A avaliação mostrou que a redução de pesos para o problema dc-MSTP é significativamente maior utilizando a HP-RNP. Isso ocorreu devido ao maior grau de paralelismo (número de Trabalhadores) da solução em FPGA em relação à executada em PC.

Como sugestões de trabalhos futuros a serem desenvolvidos a partir deste, as seguintes podem ser abordadas:

1. A investigação de extensões da HP-RNP para lidar com redes maiores, por exemplo, por meio do seu reprojeto para FPGAs com mais recursos;

2. Outra possibilidade de extensão para a HP-RNP seria sua paralelização em um cluster de FPGAs, possibilitando manipular redes ainda maiores, com até milhares de nós;

3. Aplicação da técnica HP-RNP a um problema do mundo real como, por exemplo, Problemas de Reconfiguração de Sistemas de Distribuição de Energia;

4. Por fim, propõe-se a adequação da HP-RNP para lidar com redes que envolvem grafos esparsos, uma vez que esse tipo de grafo ocorre com mais frequência conforme a escala dos PPRs aumenta. 


\section{Referências Bibliográficas}

Abuali, F. N.; Wainwright, R. L.; Schoenefeld, D. A. Determinant factorization: A new encoding scheme for spanning trees applied to the probabilistic minimum spanning tree problem. In: In Eschelman, L. (Ed.), Proceedings of the Sixth International Conference on Genetic Algorithms, Morgan Kaufmann, 1995, p. 470-477.

AlterA Cyclone ii fpga starter development board. reference manual. 2006. Disponível em http://www.altera.com/literature/manual/mnl_cii_starter_ board_rm.pdf

Altera Cyclone ii device handbook. 2007. Disponível em http://www.altera.com/ literature/hb/cyc2/cyc2_cii5v1.pdf

Altera Sopc builder user guide. 2010. Disponível em http://www.altera.com/ literature/ug/ug_sopc_builder.pdf

ALTERA Quartus ii handbook version 11.1. 2011a. Disponível em http://www.altera. com/literature/hb/qts/quartusii_handbook.pdf

AlTERA Stratix iv device handbook. 2011b. Disponível em http://www.altera.com/ literature/hb/stratix-iv/stratix4_handbook.pdf

ASPRAY, W. John von neumann's contributions to computing and computer science. IEEE Ann. Hist. Comput., v. 11, n. 3, p. 189-195, 1989.

B ̈̈СK, T. Evolutionary algorithms in theory and practice: evolution strategies, evolutionary programming, genetic algorithms. Oxford, UK: Oxford University Press, 1996.

BobDA, C. Introduction to reconfigurable computing: Architectures, algorithms, and applications. Springer Publishing Company, Incorporated, 2007. 
Brown, S.; VRAnesic, Z. Fundamentals of digital logic with vhdl design; 3rd ed. Boston, MA: McGraw-Hill, 2008.

Chapman, B.; Jost, G.; PAS, R. V. D. Using openmp: Portable shared memory parallel programming (scientific and engineering computation). The MIT Press, 2007.

Comptom, K.; HaUcK, S. An introduction to reconfirable computing. IEEE computer Society, 2000.

Cormen, T. H.; Leiserson, C. E.; Rivest, R. L.; Stein, C. Introduction to algorithms, second edition. McGraw-Hill Science/Engineering/Math, 2001.

DARWIN, C. A origem das espécies. 1859.

DARWIN, C. A origem das espécies - coleção a obra prima de cada autor. Martin Claret, 2004.

DAVE, N. Designing a reorder buffer in bluespec. In: MEMOCODE, 2004, p. 93-102.

Dave, N.; Arvind; Pellauer, M. Scheduling as rule composition. In: MEMOCODE '07: Proceedings of the 5th IEEE/ACM International Conference on Formal Methods and Models for Codesign, Washington, DC, USA: IEEE Computer Society, 2007, p. 51-60.

DE Jong, K. A. Evolutionary computation: A unified approach. MIT Press, 2006.

Delbem, A. C. B. Aumento de eficiência de soluções computacionais para problemas complexos e metodologia de modelagem de sistemas. Monografia de Livre-Docência. Apêndice E, 2009.

Delbem, A. C. B.; De Carvalho, A. C. P. L. F. A forest representation for evolutionary algorithms applied to network design. In: GECCO, 2003, p. 634-635.

Delbem, A. C. B.; De Carvalho, A. C. P. L. F.; Bretas, N. G. Main chain representation for evolutionary algorithms applied to distribution system reconfiguration. IEEE Transactions on Power Systems, v. 20, n. 1, p. 425-436, 2005.

Delbem, A. C. B.; De Carvalho, A. C. P. L. F.; Policastro, C. A.; Pinto, A. K. O.; HondA, K.; GARCIA, A. C. Node-depth encoding for evolutionary algorithms applied to network design. In: GECCO (1), 2004, p. 678-687.

DiESTEL, R. Graph theory (graduate texts in mathematics). Springer, 2005.

Eiben, A.; SMith, J. Introduction to evolutionary computing. Springer, 2003.

EISNER, J. State-of-the-art algorithms for minimum spanning trees: A tutorial discussion, manuscript available online (78 pages), University of Pennsylvania, 1997. Disponível em http://cs.jhu.edu/ jason/papers/\#ms 97 
Even, S. Graph algortithms. Computer Science Press, 1979.

GANSNER, E. R. Drawing graphs with graphviz. 2011. Disponível em http://www . graphviz.org/pdf/libguide.pdf

Garey, M. R.; Johnson, D. S. Computers and intractability: A guide to the theory of npcompleteness (series of books in the mathematical sciences). W. H. Freeman, 1979.

GOLDBERG, D. E. Genetic algorithms in search, optimization, and machine learning. AddisonWesley Professional, 1989.

GOLDBERG, D. E. The design of innovation: Lessons from and for competent genetic algorithms. Norwell, MA, USA: Kluwer Academic Publishers, 2002.

Graham, R.; Hell, P. On the history of the minimum spanning tree problem. Annals of the History of Computing, v. 7, p. 43-57, 1985.

Grama, A.; KARYPIS, G.; KumAR, V.; GUPTA, A. Introduction to parallel computing (2nd edition). Addison Wesley, 2003.

GRUiAn, F.; WeStMiJZE, M. Vhdl vs. bluespec system verilog: a case study on a java embedded architecture. In: SAC '08: Proceedings of the 2008 ACM symposium on Applied computing, New York, NY, USA: ACM, 2008, p. 1492-1497.

Hu, T. C. Optimum communication spanning trees. SIAM J. Comput., v. 3, n. 3, p. 188-195, 1974.

INTEL Getting started with the intel( $r) c++$ compiler professional edition 11.1 for linux os. 2009. Disponível em http://software.intel.com/sites/products/ documentation/hpc/compilerpro/en-us/cpp/lin/start/getting_ started_c.pdf

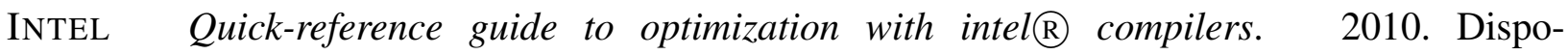
nível em http://software.intel.com/sites/products/collateral/hpc/ compilers/compiler_qrg12.pdf

Johnson, S. D.; Lenstra, K. J.; KAn, R. G. H. A. The complexity of the network design problems. In: Networks, 1978, p. 279-285.

Julstrom, B. A. The blob code is competitive with edge-sets in genetic algorithms for the minimum routing cost spanning tree problem. In: GECCO '05: Proceedings of the 2005 conference on Genetic and evolutionary computation, New York, NY, USA: ACM, 2005, p. 585-590. 
KARGER, D. R. Random sampling in cut, flow, and network design problems. In: Proceedings of the twenty-sixth annual ACM symposium on Theory of computing, STOC '94, New York, NY, USA: ACM, 1994, p. 648-657 (STOC '94, ). Disponível em http://doi . acm.org/ 10 . $1145 / 195058.195422$

Kershenbaum, A. Telecommunications network design algorithms. New York, NY, USA: McGraw-Hill, Inc., 1993.

Knowles, J.; CoRne, D. A new evolutionary approach to the degree-constrained minimum spanning tree problem. IEEE Transactions on Evolutionary Computation, v. 4, p. 2000, 1999.

KnOwles, J. D.; CoRne, D. A new evolutionary approach to the degree-constrained minimum spanning tree problem. IEEE Trans. Evolutionary Computation, v. 4, n. 2, p. 125-134, 2000.

Krishnamoorthy, M.; Ernst, A. T.; Sharaiha, Y. M. Comparison of algorithms for the degree constrained minimum spanning tree. Journal of Heuristics, v. 7, n. 6, p. 587-611, 2001.

KRUSKAL, J. B. On the shortest spanning subtree of a graph and the traveling salesman problem. Proceedings of the American Mathematical Society, v. 7, n. 1, p. 48-50, 1956.

Libralão, G. L.; Delbem, A. C. B. Codificação nó-profundidade com operador de recombinação para algoritmos evolutivos. In: XXV Congresso da Sociedade Brasileira de Computação, 2005, p. 514-523.

Libralão, G. L.; Pereira, F. C.; De Lima, T. W.; Delbem, A. C. B. Node-depth encoding for evolutionary algorithms applied to multi-vehicle routing problem. In: IEA/AIE, 2005, p. $557-559$.

LimA, T. W. Estruturas de dados efiecientes para algoritmos evolutivos aplicados ao projeto de redes. Tese de Doutoramento, Instituto de Ciências Matemáticas e de Computação -ICMC, USP, 2009.

Lima, T. W.; Delbem, A. C. B. Efficient forest data structure for evolutionary algorithms applied to network design. Accepted in IEEE Transactions on Evolutionary Computation, 2011.

Lima, T. W.; Delbem, A. C. B.; Rothlauf, F. Analysis of properties of recombination operators proposed for the node-depth encoding. In: Proceedings of the 13th annual conference companion on Genetic and evolutionary computation, GECCO '11, New York, NY, USA: ACM, 2011, p. 137-138 (GECCO '11, ).

CHIEH LIN, C. Implementation of h.264 decoder in bluespec. 2007.

MARTIN, P. A hardware implementation of a genetic programming system using fpgas and handel-c. Genetic Programming and Evolvable Machines, v. 2, n. 4, p. 317-343, 2001. 
Müller, W.; Rosenstiel, W.; Ruf, J., eds. Systemc: methodologies and applications. Norwell, MA, USA: Kluwer Academic Publishers, 2003.

Narula, S. C.; Ho, C. A. Degree-constrained minimum spanning tree. Computers \& OR, v. 7, n. 4, p. 239-249, 1980.

NikHIL, R. Bluespec system verilog: efficient, correct RTL from high level specifications. Formal Methods and Models for Co-Design, 2004. MEMOCODE '04. Proceedings. Second ACM and IEEE International Conference on, p. 69-70, 2004.

PAlmer, C. C. An approach to a problem in network design using genetic algorithms. Tese de Doutoramento, Brooklyn, NY, USA, 1994.

PALnitKaR, S. Verilog hdl: a guide to digital design and synthesis, second edition. Upper Saddle River, NJ, USA: Prentice Hall Press, 2003.

PRIM, R. Shortest connection networks and some generalizations. Journal of Bell Systems and Technology, v. 36, p. 1398-1401, 1957.

RAIDL, G. An efficient evolutionary algorithm for the degree-constrained minimum spanning tree problem. In: Evolutionary Computation, 2000. Proceedings of the 2000 Congress on, 2000a, p. $104-111$ vol.1.

RAIDL, G. R. An efficient evolutionary algorithm for the degree-constrained minimum spanning tree problem. $2000 \mathrm{~b}$.

RAidL, G. R.; JUlstrom, B. A. Edge sets: an effective evolutionary coding of spanning trees. IEEE Trans. Evolutionary Computation, v. 7, n. 3, p. 225-239, 2003.

Rothlauf, F. Representations for genetic and evolutionary algorithms. Secaucus, NJ, USA: Springer-Verlag New York, Inc., 2006.

Rothlauf, F.; Gerstacker, J.; HeInZl, A. The optimal communication spanning tree problem. Relatório Técnico, Illinois Genetic Algorithm Laboratory, Illinois, 2003.

Rothlauf, F.; Goldberg, D. E.; Heinzl, A. Network random keys - a tree representation scheme for genetic and evolutionary algorithms. Evolutionary Computation, v. 10, 2002.

Santos, A.; Delbem, A.; London, J.; Bretas, N. Node-depth encoding and multiobjective evolutionary algorithm applied to large-scale distribution system reconfiguration. IEEE Transactions on Power Systems, v. 25, n. 3, p. $1254-1265,2010$.

SEAL, D. Arm architecture reference manual. 2nd ed. Boston, MA, USA: Addison-Wesley Longman Publishing Co., Inc., 2000. 
Smith, M. J. S. Application-specific integrated circuits. Boston, MA, USA: Addison-Wesley Longman Publishing Co., Inc., 1997a.

Smith, S. W. The scientist and engineer's guide to digital signal processing. San Diego, CA, USA: California Technical Publishing, 1997b.

SOAK, S.-M. A new evolutionary approach for the optimal communication spanning tree problem. IEICE Trans. Fundam. Electron. Commun. Comput. Sci., v. E89-A, n. 10, p. 2882-2893, 2006.

XILINX Development system reference guide. 2008. Disponível em http://www.xilinx. com/itp/xilinx10/books/docs/dev/dev.pdf

ZENNER, E. Cryptanalysis of lfsr-based pseudorandom generators - a survey. Relatório Técnico, 2004.

ZhOU, G.; Gen, M. A note on genetic algorithms for degree-constrained spanning tree problems. Networks (USA), v. 30, n. 2, p. 91-95, 1997. 
APÊNDICE

\section{$A$}

\section{Obtenção dos nós e decodificação da}

Para determinar os nós $p, r$ e $a$ da RNP, são utilizadas duas estruturas auxiliares. A primeira estrutura é a matriz $\Pi_{v x}$, a qual contém a identificação do nó, sua posição, sua árvore e sua floresta. Em geral, seu funcionamento é da seguinte forma: quando um nó tem sua posição trocada por meio dos operadores 1 e 2 , uma nova coluna com as posições atualizadas é inserida na matriz. A segunda estrutura é o array $\pi$, o qual armazena para cada posição o ancestral da floresta representada naquela posição.

A forma de selecionar os nós $p, r, a$ é descrito no Algoritmo 5.

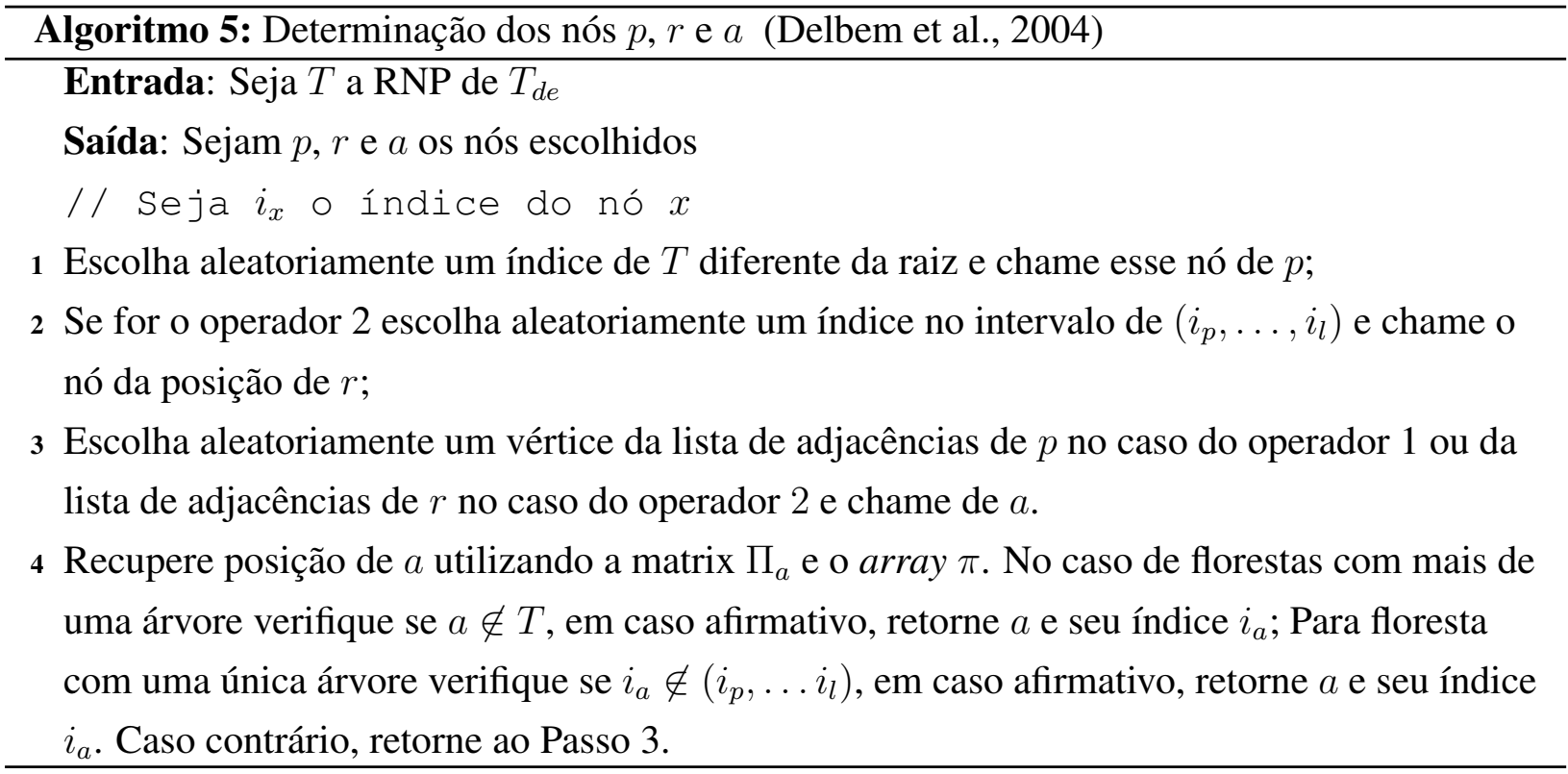


A localização de um nó em uma floresta $F$ é realizada conforme descrito na sequência (Delbem, 2009):

Seja $F_{0}$ uma floresta de $G$ codificada pela RNP e $T_{i}$ a $i$-ésima árvore em $F_{0}$ e $F_{j}$ a $j$-ésima floresta gerada depois de $F_{0}$. A localização de um nó em $F_{0}$ utiliza uma matriz auxiliar $\Pi_{v_{x}}$ para cada vértice $v_{x}$ de $G$. Para $F_{0}, \Pi_{v_{x}}$ possui apenas uma coluna $\Pi_{v_{x}}=\left[\begin{array}{c}0 \\ t_{0} \\ i_{0}\end{array}\right]$, em que $t_{0}$ é um índice da árvore que contém $v_{x}$ e $i_{0}$ é o índice correspondente a $v_{x}$ no array $T_{t_{0}}$ que é a RNP da árvore.

Suponha que uma floresta $F_{\text {posterior }}$ é obtida a partir de $F_{\text {anterior }}$, (anterior $<$ posterior $)$, e

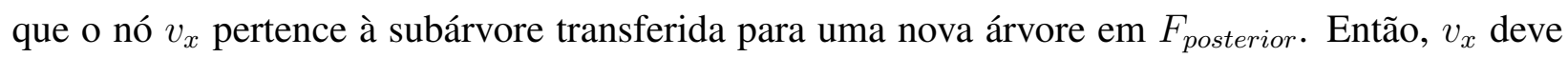
ter uma posição em $F_{\text {posterior }}$ que é diferente de sua posição em $F_{\text {anterior }}$. Com o objetivo de armazenar essa mudança, insere-se uma nova coluna na matriz $\Pi_{v_{x}}$ com os valores de sua nova posição. A matriz alterada resulta em:

$$
\Pi_{x}=\left[\begin{array}{ccccc}
0 & \ldots & \text { anterior } & \ldots & \text { posterior } \\
t_{0} & \ldots & t_{\text {anterior }} & \ldots & t_{\text {posterior }} \\
i_{0} & \ldots & i_{\text {anterior }} & \ldots & i_{\text {posterior }}
\end{array}\right] .
$$

A atualização de colunas deve ocorrer apenas para os nós da subárvore podada. No pior caso, todos os nós de $T_{d e}$ e $T_{\text {para }}$ precisam ter suas matrizes atualizadas. Na primeira linha de $\Pi_{v_{x}}$ é armazenado um identificador da floresta, que teve o nó $v_{x}$ alterado para uma nova posição. $\mathrm{O}$ último predecessor $F_{\text {anterior }}$ de $F_{\text {posterior }}$ pode ser determinado a partir de $\pi$ (array que armazena a relação de ancestralidade (Delbem et al., 2004)).

Para localizar a posição de um nós $v_{x}$ em $F_{i}$, primeiramente busca-se $v_{x}$ em $\Pi_{v_{x}}$, se $F_{i}$ existe; caso contrário, localiza-se em $\pi$ o predecessor de $F_{i}$ (chamado de $F_{k}$, com $k<i$ ) e novamente busca-se em $\Pi_{v_{x}}$. Se a busca novamente retorna um valor nulo, o processo recomeça buscando do predecessor de $F_{k}$ até que seja encontrada uma coluna para $v_{x}$ em alguma floresta. A procura em $\Pi_{v_{x}}$ pode ser efetuada usando um método de busca para conjunto de dados ordenados como, por exemplo, a busca binária, pois as colunas são inseridas de forma ordenada pelo identificador da floresta.

Para decodificar uma floresta geradora $F$ representada na RNP é necessário aplicar o Algoritmo 6 à RNP de cada uma de suas árvores. 


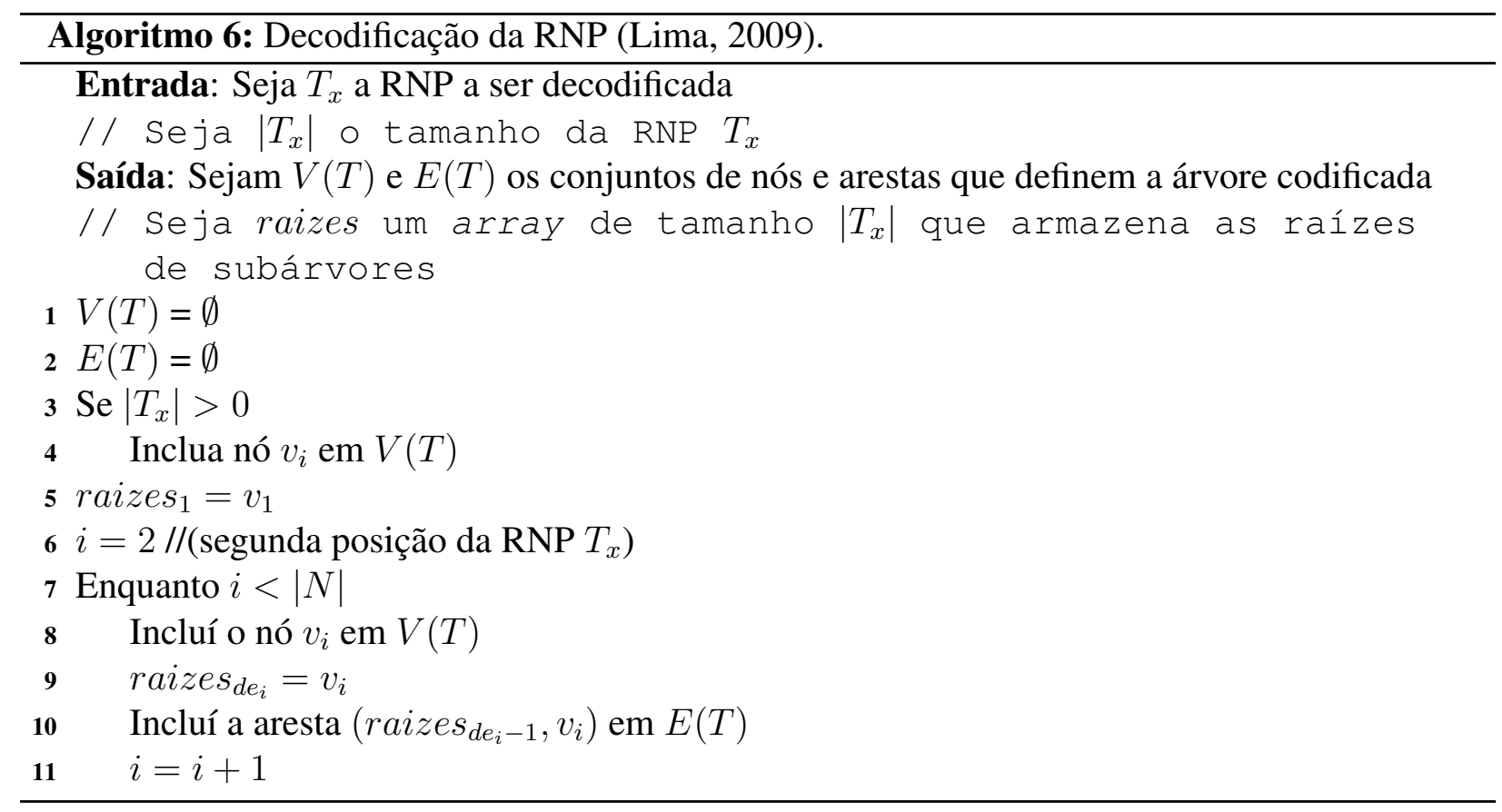

